\title{
Queer(y)ing Resettlement in Aotearoa New Zealand: An Inquiry into Family Reunification Pathway Reform for Former Refugees
}

\author{
Lauren Innes-Hill
}

\begin{abstract}
A thesis submitted to Te Herenga Waka Victoria University of Wellington in partial fulfilment of requirements for the Masters of

Development Studies Degree
\end{abstract}

2020

Te Kura Tātai Aro Whenua

School of Geography, Environment \& Earth Sciences

Te Herenga Waka

Aotearoa New Zealand 



\begin{abstract}
The 2018 Global Compact agreement between UN member states and multilateral agencies marked formal recognition of the need for international rights-based solutions to protracted displacement. These solutions sit within the migration-development nexus, specifically the recognition that resettlement encompasses development needs which span the typically siloed spheres of international and domestic policy. Literature has shown that family reunification is one of the most important factors for successful resettlement. In Aotearoa NZ, former refugees may apply for refugee family reunification (RFR) through two policy pathways, both of which offer a limited number of places. Over half of the applications are rejected each year, most on the grounds of failing to meet eligibility criteria. The question as to why so many applications for RFR are unsuccessful forms a basis for policy review.
\end{abstract}

This research seeks to understand why RFR fails former refugees in such drastic numbers. Using a theoretical framework of marginality (comprised of social exclusion, critical kinship, and queer theory), I inquired into what the key barriers to successful RFR are, and in what ways RFR policy and its associated processes may be excluding refugee families.

Adopting a qualitative methodology, I engaged in semi-structured interviews with six people involved in RFR. Through thematic analysis, I identified myriad barriers and exclusions including the logistical constraints of application and the minutia of bureaucratic demands, to wider issues of lacking cultural competence of immigration officers and indirect separation of families. Exclusions find their roots in the promotion and reinforcement of norms as they relate to hetero-western ideals of 'family', and the allied subject position for former refugee families as 'queer'. Through discursive analysis to better understand the power dynamics at work, I discuss three discourses: 'family as culturally bound/(in)eligible', 'family as more than', and 'family as culturally akin', which seek to reinforce or counter current RFR policy stipulations respectively.

General findings show that by centring queer subjects and their discourses, many of the barriers and exclusions specified by participants as currently embedded within RFR processes would be mitigated. In turn, this re-orientation would counter Eurocentric heteronormative ideas within rights-based development and in the formation and implementation of RFR policy. I conclude with speculations as to how policy reform can better recognise that family is 'more than' the 
hetero-western norms on which current policy has been established, through the application of a marginality framework to policy review. I note that this case study in Aotearoa forms a basis for adopting marginality approaches to rights-based resettlement policies in international development frameworks and scholarship, and identify further research focused on queer(y)ing resettlement processes in Aotearoa.

Key Words: Refugee, queer theory, marginality, family reunification, rights-based development, post-development, discourse analysis 


\section{Acknowledgments}

Firstly, I wish to acknowledge the many former refugees for whom reunification with family is an insurmountable hurdle. This work is for you. To resettle here with your whānau is a right, and a healing joy, that no one should be excluded from accessing.

I would also like to acknowledge the voices who did not get formally presented in this research but who have challenged, galvanised and taught me along the way: the members of Rainbow Path New Zealand; the families and friends I sat with at Immigration New Zealand huis; my former colleagues at New Zealand Red Cross; the founders and board members of organisations such as RFRT and CRF and others who work tirelessly alongside the former refugee community to support families seeking reunification in a system which cannot be navigated alone. Thank you for giving your time, for sharing coffees and insights far beyond the scope of this thesis. This work is also for you.

The irony is not lost on me, given the subject matter of this research, that without the support and contact of my family I likely would not have made it through my Master's degree. To Mum and Dad, thank you for your unwavering encouragement in all that I do. Thank you for instilling in me the value of critical thought and the lesson to challenge always the blinkers of my privilege (I'm still learning).

To Sara, thank you for your wisdom in academic supervision and in life. Thank you for embodying compassion, activism and aroha. Your encouragement and influence have sustained me through this, and it has been an honour (and quite honestly, inspiration) to work with you.

Thank you to my kaupapa whānau on this side of the Tasman; to Kezia for being a sister to me here, and my collection of friends, neighbours, and cohortees who surrounded me with wit, wisdom and wine.

Finally, to Luke for being a constant source of joy and support, and for an internationally shipped jar of peanut butter, without which VUW may never have become my thesis home. 


\section{Table of Contents}

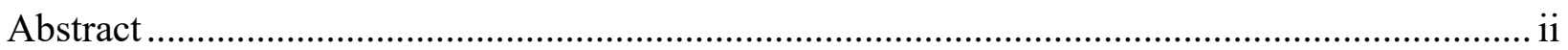

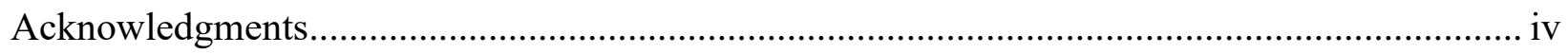

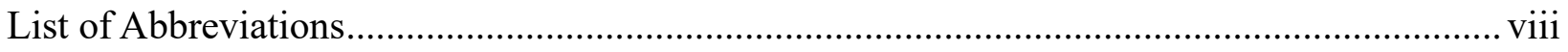

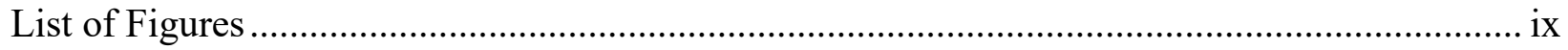

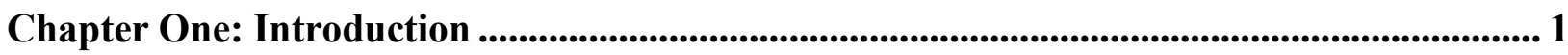

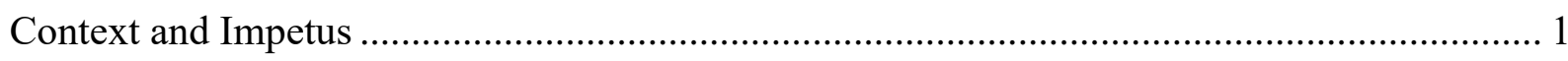

Humanitarianism and Refugee Resettlement in Aotearoa New Zealand........................... 1

Family Reunification in Aotearoa NZ ..................................................................... 3

The Case for Refugee Family Reunification (RFR) ......................................................... 5

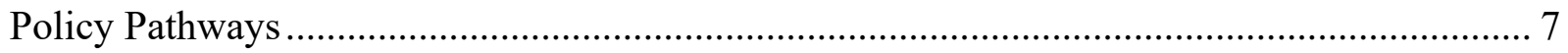

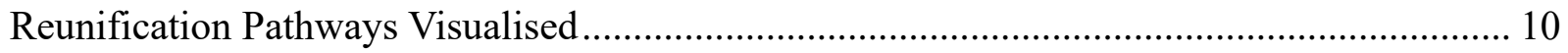

The Changing Landscape of Refugee Family Reunification ......................................... 12

Influences from Development Literature ................................................................ 14

Post-development, queer theory and the Aotearoa NZ context .................................... 14

Queer(y)ing development: Development with a body ............................................ 15

Feminist theory and critical kinship as conceptual influences......................................... 17

From Observation to Research Question ..................................................................... 18

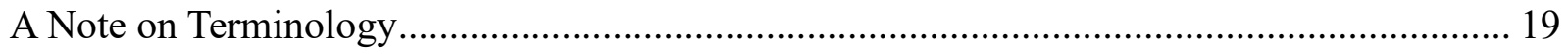

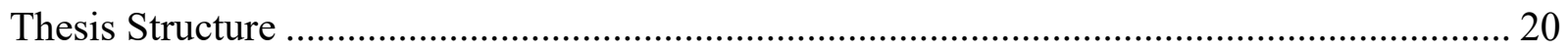

Chapter Two: Literature Review and Conceptual Framework .............................................. 22

Locating Refugee Studies Within Development Scholarship: the SDGs and Rights-Based

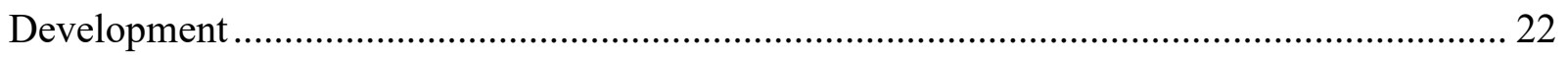

Development and Marginality: Towards a Conceptual Framework ..................................... 24

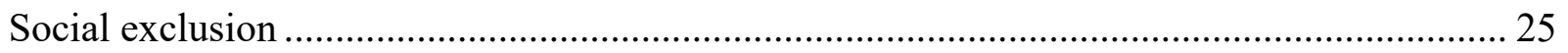

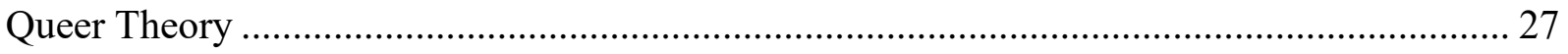


Social Exclusion, Queer Theory, and the SDG's: Revealing the Migration Development Nexus 31

Queer Subjects and The Exclusion of Families; Lessons from Critical Kinship.................... 33

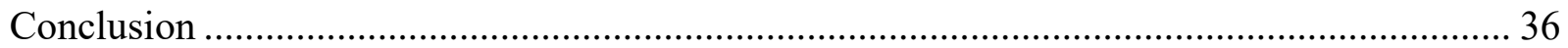

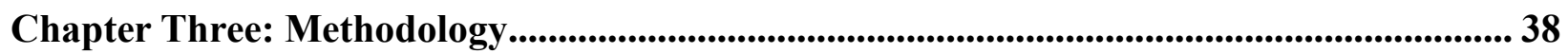

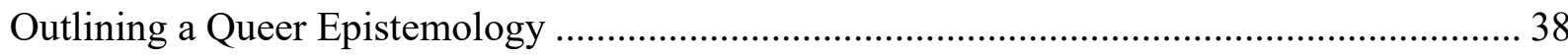

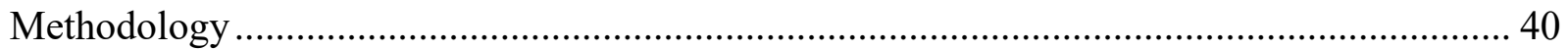

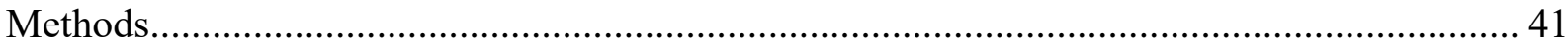

Ethics and Representation: Queer Infused, Collaboratively Inspired ................................... 52

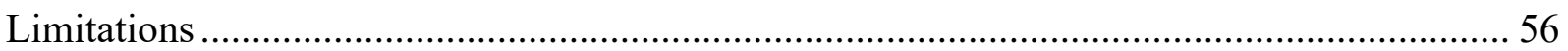

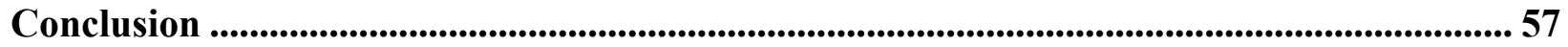

Chapter Four Theme 1: Barriers.......................................................................................................... 58

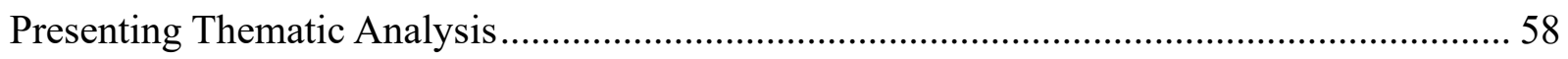

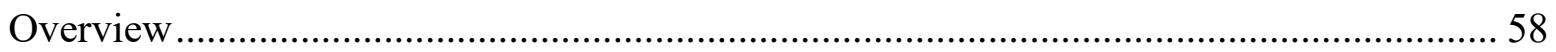

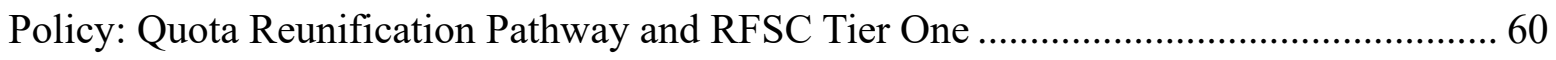

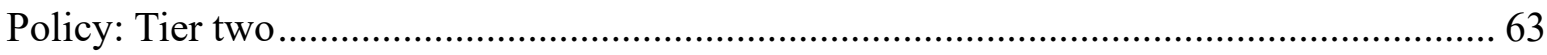

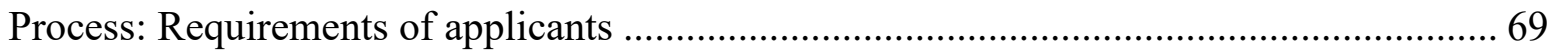

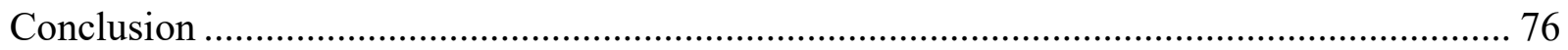

Chapter Five Theme 2: Exclusions........................................................................................................ 77

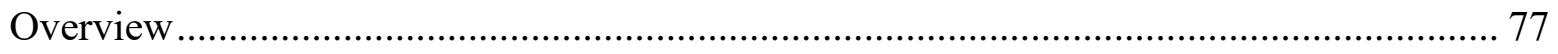

Policy: Exclusions in Regard to Narrow Definitions of Family .................................... 79

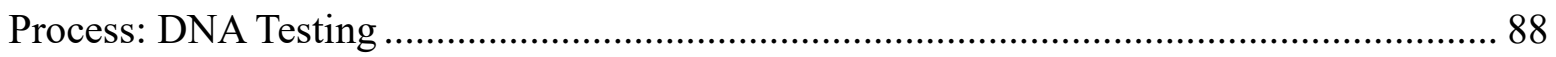

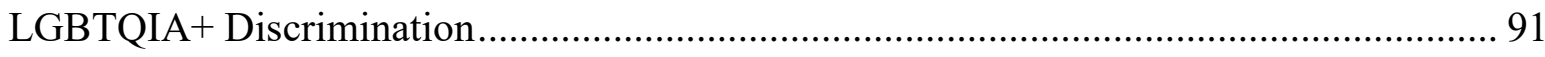

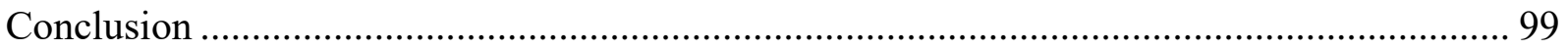

Chapter Six: Discussion 1 Dominant and Counter Discourses................................................. 100

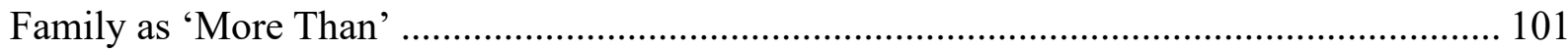


Family as Culturally Bound/ Culturally (In)Eligible ................................................ 108

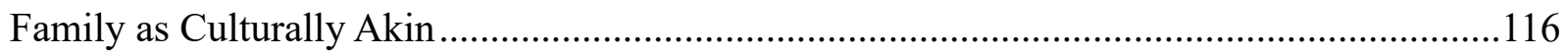

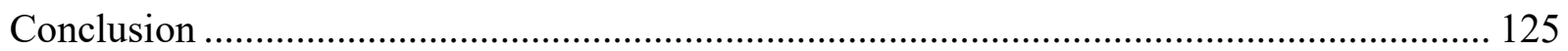

Chapter Seven: Discussion 2 Limits of Agency and Discourse ........................................... 127

Governmentality, biopower, and its Subversions in Relation to RFR Policy Discussion....... 127

Resistance as Performer: Utilising Constructed Subject Positions for RFR Goals ............... 132

Resistance as Polyglot: Finding Agency Through Multiple Contradictory Discourses and

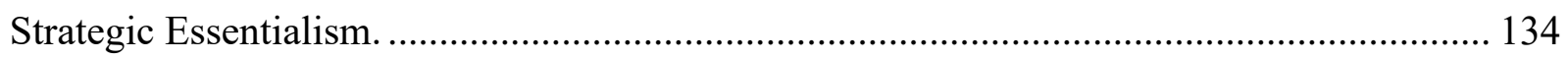

Speculation on Silence: Hesitations, Margins and the 'Not Yet' of Justice for Rainbow

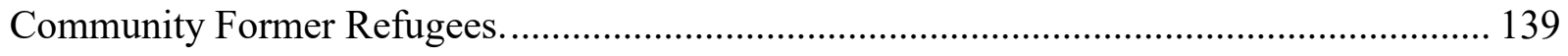

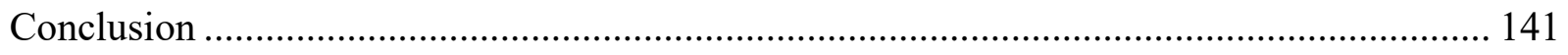

Chapter Eight: Conclusion and Recommendations for Policy Reform ................................. 143

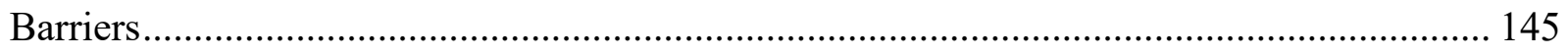

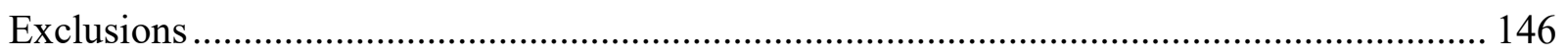

Heteronormativity, The Neo-Liberal Agenda, and the 'Truth Effects' of Colonial Power ..... 149

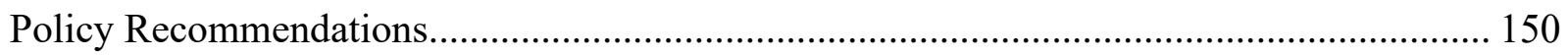

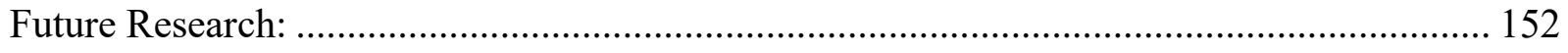

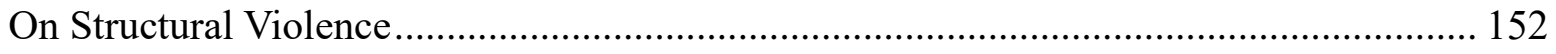

On Rainbow Community Experiences.............................................................. 153

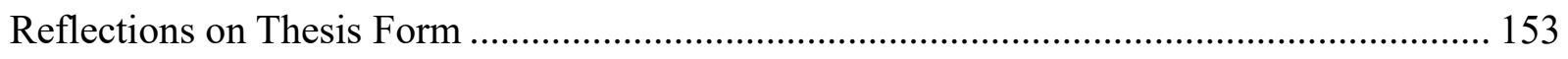

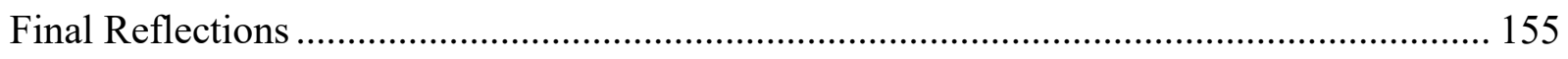

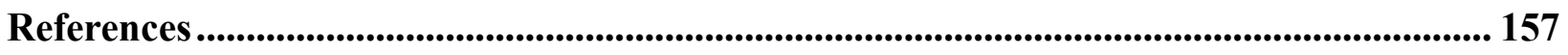

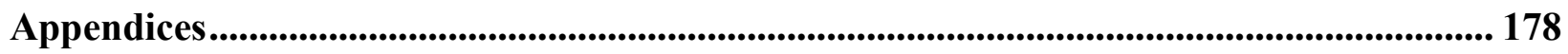

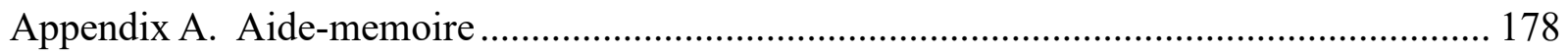

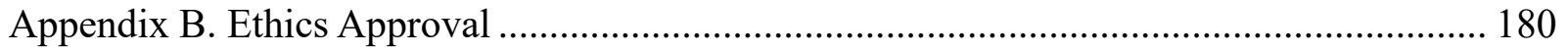

Appendix C: Data Obtained Under OIA Request ........................................................... 181 


\section{List of Abbreviations}

1951 Convention

1967 Protocol

FDA

INZ

LGBTQIA+

MBIE

NGO

RFR

RFSC

RQB

SDGs

$\mathrm{T} 1$

$\mathrm{T} 2$

UNHCR
1951 Convention relating to the Status of Refugees

1967 Protocol relating to the Status of Refugees

Foucauldian Discourse Analysis

Immigration New Zealand

Lesbian Gay Transgender Queer Intersex Asexual + Ministry of Business Innovation and Employment

Non-Governmental Organisation

Refugee Family Reunification

Refugee Family Support Category

Refugee Quota Branch

Sustainable Development Goals

Tier one Refugee Family Support Category Pathway

Tier two Refugee Family Support Category Pathway

United Nations High Commissioner for Refugees 


\section{List of Figures}

Figure 1.1 Family Reunification Pathway options for refugees arriving via UNHCR Quota pathway.

Figure 1.2: Refugee Family Reunification/Support pathway options for Convention Refugees

with existing family members in Aotearoa New Zealand.

Figure 1.3. Refugee Family Support Category Pathway options for Convention Refugees with no existing family in Aotearoa New Zealand.

Figure 1.4: Timeline of key milestones in resettlement policy on or intersecting with RFR ....... 13

Figure 2.1: Applying the conceptual framework of marginality to Refugee Family Reunification 36

Figure 3.1: Structure of RFR policy processes and its actors. 42

Figure 3.2: Structure of RFR policy processes, its actors, and corresponding research participants

Figure 8.1: Barriers to RFR

Figure 8.2: Exclusions to RFR in policy and process. .147 


\section{Chapter One: Introduction}

\section{Context and Impetus}

\section{Humanitarianism and Refugee Resettlement in Aotearoa New Zealand.}

It is a point of national pride, reflected in both political rhetoric and public opinion over the years, that as a signatory to the 1951 Refugee Convention and the related 1967 Protocol, Aotearoa New Zealand ${ }^{1}$ joins 195 other countries who are formally committed to the protection of refugees and asylum seekers (Beaglehole, 2009; Humpage, 2019). While once dominated by a reluctance to take refugees from non-European origins (Beaglehole, 2009), Aotearoa NZ's acceptance of refugees from myriad national and ethnic backgrounds since the early 1980s has become a cornerstone of its identity as a humanitarian actor in the global sphere (Rt Hon Jacinda Ardern, 2017).

Within Aotearoa NZ itself, the desire to identify as a humanitarian nation is clear. While discrimination and hostility contribute significant barriers to successful resettlement for former refugees in Aotearoa NZ, research from the field cites public response to policy as positive, noting "many New Zealanders view with pride the country's humanitarian impulse with regard to refugees over many decades" (Marlowe et al., 2014, p. 66). A recent survey undertaken by Refugees as Survivors NZ reports that over half of the 1000 participants surveyed were in favour of refugee acceptance and support. Among reasons specified in favour of refugee intake were global responsibilities given Aotearoa NZ's capacity, and self-identification as a "kind and open nation” (RASNZ \& Colmar Brunton, 2020, p. 23).

Further with growing public compassion for the former refugee community following the Christchurch attacks in March 2019 (epitomised by a threefold increase in public volunteer support for refugees), the challenge to measure up to the political rhetoric on humanitarian

1 I elect to use the name Aotearoa New Zealand in recognition of the name(s) given to this country by Māori as Tangata whenua. I adopt the common abbreviation for 
assistance and national identity has been articulated as of critical importance across all points of the political spectrum of late (Amnesty International, 2020; Edwards, 2019; Iddamalgoda, 2019; Todd, 2019). Arguably, with such an opportunistic political climate, research into refugee pathway reform in Aotearoa NZ has never had a more receptive audience.

The defining values of humanitarianism were identified by Jean Pictet (1979) of the International Committee of the Red Cross and comprise of four core principles: humanity, impartiality, neutrality and independence. The first two of these principles arguably encompass what is meant by references to Aotearoa NZ refugee policy as 'humanitarian'. Humanity denotes attention to all people and a purpose to "to protect life and health and to ensure respect for the human being" (Pictet, 1979, p. 1) and impartiality distinguishes that assistance be provided on a basis of need irrespective of religion, race, gender, or political opinion. As one of only 35 countries with an annual settlement programme, Aotearoa NZ's long (albeit contentious) history of offering refugee assistance and settlement opportunities is often framed as "exceptionally humanitarian" although many scholars today question this in light of current global need and the sizeable intake of refugees into other comparable signatory states (Humpage, 2019, p. 2).

In 2016 the Syrian refugee crisis instigated public calls for an increase in Aotearoa NZ's annual refugee quota intake, the national government of the time raised the number from 750 to 1000 per year. This was not insignificant given the quota had not been increased since 1987. However, against a backdrop of 22.5 million refugees worldwide, many felt Aotearoa $\mathrm{NZ}$ was falling short of its global responsibilities, demonstrated by the 20,000 plus signatories joining a successful public petition to double the quota (ActionStation, 2016; Walters, 2018).

A new coalition government in 2017 brought renewed promise to refugee policy in Aotearoa NZ with significant changes including an extension of the refugee quota for its annual settlement programme, additional investment in public services, and the introduction of a Pacific Climate Change Pathway for those displaced by the increasing impact of climate change. In September 2018 Prime Minister Jacinda Ardern announced an increase in quota numbers by $50 \%$ referencing her pride in Aotearoa NZ's offering of "such a significant and historic increase" in intake of 'Quota Refugees' to 1500 per year by 2021 (New Zealand Government, 2018). 
Quota refugees are known as such because they have been granted refugee status by UNHCR. Their applications have met refugee convention criteria prior to arriving in the country as one of a certain number or "quota" agreed upon for intake by the New Zealand Government. Actual intake numbers over the years have ranged from 750 quota refugees in 1997 to 1020 quota resettlement cases in 2017-2018. While the current government's commitments to quota increase is unprecedented in size, it is also important to note that these numbers are markedly small compared to other states (such as neighbouring Australia whose intake stands at 20,000 per year). Further, the recently increased national quota represents only a fraction of immigrants arriving in Aotearoa NZ in 2018, of which there were 68,000 (Humpage, 2019; MBIE, 2018), undermining ideas that refugee intake significantly alters the impact of immigration on state resources.

In addition to arriving via the quota programme, around 300 applications are made per year from asylum seekers, the majority of whom arrive on valid visas and make claims after living (and often working) in the community for one year or more. Only 5\% of asylum seekers are reported to make claims on arrival at an Aotearoa NZ airport without appropriate documentation (MBIE, 2018). Over half of these asylum claims made on arrival are approved and claimants become referred to as "convention refugees". They then have the right to apply for permanent residency although this process can be long and "laden with hurdles...with severe health and well-being impacts" (A Bloom \& Udahemuka, 2014, p. 79).

\section{Family Reunification in Aotearoa NZ}

Former refugees who arrived via both the Convention and Quota pathways are (theoretically) given the opportunity to sponsor family members under one of four immigration policies: The Refugee Quota Family Reunification Category; Refugee Family Support Category Tier 1 and 2; and the "Special Directions" request for ministerial discretion on strong humanitarian grounds. Due to numerous obstacles in refugee policy and the, presently overwhelmed, bureaucratic processes of Immigration New Zealand these pathways are currently inaccessible or unavailable to many and highlight the need for policy review, as will be explored further in both this chapter and the proceeding research. 
It is understood that reunification with family members is the single most influential factor for successful resettlement and trauma recovery for former refugees in Aotearoa NZ (Changemakers Refugee Forum, 2009; Choummanivong et al., 2014). Those arriving via the quota refugee pathway are offered reunification with either a partner, child or parent on whom they depend.

At the time of writing, only 300 places are available to former refugees who wish to be reunited with an additional family member. In 2019741 people applied for family reunification under the refugee family support category (MBIE, 2020). Of these applications, 61\% (453) were rejected, most on the grounds of failing to meet eligibility criteria. On this basis alone, the case for review of refugee family reunification (RFR) policy in Aotearoa NZ is incontrovertible. While this is reflected in government commitments to both review and fund RFR policy over the next three years, the nature of this review appears to be focused on increasing numbers alone. There remains very little recent literature that seeks to understand why RFR policy fails our former refugee communities in such drastic numbers.

This research aims to address this gap. I begin my inquiry from the perspective of social exclusion. I seek in both my research questions, and later discussion, to consider who is excluded from reunification processes; who does not 'fit', and why. In asking specifically about the exclusions experienced by those most marginalised groups in the refugee population (LGBTQIA+ or those who trouble ideas of the hetero-nuclear family model), I challenge the socalled 'norms' which drive current Refugee Family Reunification policy criteria in Aotearoa NZ. This research aims to capture the barriers and exclusions former refugees face in applying for RFR, and to explore further the discourses which underpin these. I also aim to document policy recommendations from participants advocating for and working in RFR processes.

In what remains of this introductory chapter I briefly review the literature on family reunification in Aotearoa NZ, its importance, impact and current policy pathways. I then outline influences from development literature and my interpretation of resettlement and development studies in a post-development era as they pertain to the Aotearoa NZ context; particularly how queer development research offers an example for its methodological application to RFR review. I add 
to this an acknowledgement of the interdisciplinary contributions of critical kinship woven into some of the core themes and understandings discussed throughout my findings and analysis. Connecting these insights with my motivations to undertake this research, I then introduce the research questions and design. Next, I share my rationale for the use of terminology as it pertains to resettlement research and the communities for whom this research exists. Last, I finish with an overview of my thesis structure, signposting what is to come from context to conclusions.

\section{The Case for Refugee Family Reunification (RFR)}

There is growing understanding as to the critical nature of family reunification for former refugees, both in terms of emotional and mental wellbeing and in terms of 'successful' graduation from resettlement services and participation in the social and economic fabric of Aotearoa NZ society. In this research, I consider and define family reunification as Cecile Rousseau (2004) and C. Choummanivong (2014) do: simply the bringing (back) together of family that has been separated for various reasons along their journey from flee to resettlement. For former refugee families, unlike migrant families, separation is marked often by trauma, or at least is a result of circumstances outside of choice. This leaves families in a state of deep anxiety about separation, wrestling with uncertainty and grief and unsurprisingly impacting former refugees' capacities and experience in third-country resettlement (Rousseau et al., 2004).

In 2010 an extensive research initiative into International Migration Settlement and Employment Dynamics provided overwhelming evidence of the need for improved refugee outcomes in Aotearoa NZ (IMSED, 2010). It prompted the implementation of a National Refugee Resettlement Strategy in 2012, a whole government approach to improving resettlement outcomes. The strategy centres on outcomes for self-sufficiency, participation, education, housing, health and wellbeing (Immigration New Zealand, 2012). While the efficacy of this strategy has come under some critique for omitting to consider wider social and structural issues (Marlowe et al., 2014; McBrien, 2014), it does provide a commitment to improved outcomes for former refugees and a framework of accountability from which to address RFR in Aotearoa NZ, most notably health and wellbeing. 
Choummanivong et al., in undertaking a 2011 study into the impact of family reunification on mental health and resettlement outcomes in Aotearoa NZ, found that $85 \%$ of participants named family reunification issues as their paramount obstacle for successful resettlement. This research followed a 2009 case review into refugee family reunification in the greater Wellington region $(\mathrm{n}=32)$ which found $93 \%$ of resettled refugees requiring mental health support from the Refugees as Survivors Trust, once reunited with their families, showed such abatement in symptoms that they were able to be discharged from the service. (Changemakers Refugee Forum, 2009). Ratifying the findings of this review, one participant in Choummanivong et al.'s later ethnographic enquiry across major resettlement centres nationwide captured how anxiety and feelings of guilt over loved ones' safety, inhibits resettlement:

"For the most part I felt unsettled because it was hard having to picture what your loved one was going through each moment I was trying to enjoy this new environment. (Focus Group 2) “(Choummanivong et al., 2014, p. 95).

In contrast, the emphatic responses from former refugees who have successfully undergone family reunification pathway processes (as reflected in the aforementioned statistics relating to mental health service use), are overwhelmingly positive.

Countless reports from support recipients of Auckland Refugee Family Trust capture the elation at "becoming one again" relaying feelings of completion, hope and describing reunification with loved ones being "like a dream" (Auckland Refugee Family Trust, 2020). While often the ramifications of involuntary separation can make reunification complex, and adjusting to a new life together again is not without its difficulties, what becomes clear here is that to former refugees, family reunification is, as Rousseau et al., (2004) refer to it, the panacea to end their journey and thus, their suffering. Such a view of RFR processes gives weight to the role reunification has to play in the mental and emotional well-being of those resettling in Aotearoa NZ.

Also revealed through Choummanivong et al.,'s study is in-context evidence for arguments recognising the fundamental role of family reunification for the practical aspects of societal 
integration (Ager \& Strang, 2008). Participant responses in their study often referred to the importance of family and community support:

"My sister helped us to settle in New Zealand when we arrived because my

elder sister was here before ... she showed us hospitals, shopping centres and schools ... she used to interpret for us all the time. (Focus Group 5)

When I was coming here some Somali community supported me like showed me how to shop and catch up the bus. They also helped me find the house.

Without them I would not know what to do. (Focus Group 4)

I think I put my faith and my trust in God. And with the members of my family and my community parish who supported me. Make me feel settled ... because when I lived in Africa my connections with my community parish was great. (Focus Group 10) “(Choummanivong et al., 2014, p. 96)

It is unsurprising that when the mental and emotional needs for reunification of former refugee families are addressed, they are able to refocus energy on the everyday priorities of resettlement such as obtaining employment, community involvement and language learning (Wilmsen, 2011); all of which alleviate the concerns of and meet the voiced strategic aims of both the New Zealand Government (Immigration NZ) and former refugees themselves when it comes to resettlement outcomes.

\section{Policy Pathways}

The literature suggests widely understood and empirically supported arguments in favour of family reunification as benefitting both third country society and those undergoing resettlement. Considering this, questions arise as to why, almost a decade after the discussed studies, RFR as an immigration pathway continues to result in more rejections than acceptances.

In the case of a former refugee who arrived in Aotearoa NZ under the annual quota for UNHCRmandated refugees there is provision to apply for one "immediate" family member to be granted 
a resident visa to join them in Aotearoa NZ. Known as the Refugee Quota Family Reunification Residence Category, this pathway classes "immediate" family members as only those which fall under partner or dependent child, excluding aunts, uncles, siblings, cousins, grandparents or any other relatives (Community Law, 2019). There is only provision for reunification with a maximum of one adult and one dependent per person.

A secondary pathway exists for those who do not qualify for residence under the quota family reunification pathway. Known as the Refugee Family Support Residency Category this scheme enables former refugees to sponsor family members in their applications for a residence visa. This category is tiered according to whether an applicant already has family in Aotearoa NZ. Tier One (T1) offers up to 300 places available for sponsored family members of former refugees to join them in Aotearoa NZ. This tier is open to a wider variety of family members such as parents, adult siblings and children, grandparents, aunts/uncles, and nieces/nephews (including that sponsored person's partner or dependent children). However, it is important to note that former refugees can only register as a sponsor for these family members if they do not already have "immediate" family in Aotearoa NZ; "immediate" family here referring to partners, parents and children who are 21 or older (Community Law, 2019).

With so few places available (300 for every 1,500 Quota refugees) and restrictions on those who already have a family member in the country, opportunities to register for application have been few and far between. When a second tier opened up in 2012 allowing reunification with extended family for those who already have immediate family in the country, Immigration New Zealand were so inundated with registrations $(6,000)$ they closed this pathway after just two days. Tier two (T2) enabled residents who had been in the country for three or more years to sponsor parents, adult siblings, and adult children. If a T2 sponsor has a grandparent as legal guardian, they may also qualify under this scheme. T2 excludes aunts/uncles and nieces/nephews.

Given the differing nature and importance of familial configuration according to cultural background, sexuality, and individual circumstance, (all of which will be discussed in the following chapters), T2 provided many with an important opportunity for reunification when it re-opened in November 2017. Despite its prompt closure and the ongoing prioritisation of T1 applications over the processing of registrations still pending for T2, many remain hopeful of this 
opportunity becoming available again. At this stage, Immigration New Zealand anticipate it will likely be another 3-5 years before this pathway may be re-opened citing an overwhelm of case load for processing (Immigration New Zealand, pers comms, 2019). 


\section{Reunification Pathways Visualised}

The basic scaffold of these pathways is visualised below. I have created these figures to clarify what is classified as eligible under each policy. Each figure follows options available to the stated refugee status and their existing family status in NZ.

Figure 1.1. Family Reunification Pathway options for refugees arriving via UNHCR Quota pathway.

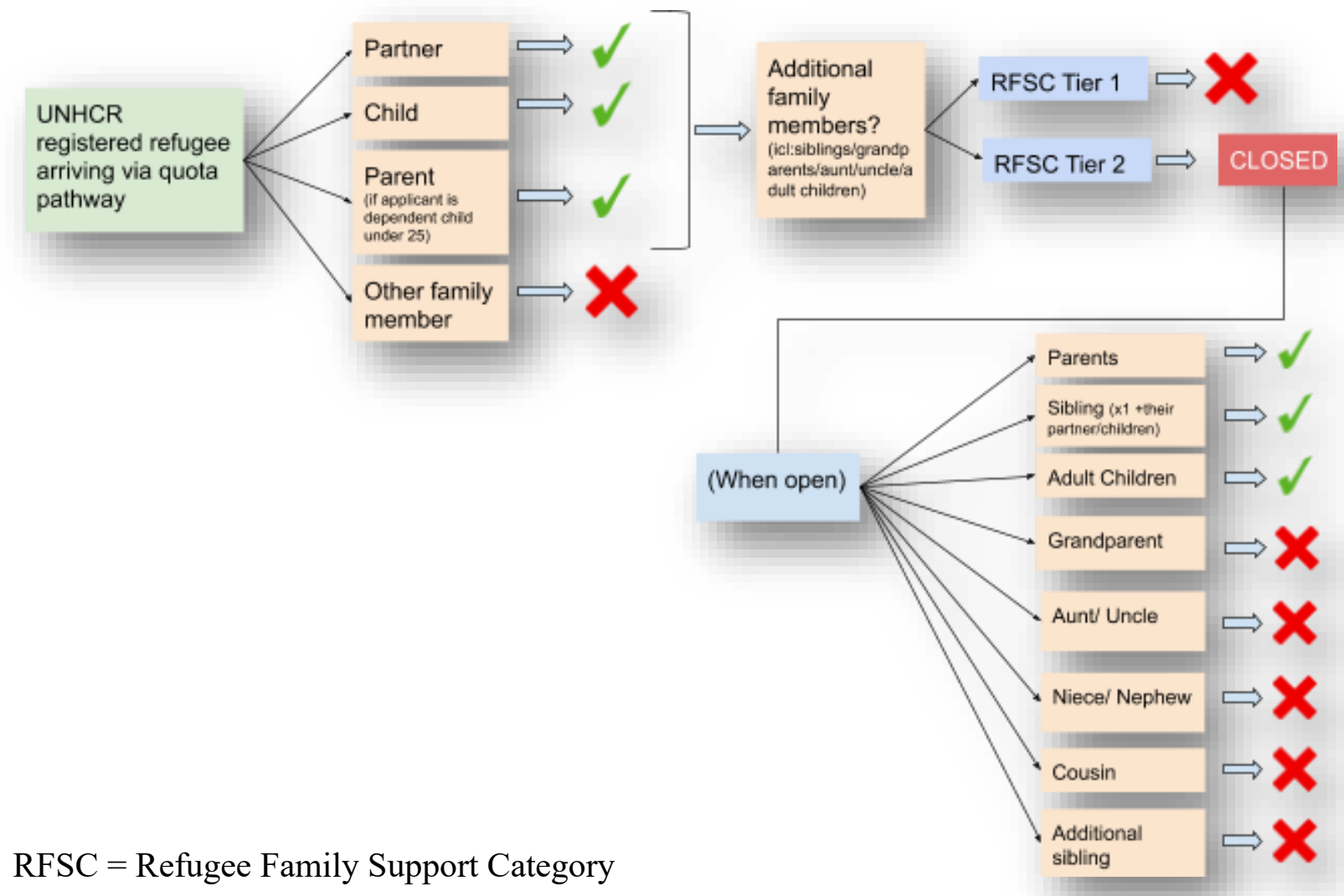


Figure 1.1: Refugee Family Reunification/Support pathway options for Convention Refugees with existing family members in Aotearoa New Zealand.

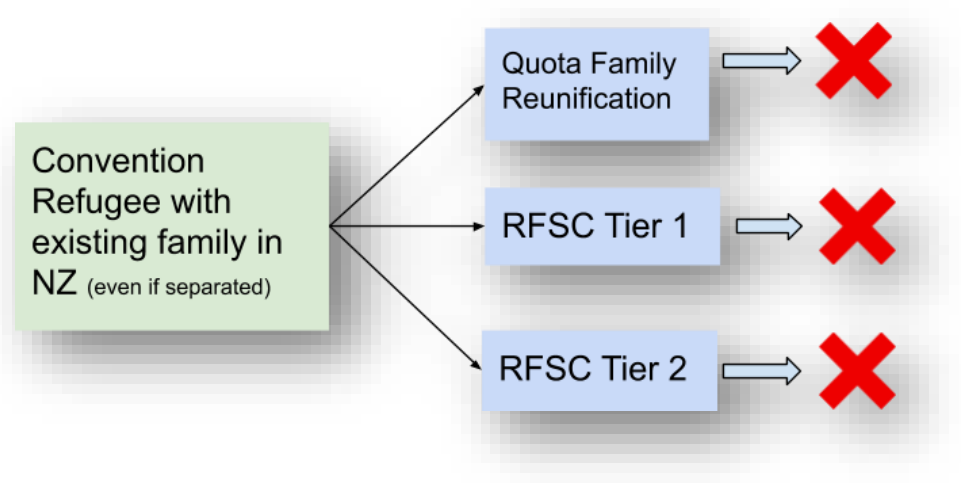

Figure 1.2. Refugee Family Support Category Pathway options for Convention Refugees with no existing family in Aotearoa New Zealand.

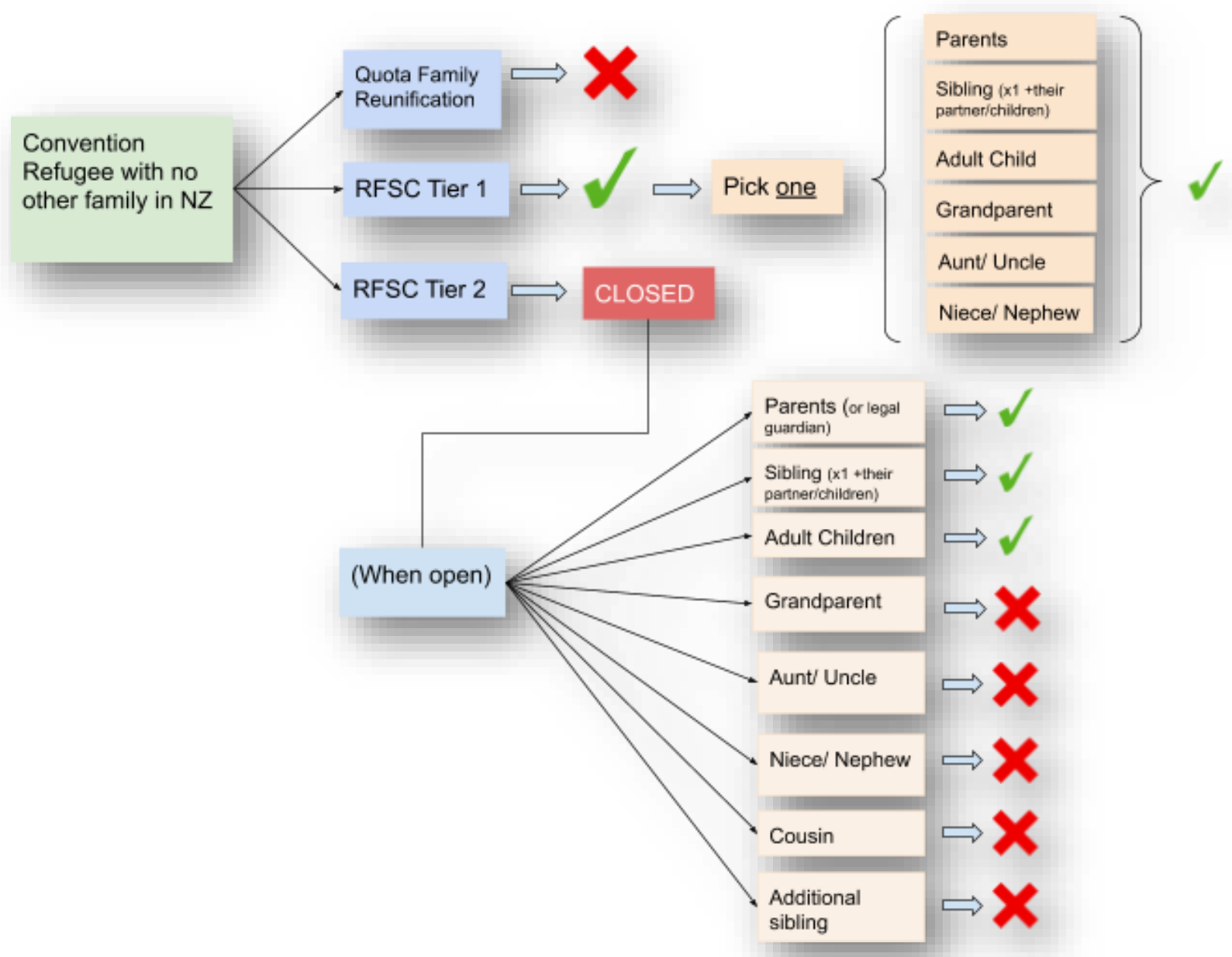




\section{The Changing Landscape of Refugee Family Reunification}

When I set out to begin this research, there was little to no reference to refugee family reunification policies in either academic or grey literature since it was last reviewed by a collective of Wellington refugee support services in 2009. Commitments to "Review, and adequately fund and support, the family re-unification scheme for refugees" are featured in the 2017 Confidence and Supply Agreement between New Zealand Labour Party \& Green Party of Aotearoa New Zealand (2017, p. 5), however little information on this was available. Most notably, discussion of refugee family reunification pathways was absent amidst the 2018 quota increase announcements, and with a general election looming as I embarked on fieldwork, it was not clear if the window for policy review or support had been missed. Then, however, on $14^{\text {th }}$ May 2020, the Labour-led coalition government announced an allocation of \$22million to review and support refugee family reunification over three years beginning in 2021. This announcement formed part of the 2020 Wellbeing Budget (New Zealand Government, 2020) and was to include a doubling of current caps on places available from 300 to 600 , reflecting the increase in quota intake. I have outlined below a timeline to indicate the intersection of this research and the everevolving landscape of RFR policy, it is hoped that by visualising this process I am able to identify and convey prior milestones and future potential as it pertains to RFR and the intentions of this thesis. 
Figure 1.3: Timeline of key milestones in resettlement policy on or intersecting with RFR

Refugee family reunification (RFR) policy

in Aotearoa

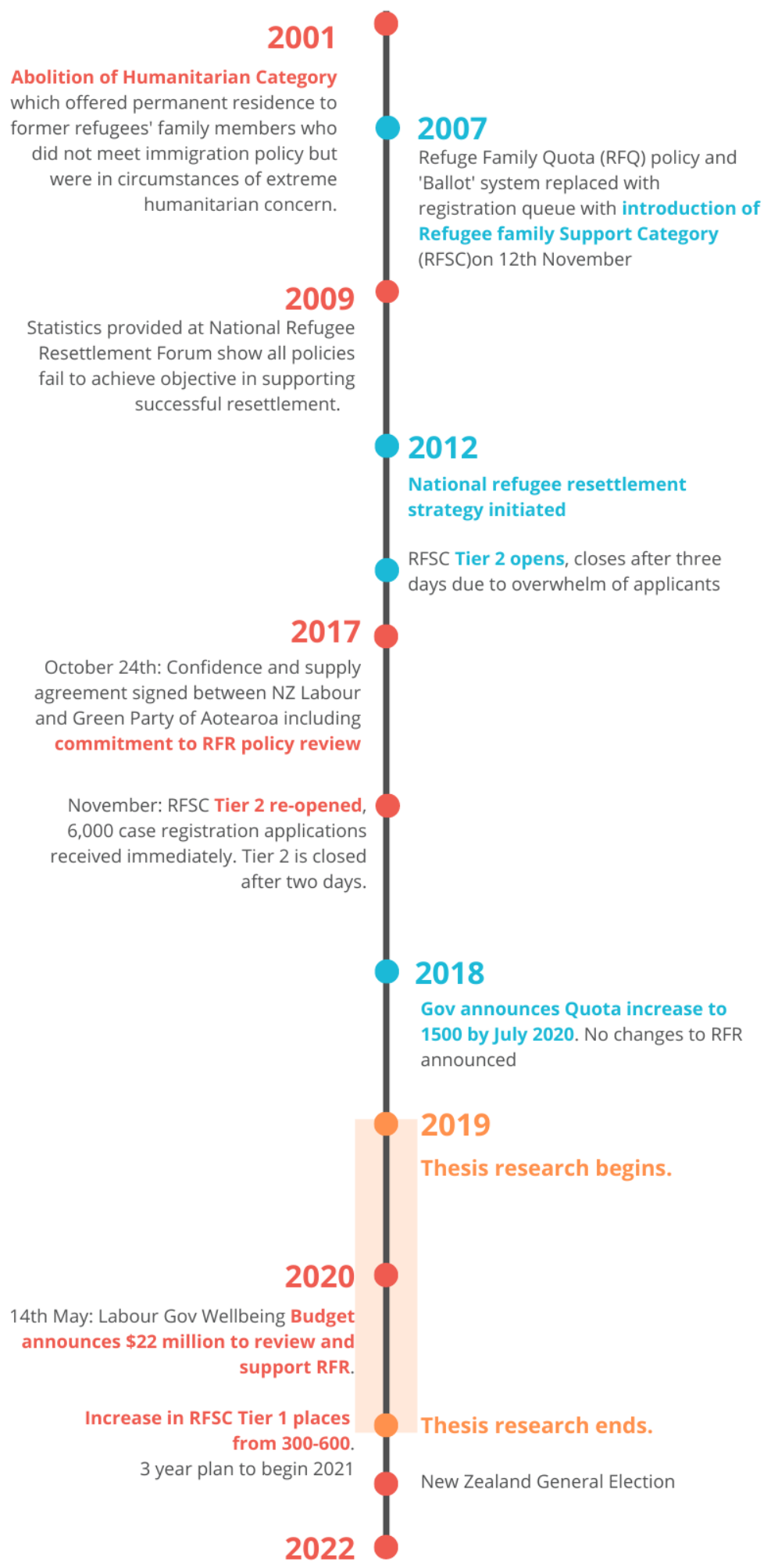

\section{7}

registration queue with introduction of

Refugee family Support Category

(RFSC)on 12th November

RFSC Tier 2 opens, closes after three

days due to overwhelm of applicants

October 24th: Confidence and supply agreement signed between NZ Labour nd Green Party of Aotearoa including

commitment to RFR policy review

November: RFSC Tier 2 re-opened, 6,000 case registration applications after two days. 


\section{Influences from Development Literature}

\section{Post-development, queer theory and the Aotearoa NZ context}

Post-development critiques of development as a new form of western imperialism underpin the desire for this research to focus within an Aotearoa NZ context. Understanding that ideas of the 'Third World' are constructed from colonial discourse and, more recently, neoliberal agendas of hegemonic western powers, the task of development studies is shifting to "validate, protect, and revive non-Western ways of life" (Matthews, 2010, p. 1). Queer and feminist development theory have emerged as alternative development discourses. While queer and feminist development approaches do find their origins in predominantly western academia and practice, their critical and reflexive approach works to challenge embedded western hetero-patriarchal norms. Such challenge contributes to the pursuit of countering neoliberal hegemonic power in a globalised world, where too often development is a bilateral tool utilised for geopolitical interests or inadvertently contributes to perpetuating ideas of western superiority (Escobar, 1992).

These ideas of western superiority often and unfortunately, extend to the treatment of former refugees as they resettle in the global north. The dominance of western heteronormative structures frequently rendering former refugees excluded from opportunities offered by state structures and policy. The task of this development research is to explore how these heteronormative structures manifest in policy in Aotearoa NZ and in what ways those on the margins are affected or excluded, to seek a basis of understanding from which policy reform may eventually emerge.

Understanding that Aotearoa NZ itself has a history of colonisation and ongoing western oppression of indigenous peoples, this research understands that true policy reform must turn attention to Tikanga as first law of the land. Paying credence to Ti Tiriti and Indigenising our approach to immigration would involve recognising the status and rights of Māori as Tangata Whenua while also giving "substance to the fullness of multiculturalism" (Kukutai \& Rata, 2017, p. 33). Kukutai \& Rata (2017) outline a framework for an immigration policy based on manaakitanga which will be explored later within this thesis. A fuller engagement with 
indigenising approaches to policy is beyond the scope of this thesis; but connections are made to it at different points throughout.

\section{Queer(y)ing development: Development with a body}

Queer theory offers a means to interrogate mainstream development approaches to practicerevealing and interrogating their assumptions, biases, inclusions and exclusions associated with cis-gender patriarchal heteronormativity. Recognising the importance of deconstructing colonial hetero-patriarchal influence on refugee policy (and community development more broadly in Aotearoa NZ) therefore led me naturally to queer theory.

Cornwall and Jolly note that "there is a silence at the heart of mainstream development." (2006, p. 1) when it comes to sexuality. Importantly, they define sexuality as encompassing far more than whether, and with whom, one has sex; elsewhere Cornwall, Correa \& Jolly discuss sexuality as:

"about the social rules, economic structures, political battles and religious ideologies that surround physical expressions of intimacy and the relationships within which such intimacy takes place... and where society and the state collude in policing gender and sex orders, it can be about the very right to exist." (2008, p. 6).

Understanding that development itself must be "fundamentally concerned with the well-being of people as whole people- not just in relation to their utility or capacities, [economic needs and civil rights] ...but in terms of all that makes us fully human." (Cornwall et al., 2008 p.18) is of critical importance to the pursuit of social justice and the subversion of power structures that seek to undermine it. This is particularly relevant in a post-development era where theorists challenge the prevalence of materialism (as influenced by western neoliberal thought) in defining development needs and basic rights (Hart, 2002; Sachs, 2009). Cornwall, Correa and Jolly conceptualise this approach as development, not just with a human face, but 'with a body' (2008). 
Applying a queer lens to research in this context actively brings those marginalised, queer, bodies to the forefront of policy review. Susie Jolly (2011) uses queer theory to explicate the means by which dominant western Gender and Development (GAD) approaches reinforce heteronormativity in research for community development (most notably assuming heterosexual family units in needs-based analysis in China). Heteronormativity is here referred to as in Jeppesen's definition: "The dominant sexual model of social, cultural, political, and economic organization, including the way it organizes identities, experiences, regimes of truth and knowledge, and ideologies of gender and sex" (2016, p. 1).

Jolly reflects on her experiences with a development-focused research project on gender and poverty in rural China. She notes the use of household interviews as a means of needs-based analysis with questions entirely focused on assumed heteronormative household relations. The realities of participant family set-ups, however, did not fit within these heteronormative social models; as Jolly laments: "We started with, and stayed with, rigid ideas about family set-ups, rather than recognising the diversity of their relationships and assessing how these connected with the hardship that we were trying to measure." (Jolly, 2011, p. 19). The heteronormative assumptions biased the information and understanding of need gathered, dictating how familial relationships were viewed in both the implementation and evaluation of development work (and indeed policy).

Jolly's use of queer theory to undertake an exposition of subconscious western/heteronormative bias and its consequent discrimination and omission of myriad alternative family structures can also be applied to a critical analysis of the current family reunification pathway, and its limitations in how it defines qualifying family applicants. Reading Jolly's reflections made me wonder about how former refugee families were viewed and understood, what kinds of questions were asked of and about them in the gathering of information for policy, development programs, and service provision. When I investigated this further, I could find no answer so decided to design this research project to find out. 


\section{Feminist theory and critical kinship as conceptual influences}

Due in part to its emphasis on challenging the intersection of power and construction of normative ideas, there is a tendency for queer theory to contribute to and draw from multiple disciplines. In much the same way I approach my queer(y)ing of RFR policy from an academically interdisciplinary perspective.

This research takes a particular interest in the troubling of norms as they relate to hetero-western ideals of 'family' and the interplay between these embedded norms and family reunification policy for former refugees. Queer theory and feminist development theory provide a theoretical grounding. In addition, critical kinship helped me better understand the prevailing interpretations and criticisms of defining 'family' (a foundational aspect of reunification policy). Having rejected definitions of the family as related by biology or marriage, and problematised the mechanisms and motivations from which these definitions are promoted, critical kinship offers a new framework of kinship, one of relatedness. Viewing kinship as the description of a practice "a performance of forming and maintaining relationships" (Aikman, 2019, p. 11; Carsten, 2000) scholars have been able to draw on the multiplexities of relationships within families that exist outside of normative markers of biology and marriage to better understand the relational choice of kinship within and across cultures.

There is a rich body of ethnographic work that seeks to achieve this greater understanding of kinship as relational choice and does so by offering nuanced explorations of queer kinship bonds. Although my research does not exclusively focus on the LGBTQIA+ experience, nor is it an anthropological thesis, I have been heavily influenced by the work of queer anthropology and kinship studies in its elucidation of the fluidity of kinship bonds and its clear example that family structures can exist outside of the conventional hetero-western model. Notably, Kath Weston's Families We Choose: Gays, Lesbians, Kinship (1997) and Hailey Aikman's Exploration of Queer Experiences of Motherhood in Aotearoa New Zealand (2019) deepened my understanding of queer critical kinship studies and led to recognition of its applicability to the questions at hand in my research. Both works also highlighted the lived experiences of structural violence and social exclusion faced by many people living in families which do not conform to western heteropatriarchal norms. 
Salient across critical kinship literature is the caution to pay attention to the mechanisms which promote politically beneficial, socially constructed norms of the heterosexual nuclear family. This same caution I felt was pertinent to the examination (queer(y)ing) of family reunification policy and its impact on those who trouble these hetero-western norms.

\section{From Observation to Research Question}

My motivations to write this thesis came in some part from an embryonic understanding that former refugee family's trouble hetero-western norms. They may be overtly LGBTQIA+ or 'deviant' in their subversion of biological or marital relatedness and this can be to the detriment of their ability to continue practice of maintaining kinship relationships after resettlement in Aotearoa NZ. Working in the resettlement space in Wellington I often observed former refugee families struggle to attain RFR approval, and even families that were together in Aotearoa NZ had a difficult time getting appropriate welfare or housing support as a result of their nonnormative family configurations. When former refugees would arrive to meet with our team, often the first thing they asked was how to bring their family to join them in safety. Recognising that this 'how' was dependent on a family's ability to meet policy criteria, which appeared to exclude non heteronuclear family configurations, I began to research further.

Adopting a social constructivist epistemology and using a conceptual framework of marginality my research sought to uncover the experiences of those who trouble norms, in this case as it pertains to ideas of the family embedded in policy. I therefore asked the following questions:

- What are the common/key barriers to refugees successfully engaging in family reunification processes (from application to settlement)?

- In what ways are NZ's family reunification policy and its associated processes exclusionary to those who 'trouble' hetero/western norms?

- What are the subsequent priorities for policy reform?

My participant base consisted of actors from the various sectors and services which form part of the overall structure of family reunification and resettlement in Aotearoa NZ. These ranged from 
refugee background rainbow community members engaged in advocacy to management staff at Immigration New Zealand. While my research draws from the experiences and information shared by these participants, who form part of the very processes it seeks to examine (reunification law, resettlement and social service provision, charitable support etc.), the centre point of the refugee reunification structure is the lived experiences of former refugees themselves. Such experiences are brought to life through ethnographic research and literature that focuses on the pressures upon, and resilient tenacity of, former refugees in Aotearoa NZ (A Bloom \& Udahemuka, 2014; Choummanivong et al., 2014; Department of Labour (DoL), 2004).

This study did not seek to document these, nor did it work directly to obtain ethnographies of experience from former refugees themselves. However, recognising the picture of resettlement that previous research has offered, is foundational to understanding how these barriers discussed are situated within a context of resilience and suffering. Language barriers, loneliness and community alienation, ongoing anxiety for family members still in danger, post-traumatic stress and, in some instances, significant poverty, are continually combining and colliding with former refugees' pursuit of family reunification (Choummanivong et al., 2014; Keeble, 2017).

I employed thematic and discursive methods of analysis, the latter heavily influenced by the work of Michel Foucault and his attentiveness to power and the leveraging of discourse to establish a status-quo. Foucauldian discourse analysis (FDA) enabled me to interrogate underlying ideas and assumptions within RFR policy, and to document those marginal discourses which challenge them. I reflect critically throughout on my positionality as a tauiwi researcher, who benefits form cis-gendered privilege and who has not experienced refugeehood.

\section{A Note on Terminology}

In this thesis I understand the term 'refugee' as a person who has been forced to flee their home due to war, violence, conflict, disaster or persecution (Ford, 2012; UNHCR, 2010). I recognise that the experiences and causes of displacement may be diverse, but acknowledge the limitations and pressures refugees contend with as they attempt to ensure their safety, and that of their families, are comparable (Fitzgerald, 2017; Kamri-McGurk, 2012). I use the terms former 
refugee and refugee background interchangeably in this thesis to denote someone who is resettling in a new country, having survived a refugee experience (regardless of visa type or status). I also use these terms in acknowledgment that a refugee experience impacts upon an individual's current reality.

I also refer to people in the community who are non-heterosexual or non-cisgender as per the standard initialisation LGBTQIA+ (Lesbian, Gay, Bisexual, Transgender, Queer, Intersex, Asexual), I chose to use the common addition QIA+ to include those who are not lesbian, gay, bisexual, or transgender but who still face societal marginalisation based on their gender identity or non-heterosexuality. I also use the term rainbow community as an "umbrella term to describe people whose sexual orientation, gender identity, gender expression or sex characteristics differ from majority, binary norms." (RainbowYOUTH et al., 2018, p. 2); I find this to be the most inclusive nomenclature for the rich diversity of the rainbow population.

\section{Thesis Structure}

This thesis is organised into seven chapters (this being the first), chapter two locates refugee resettlement in the broader field of development studies and more specifically, rights-based approaches. Here, I outline a conceptual framework of marginality, and outline its alignment with my queer, social constructivist epistemology.

Chapter three expands on this epistemology with an explanation of my methodological approach to participants, interviews, and analysis. I reflect here also upon ethical considerations and my positionality as a researcher and note the limitations of this work.

Chapter four and five share the research findings per the key questions (above). These have been organised thematically, exploring barriers and exclusions in turn. Here, I share and draw reference and comparison from what existing research literature exists on the topic of RFR in Aotearoa NZ. 
Chapter six presents a discussion of dominant and counter discourses through my use of Foucauldian discourse analysis (FDA). I observe and expound three main discourses on 'the family' and discuss their implications for understanding RFR policy and its intersections with mechanisms of power and governance.

Chapter seven follows closely on from chapter six, with an emphasis on the limits of agency and discourse. I expand on ideas of governmentality and biopower which emerged from the FDA and continue to discuss the implications of this research for understanding RFR policy in the Aotearoa NZ context.

Chapter eight gives an overview of recommendations for policy reform. I then present my conclusions which draw attention to the need for greater research in the family reunification space that challenges constructions and promotions of heteronormative, Eurocentric ideas within policy frameworks. 


\section{Chapter Two: Literature Review and Conceptual Framework}

This chapter locates this research in the field of Development Studies. It outlines a conceptual framework of development from a marginality perspective suitable for Refugee Family Reunification research. I first address the ascendancy of rights-based approaches to international development, and indeed migration discourse, and how these manifest in the Sustainable Development Goals (SDGs). From here I discuss the need for attention to marginalised peoples in development processes and evolve a conceptual framework of marginality informed by social exclusion, critical kinship and queer theory. I outline both social exclusion and queer theory, what they are and why they are apt lenses through which marginality can be better understood. By way of example, I then apply these lenses to previously explored rights-based development approaches (the SDGs).

Next, I discuss refugeehood and queer experiences as being at the margins of rights-based development and identify a migration development nexus. I then dig further into understanding what is meant by 'queer subjects' (as marginal bodies) reflecting specifically on the exclusion of families from the majority of rights-based approaches to migration and development. Drawing from critical kinship literature I explore socially-constructed ideas of the family as a western heteronormative nuclear unit and its criticisms. I distinguish the focus of this research as interested in the experiences of queer subjects (that is simultaneously LGBTIQ+ individuals, and families which trouble the hetero-norm). Having outlined a conceptual framework of marginality, I then turn my attention to what a queer epistemology of social constructivism would look like for the purposes of this research, which seeks to centre the experiences of queer subjects in RFR policy review.

\section{Locating Refugee Studies Within Development Scholarship: the SDGs and Rights-Based Development}

Refugee studies have always been intimately connected to the study of development and policy (Black, 2001). Numerous scholars approach this connection from the perspective of development-induced-displacement. They suggest the role of western interventions in the global 
south, be it through economic extractive activities, local industrial projects, or geo-political conflict, cannot be ignored in its rendering of forcible relocation (Feldstein, 2017; Institutionsais, 2003; Kothari \& Harcourt, 2004; Rogers \& Wilmsen, 2020). Much migration literature recognises that forced displacement can result in the "intersectionality of disadvantage" (social dislocation, marginalisation, and economic deprivation) that development studies has historically sought to address (Yacob-Haliso, 2016, p. 53) .

This implicit connection between forced displacement and development is also evident in the emergence of 'rights-based' universal development discourse. As rights-based discourse began to influence global commitments to sustainable development under the UN (Langford, 2010), so too did the notion of rights begin to permeate the actions of UNHCR in both their protection of and promotion of third country resettlement (Griek, 2009).

Established in September 2015, the 2030 Agenda for Sustainable Development marked a notable shift in global development instigating a broad set of 17 Sustainable Development Goals (SDGs) and 167 targets. These targets, unlike their predecessor the Millennium Development Goals, are explicit in their desire to encompass all human rights listed as "economic, civil, cultural, political, social rights and the right to development" (UN, 2015: np). Universal in nature, these goals seek to recognise that all nation states face challenges to achieving the dimensions of social political and economic development captured in the SDGs. This conscious move away from ideas of hierarchy inherent in notions of the 'Third World' or 'developing' nations seeking to catch up with western 'developed' nations reflects a post-colonial shift in development discourse, a shift which remains critical of imperialist notions embedded within development agendas (Power, 2003; Radcliffe, 2005; Robinson, 2003). In this vein, some literature rightfully criticises the continuance of western neoliberal bias in the implementation and monitoring of SDGs (Struckmann, 2018). However, understanding that mainstream multilateral institutions officially recognise development to be a universally relevant pursuit further determines the relevance of refugee resettlement to development scholarship.

Favour for rights-based development approaches is expressed by many scholars as preferential due to its provision of a universal reference point for accountability (Gready, 2008). Additionally, many development practitioners and theorists suggest that rights-based approaches ensure the 
process of development is explicitly political. This politicisation occurs via the rights-based agenda for equal distribution of resources and advocacy for marginalised groups' access to these resources therein (Cornwall \& Nyamu-Musembi, 2004). These ideas find their origins in the New International Economic Order (NIEO) movement of the 1980s led by newly independent member states from the global south within the United Nations and culminating in The $1986 \mathrm{UN}$ Declaration on the Right to Development. This movement introduced development as operating on a global dimension rather than within the confines of state-citizen relations. By stressing the "the collective obligation of all states to create a just and equitable international environment for the realization of the right to development" (Cornwall \& Nyamu-Musembi, 2004, p. 1422), the 1986 declaration on the right to development lay a framework for non-discrimination and accessibility on a global scale, therefore necessitating consideration of stateless persons, refugees and migrants in rights-based development policy.

In the past decade, catalysed by events such as the Syrian refugee crisis and an ever-more globalised world, recognition of refugee migration and long-term development goals has continued to gain traction. In 2018 the "first-ever UN global agreement on a common approach to international migration" was established through the inter-governmentally negotiated Global Compact agreement (United Nations, 2019). This agreement marks the recent coming together of UN member states and multilateral agencies (UNHCR, World Bank and ILO) to create solutions and responses to protracted displacement. However, it should be noted that while rights-based approaches to refugee resettlement have become the standard for third country resettlement policy globally, the separateness of refugee resettlement from the accountability frameworks of the SDGs continues (Nahmias \& Baal, 2019). Further, to what extent global agreements on rights-based migration and development approaches have been reviewed for embedded exclusions of marginalised peoples is unclear in the literature.

\section{Development and Marginality: Towards a Conceptual Framework}

Informed by a rights-based approach, Von Braun and Gatzweiler (2014) discuss development from a marginality perspective, pointing to the need of understanding the "increasingly complex drivers of persistent poverty at societal and ecological margins." (2014, p. 4). Poverty here is considered as beyond the material deficit constructs of poverty which dominated early 
development theory. Authors note that poverty is indeed the absence of the multidimensional aspects that constitute human wellbeing. This emphasis on holism is implied in their opening definitions of development:

"Development is a process through which an individual, a community or a nation can progress economically, socially, culturally, psychologically and spiritually. The centre of any development is the human being, and human wellbeing is the ultimate goal of development." (Von Braun \& Gatzweiler, 2014, p. 4)

This interpretation of development as a process that must be approached from the perspectives, needs, and experiences of those at the margins of society, lays a foundation for analysing community needs of former refugees in Aotearoa NZ from a conceptual framework of marginality. Marginality in development literature has been explored at length through the lenses of social exclusion and queer theory. I will explicate each of these in turn.

\section{Social exclusion}

Theories of social exclusion first emerged in development literature as a subset of rights-based development, or the individual right to development. Ideas of the right to development gained traction as a result of Amartya Sen's capabilities approach. Sen first introduced the capability approach to economic theory in the 1980's, putting forth the argument that development must be viewed not from the perspective of what people lack, rather from the strengths-based perspective of what they are able to do. Interested in a person's capabilities (freedom and agency) to achieve functionings (various things a person may value doing or being), Sen (2001) set about conceptualising a capabilities approach which became the predominant paradigm for understanding and quantifying human development. This paradigm is still dominant today in rights-based approaches underpinning multilateral commitments to the SDGs and global evaluative frameworks such as the Human Development Index. 
A post-development critique of Sen's capabilities framework rightly points out its use as a measurement tool in the perpetuation of hierarchical ideas of 'developed' and 'underdeveloped' countries; ideas which are premised on Eurocentric notions of development and industrialisation that omit to address the local, socio-political and cultural contexts of the peoples and societies to which they are applied (Salleh, 2016; Weber, 2017). However, Sen's view of poverty as "capability deprivation (that is, poverty seen as the lack of the capability to live a minimally decent life)" (Sen, 2000, p. 4) is crucial in locating the origins of social exclusion in development discourse and practice.

Sen argues primarily that the inability to be able to interact freely with others is an important deprivation in itself in that it "relates to the importance of taking part in the life of the community, and ultimately to the Aristotelian understanding that the individual lives an inescapably "social" life." (Sen, 2000, p. 4). However, the impact of social exclusion in leading to "other deprivations" (i.e. the inability to gain employment leading to economic poverty) form the main body of Sen's argument for considering social exclusion and its application as a factor in development policy and discourse.

Development theorists have since interpreted social exclusion as operating in three main spheres: economic, political and social (Estivill, 2003; N. Fraser, 2010; Vaast \& Mills, 2018). It has been established that the economic aspect of social exclusion (access to and ownership of resources) has had much emphasis placed upon it within development discourse. Exclusion, as it relates to the political sphere, is also well established through a universal human rights-based discourse. Social exclusion, however, and its intersection with these spheres remains an area of increasing understanding and nuance.

Estivill (2003) conceptualises the social aspects of exclusion as characterised by "successive ruptures" (2003, p. 19) or the disturbance of mainstream cultural and social values: i.e., what is acceptable in relation to dominant norms and the power structures built upon and within them (Estivill, 2003; Vaast \& Mills, 2018). There is a confluence of interest in the disruption of dominant norms and power structures in the lenses of social exclusion and queer theory as explicated by Estivill. This thesis will therefore follow the lead of queer development authors Vaast and Mills (2018) in drawing on Estevill's definition of the term: 
"Social exclusion may therefore be understood as an accumulation of confluent processes with successive ruptures arising from the heart of the economy, politics and society, which gradually distances and places persons, groups, communities and territories in a position of inferiority in relation to centres of power, resources and prevailing values." (Estivill, 2003, p. 19)

While these factors (power, resources and prevailing values) are interlinked, they hold certain characteristics relating to the amount people can fully participate in different realms of society. Kabeer (1994) notes the relationship between exclusion as not only predicated on who one is (subjective understandings of self) but on externally-applied identity categories (how one is categorised by others), and concludes that social exclusion is fundamentally related to one's actual and/or perceived identity. Kabeer argues that social exclusion operates on this individual level as much as on an institutional and societal level and that the various factors that 'lock out' groups and individuals are a confluence of all three aspects of power, resource and prevailing values.

In considering refugeehood, scholars have long applied social exclusion to mainstream development policy to promote, as I have done thus far, its place within the work and study of social justice (Silver \& Miller, 2003). Others, such as Kabeer, have extended understandings of social exclusion to recognise the individual nature of exclusion as it pertains to identity and imposed categorisation within socio-political contexts. Queer theory makes space for these identities, and their resistance to normative systems of categorisation, to become the central focus of research.

\section{Queer Theory}

\section{Resisting heteronormativity}

Emerging in the 1990's from multiple critical and cultural contexts, queer theory takes a constructivist approach to gender and sexuality recognising the role of social context in determining the categorisation of gender, sexual, and familial kinship forms according to cultural 
'norms'. As a critical theory approach developed largely within western academia, queer theory interrogates the cultural norms and consequent categorisation of sexual identities from this context, all of which are predicated on heterosexuality. Eurocentric heteronormativity assumes that heterosexuality is the default, or normal, mode of sexual orientation and underpins the structuring of societal norms around gender binaries of male/female. Adrienne Rich (1980) asserted further that heterosexuality is enforced as a norm by patriarchal and heteronormative society, she called this process "compulsory heterosexuality".

By challenging finite identity categories based upon these heterosexual assumptions, queer theory contests binary ideas of gender, sexual, and familial kinship forms as either normative or deviant. Queer theorists achieve this largely by foregrounding the experiences of the 'deviant'; people who do not fit into normative categories (gay/straight, male/female) of heteronormative kinship forms or gender roles. In doing so queer theory's seeks to destabilise identity categories of gender and sexuality and thus critique the social organisation that these categories underpin. This destabilisation extends beyond the purposes of critique to form part of a search for social justice, a reckoning of marginalising structures and systems.

\section{Feminist and poststructuralist origins - resisting binaries and reconceptualising power}

Most often queer theory's emergence is attributed to the foundational work of feminist political and scholarly activity (Turner, 2000; Watson, 2005). Certainly, its critiques of "the practice and representations that produce and circulate gender hierarchies" (Watson, 2005, p. 71) find their academic origins in both gay and lesbian studies and feminist theory. So too does the term 'queer' emerge as an alternative to homonormative sexual identities; that is those based upon heterosexuality and binary categories of gender therein (DeLauretis, 1991). As Turner observes:

"The term queer allowed for the possibility of keeping open to question and context the element of race - or class, age or anything else-and its often complicated, unpredictable relationship to sexuality.” (Turner, 2000, p. 133)

Indeed, Judith Butler (1993) took this conceptualisation of queer further, introducing the idea of gender as performative and seeking to disrupt and subvert the adoption of gestures, movement 
and clothing which signify gender in order to argue heterosexuality as contingent. This laid groundwork for the centring of queer subjects in queer research, to disrupt norms.

However queer theory also finds its origins in post-structuralism and theories of discourse (Watson, 2005). Theorists such as Jacques Derrida (1978) and Jacques Lacan (1973) explored ideas of symbolism and language as constructing identity and sexuality, and binaries of proper/improper. They maintained that to understand an object or text one must study the systems of knowledge which produced it. Arguably one of the most influential poststructural theorists for queer theory was Michel Foucault. Foucault maintained that identity is historically situated and highlighted the role of discourse in creating knowledge "i.e. things do not exist waiting to be discovered - the discourse speaks the object (i.e. sex/sexuality) into being as well as its subject (the homosexual)." (Watson, 2005, p. 70). Foucault also reconceptualised ideas of power not as something owned or exercised but as a "matter of relationships and interactions among individuals" (Watson, 2005, p. 70). The consequences of this idea of power as relational were significant for queer theory as it claimed that in relationships where power operates (e.g. between state and citizen, or two individuals, to enforce heteronormativity), the possibility for resistance through reverse discourses occurs as well. Recognising this possibility for resistance is crucial to understanding forms of social exclusion as volatile, able to be resisted by the queer subjects it leaves out and overhauled by marginal frameworks of power/knowledge.

\section{Criticisms}

Queer theory's emergence from academic contexts forms the basis for many of its criticisms. Its position within academia is seen by many as representative of the high theorising of elitist educational institutions which fails to produce tangible solutions. Berlant and Warner (1995) challenged its status as an academic theory citing its ineffectual problem solving capacity. They referred to it instead as involving "a certain amount of...prancing and squatting on the academic stage" (1995, p. 348). Kirsh (2000) and Garber (2001) further criticised the reduction of queer theory in the academy to a popular buzz word: "a repackaged and revitalised commodity used by universities in their efforts for renewed consumption" (Watson, 2005, p. 76), locating it within wider criticisms of capitalist commodification of progressive ideas. 
As a theory largely originating in white, western academia there is a body of valid criticism that seeks to demand greater intersectionality in queer scholarship. The need for greater attentiveness to class relations (M. Fraser, 1999) and race (Samuels, 1999) remains a salient challenge in contemporary queer literature. However, I argue these criticisms should be seen as constructive in steering the evolving field of queer theory rather than as means to dismiss it altogether; for it continues to provide a crucial lens for researchers like me interested in social exclusion and marginality, as well as, "a framework for understanding the constitution of identities...and as a method to disturb the heteronormative, taken-for-granted positions/assumptions about sex, gender and sexuality in which ...persons are rendered as problematical against a stable heterosexual norm" (Watson, 2005, p. 79).

\section{Queer theory and its relevance to development and migration studies}

Interdisciplinary in nature, queer theory brings attention to issues of power, access and prevailing norms. In doing so, queer theory enables researchers to bring to the fore those who are marginalised within socio-economic spheres, thus challenging the efficacy of social policy. Queer theory not only recognises exclusions but seeks to centre those excluded, 'queer' bodies as a productive practice of theory for improved social outcomes (be they through policy or otherwise). As already discussed in my introductory chapter, the application of queer theory to policies and programmes of development prevents the reproduction of exclusionary norms. Norms which may otherwise occur through development initiatives (aid, policies, programmes) occurring within, and thus reinforcing, the already established status quo.

Queer theory's practicality in resisting the reproduction of exclusionary norms is crucial for migration scholarship. Luibheid (2008), for instance, has pointed out that the embedded intentions (subconscious or not) to reproduce normative hierarchies of power are revealed when resettlement policy is placed under the lens of queer theory. This process reveals how "migration regimes and settlement policies contribute to producing not only those who become variously defined as "queer," "deviant," or "abnormal" but also those who become defined as normative or "normal" within a binary structure intimately tied to racial, gender, class, cultural, and other hierarchies" (Luibhéid, 2008, p. 171). If RFR policy is to be reformed in Aotearoa NZ, it is vital to do so from the perspective of those most excluded, "deviant" and most marginalised bodies. 
Queer theory exposes the production of and preservation of the 'normative' in context; in this case the context of RFR in Aotearoa New Zealand (be it social hierarchy, gender identity, sexuality, familial structures and definitions). By doing so, it allows researchers to challenge and expand ideas of family within the power structures that shape resettlement in Aotearoa NZ. The task of the queer scholar in migration studies is thus "to foreground and challenge regimes of power and knowledge that generate structures of impossibility where particular groups are concerned, and to examine how individuals negotiate them" (Luibhéid, 2008, p. 171).

\section{Social Exclusion, Queer Theory, and the SDG's: Revealing the Migration Development Nexus}

Given its attention to the individuals' capabilities to participate in community life, social exclusion offers an appropriate lens through which to consider the lived experience of former refugees. Queer theory adds to this in its attention to those who trouble norms and may thus be ignored or excluded from approaches to solutions, and indeed the broader practice and study of development. A review of both post-development and queer development literature outlines the mechanisms of social exclusion as they pertain to the formation and execution of sustainable development goals.

Adopting the new UN framework for a post-2015 development agenda, The New Zealand Ministry of Foreign Affairs and Trade (MFAT) note that as a United Nations member state New Zealand is firmly committed to the 17 goals and 169 targets which make Agenda 2030 (MFAT, 2020). The SDG agenda was built upon the criticisms of its predecessor the Millennium Development Goals which omitted to explicitly include issues of gender equity, LGBTQIA+ rights, violence against women and reproductive health, arguably due to its prioritising of consensus and 'buy in' from more conservative member states (Fukuda-Parr, 2016; Naila Kabeer, 2015; Palmary \& Nunez, 2009). However, as many authors point out, sexuality and its congruent issues remains a "battleground" within the United Nations human rights system (Vaast $\&$ Mills, 2018) and has impacted the (re)formation of development goals in a post-2015 era. 
Despite rigorous and extensive consultation processes with the Addressing Inequalities Networked Alliance (AINA) to establish measures that would address social exclusion among sexual and gender (and to some extent ethnic) minorities, language on sexuality and gender included in the SDGs is diplomatically vague. This is again largely due to contestations from member states that held conservative views, some of whom have ratified laws criminalising LGBTQIA+ populations (Fukuda-Parr, 2016; Vaast \& Mills, 2018). While the SDG's call for development to "leave no one behind" reflects commitments to eradicating social exclusion and marginalisation and is meaningful in acknowledging poverty's multidimensionality, much of the literature argues that by not recognising specific barriers faced by those affected by issues of persecution on the basis of gender and sexuality the SDGs are complicit in exclusionary development policies (Stuart \& Woodroffe, 2016; Vaast \& Mills, 2018).

Vaast and Mills (2018) further argue that the SDGs' failure to "engage in any meaningful way with the lived reality of LGBTQIA+ people" is "not an inadvertent oversight" and that omission to 'name' those people is a denial of their equal right to participate in social, economic and political spheres. It "thus invisibilizes their experiences of discrimination and exclusion" (2018, p. 61). In seeking to identify, through a queer theory lens, what an alternative development era that was sensitive to sexual orientation, gender identity and expression (SOGIE) would look like, they identify two mechanisms by which social exclusion is entrenched in structures of policy processes at national and international levels (and where SOGIE sensitive development policy could sit in its place).

The first of these mechanisms looks at national laws and policies centring on civil and society actors and calls into focus the need for policies that "address multiple forms of inequality experienced by all citizens but especially by those experiencing socio-legal and economic discrimination." i.e., LGBTQIA+ or ethnic minorities which 'queer' neoliberal-hetero-patriarchal norms and structures (Vaast \& Mills, 2018, p. 66). The second mechanism is that of exclusionary development policies at an international level, that is the role of international actors such as the UN who work with state governments to implement development frameworks (i.e. the SDGs) as well as bilateral agreements between states according to geopolitical interests. Here is where 
ideas of a revised international rights-based commitment to explicitly protecting LGBTQIA+ and other minorities would sit.

Arguably, the place for addressing social exclusion (its perpetuation and eradication) as it pertains to refugee resettlement sits in neither of the mechanisms identified above, but rather at the nexus of the two. While international and multilateral commitments to the resettlement of refugees (be it via pacific climate pathway agreements or as signatories to the $1951 \mathrm{UN}$ convention) dictate entry opportunities and protections available to those on the margins, it is also the domestic policies of third country settlement states that dictate how those marginalised bodies may be included in economic, political and social spheres - including how this manifests in their ability to live as family.

Sitting as it does in the centre of these two identified mechanisms of social exclusion straddling both international and domestic development policy, resettlement does not 'fit' within these separate frames of understanding social exclusion at a policy level. In straddling the realm of foreign policy and geopolitical commitments to offer asylum, as well as the domestic policies of social welfare provision, refugee resettlement tends to fall between the cracks. Furthermore, the SDGs and rights-based development focus on the individual as the core 'unit' for measurement and intervention. This focus means policy solutions specific to families also fall between these cracks.

Given the centrality of family and relationality in migration, and more specifically in RFR, attention to the marginalisation of families within the migration development nexus is critical. I therefore include within my framework of marginality the lens of critical kinship studies and its contributions to understanding non-heteronormative family configurations as queer subjects in this research.

\section{Queer Subjects and The Exclusion of Families; Lessons from Critical Kinship}

So far in this chapter, I have explored how post-colonial development theorists and queer theorists alike have built upon Sen's early notions of social exclusion to understand its role as a 
"relational process of marginalisation" (Vaast \& Mills, 2018, p. 58) that concentrates power and resources in the hands of a dominant group. This concentration of power further perpetuates norms - in this case, normative ideas of family, sexuality, relationship and economy - which in turn, ensure exclusion is "embedded in cultural and social processes that stigmatize, 'distance' (Estivill, 2003) or 'lock out' (N. Kabeer, 2000) specific groups of individuals" that challenge, or queer, these norms (Vaast \& Mills, 2018, p. 59).

In considering RFR from a conceptual framework of marginality I intend to approach policy review from the perspective of these individual groups which challenge, or queer, norms (also referred to here as 'queer subjects'). In order to do so, I must first establish what is meant by normative ideas of family in a predominantly western context such as Aotearoa New Zealand. Here, I draw from critical kinship to identify, define and critique the construction and promotion of the western-heteronormative nuclear family. I then clarify what is meant by 'queer subjects' as this term pertains to this research and my corresponding epistemological approach.

I have already outlined in my introductory chapter, the emphasis of critical kinship as a lens through which to view family as a practice of relatedness rather than as a biological phenomenon. In addition to the Eurocentric imperative of genetic relatedness in kinship discourse, many Critical Kinship scholars argue that in defining family as established through biology or marriage only, western patriarchal hierarchies are further perpetuated. For example Schneider notes, albeit fleetingly, that in promoting the heteronormative nuclear family as a cultural unit, heterosex is actively produced rather than something that can be considered to be a 'natural' phenomenon (Schneider, 1980, pp. 30-38). Such ideas have been echoed and elaborated upon in the fields of both gender studies and queer theory (Butler \& Walsh, 2002; Lévi-Strauss, 1970).

Further, scholars note the use of western scientific language - nuclear - to determine family as a group consisting of two parents of differing genders and their children, separate from other relatives. They argue that such language signifies the leveraging of rational scientific discourse to present heteronormative familial configurations as a natural phenomenon; a 'norm'. Literature from these fields argues that the perpetuation of heteronormative patriarchal hierarchies through the idea of the nuclear family and its associated gender roles, supports the goals of reproducing 
labour under capitalism. Gayle Rubin (1975), for example, argued that the cultural normalisation of the heterosexual nuclear family unit serves as a means to reinforce the gendered roles of the household. These roles, in turn, encourage reproduction, and thus the production of labour.

Rubin built upon earlier conclusions of Lévi Strauss (1970) that the promotion of kinship as biologically defined through the heterosexual nuclear family unit serves the purpose of a "division of labour by sex", which is "to insure the union of men and women by making the smallest viable economic unit contain at least one man and one woman" (Rubin, 1975, p. 178). In demonstrating the ways in which western cultural constructions of heteronormative kinship models serve to ensure the production of surplus capital, Rubin inferred that the logic of capitalism underpins the definition of kinship as genealogical relatedness, an argument which repeats throughout gender studies and critical kinship literature (Haraway, 1991; Riggs \& Peel, 2016).

Recognising the construction of heteronuclear family units as normative in Aotearoa NZ, and its intersection with economic motive under the neo-colonial governance of a capitalist system, is critical to understanding how families who trouble this can be excluded. I explore these ideas further in my application of Foucauldian discourse analysis and subsequent discussion chapters (Chapters 6 and 7).

Critical Kinship reveals the construction of heteronuclear family configurations as normative in western-influenced societies. Recognising that the queer subject is " by definition whatever is at odds with the normal, the legitimate, the dominant" (Halperin, 1995, p. 62), I therefore consider former refugee families who deviate from the norm of heteronuclear family configurations in Aotearoa NZ to be queer subjects in this research.

Queer subjects, under a framework of marginality informed by critical kinship, queer theory and social exclusion, are the heart of this research and comprise simultaneously of former refugees who are LGBTQIA+ and/or families that don't fit the particular understandings of normative kinship embedded in RFR policy. By centring these queer subjects in my approach to policy review, as informed by a framework of development from a marginality perspective, I embody a 
queer epistemological approach. This conceptual framework and its contributions to my epistemological orientation is illustrated in Figure 2.1 below.
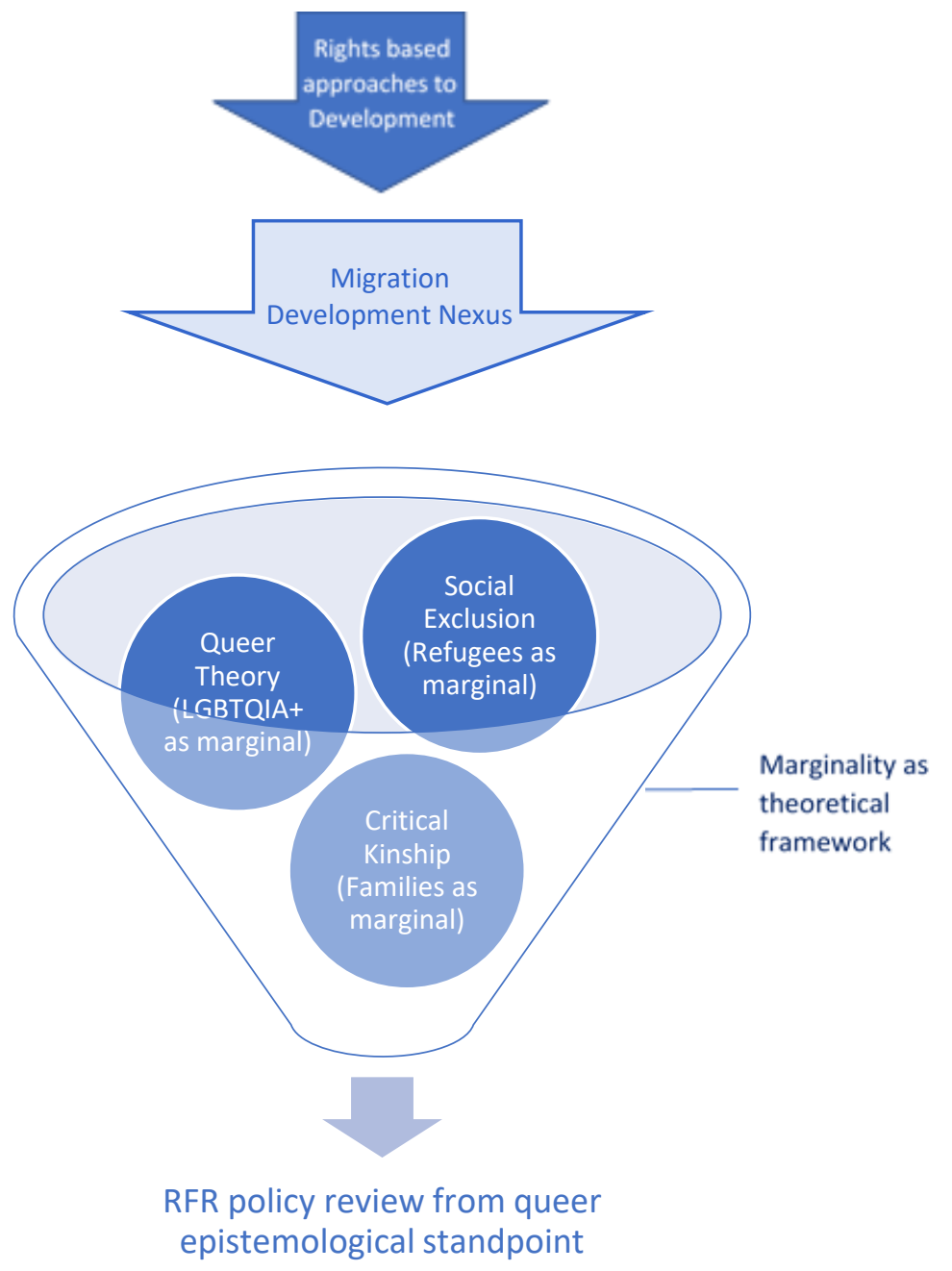

Figure 2.1: Applying the conceptual framework of marginality to Refugee Family Reunification

\section{Conclusion}

Following the mainstreaming of rights-based development approaches through global commitments to the SDGs, refugee resettlement has become widely recognised as a component of development policy. This is further reflected in the 2018 Global Compact, for which Aotearoa 
$\mathrm{NZ}$ voted in favour. However, when the SDGs are considered through the confluent lenses of social exclusion, queer theory and critical kinship, a migration development nexus is exposed; and those most marginalised bodies, specifically former refugee families and LGBTQIA+ members who trouble hetero norms, fall through the cracks. Because refugee resettlement sits within this migration development nexus, there exists a gap in the literature for critical policy analysis as it pertains to these processes of marginalisation. By approaching RFR policy from the theoretical lens of marginalisation (composed of critical kinship, social exclusion, and queer theories) and the experiences of queer subjects, I hope to highlight its role as a mechanism for excluding former refugee families which queer dominant norms, thus addressing this gap. 


\section{Chapter Three: Methodology}

\section{Outlining a Queer Epistemology}

My concern for marginality and social exclusion within the migration-development nexus positioned my work as a researcher within the goals of critical theory, which seeks to challenge established social order as a means to bring forth more justice for those marginalised by it. It meant this thesis sought, in the spirit of queer theory, to ask questions rather than seek answers (Dilley, 1999). I therefore oriented my research design to emphasise understanding over explanation through adoption of a queer-informed social constructivist epistemology.

Such an epistemology enables me to highlight the ways in which RFR excludes former refugee families which queer dominant norms. It does so by inherently recognising that social processes and norms are a product of the dominance of particular knowledges or world views. By acknowledging this relationship between power and heteronormative worldviews, a social constructivist epistemology allows me to explore multiple ways of knowing, privileging those knowledges, and people, which queer norms.

I begin this chapter with an explanation of social constructivism as queer epistemology. I then outline my methods of interview, thematic analysis and Foucauldian discourse analysis (FDA). I then introduce my participant base, and critically reflect on ethics and representation which were queer infused and collaborative inspired. Throughout, I link methods to my social constructivist epistemological stance and my qualitative and interpretive methodology.

\section{Social Constructivism}

I have already identified the origins of queer theory in post-structuralism. Within this, sits the theory of social constructivism. Social constructionism considers knowledge not as objective truth but rather as contingent on factors such as cultural and historic specificity, which influence and shape how we see the world. If worldviews and identities are 'products of historically situated interchanges among people' (Gergen, 1985, p. 5) then what is deemed to be knowledge is not only contingent on the past, but prone to change in the future. 
While social constructionism maintains this anti-foundationalist position on knowledge, it also maintains a critical approach to the influence of knowledge as taken-for-granted. Jørgensen and Phillips (2002) noted that social constructivist approaches recognise a relationship between knowledge and social processes. Social processes are established through the dominance of particular knowledges or worldviews, while also maintaining and perpetuating those knowledges as taken-for-granted truths about the world. This relationship is particularly relevant to researching RFR, as policy quite literally shapes how social processes of RFR unfold.

A social constructivist framework of analysis, through Foucauldian discourse study, also enables me to interrogate the formation of those knowledges on which policy was built and how those policies continue to shape and maintain a status quo of the heteronormative family in Aotearoa NZ. I therefore approach Foucauldian discourse analysis as a method within the wider epistemology of social constructivism later in this chapter.

\section{Ways of knowing: an extended epistemology}

Also of significance for my concern with marginality is the work of Heron and Reason (2008) who incorporated researchers' concern for understanding over explanation into their methods of cooperative inquiry. Cooperative inquiry can be summarised as " a form of second person action research in which all participants work together in an inquiry... as co-researchers and as cosubject" (John Heron \& Reason, 2008, p. 366). This method, which I examine further in subsequent chapters, draws from an extended epistemology of 'ways of knowing'. Developed, in a similar spirit to queer theory, as an alternative approach to positivist-oriented academia (that which posits, tests, categorises and defines), Heron and Reason's “radical epistemology" (2008, p. 367) focused on multiple ways of knowing to uncover not only what is known, but how. In doing so, the 'ways of knowing' approach embodies the social constructivist/Foucauldian notion that knowledge and truths are situationally contingent and thus what is seen as true or normative can be challenged by the breadth of human experience.

In an earlier work the four ways of knowing were outlined by Heron, Reason and Bradbury as:

\footnotetext{
"Experiential knowing is through direct face-to-face encounter with a person, place or thing; it is knowing through empathy and resonance, that kind of in-
} 
depth knowing which is almost impossible to put into words; presentational knowing grows out of experiential knowing, and provides the first form of expression through story, drawing, sculpture, movement, dance, drawing on aesthetic imagery; propositional knowing draws on concepts and ideas, and practical knowing consummates the other forms of knowing in action in the world." (J Heron \& Reason, 2006, p. 9)

\section{Application to Policy Review}

Adopting a queer epistemological standpoint informed by social constructivism and 'ways of knowing', this research sets about collating and analysing knowledge and experience from actors across the RFR policy process in Aotearoa New Zealand in 2020. However, given the sociopolitical context of ongoing policy review, and the influence of cooperative inquiry, this research has also always been explicitly action-oriented in its interest in both following and facilitating change. Therefore, as I discuss later, space for such consideration was plainly outlined (asked) in the collection of primary information to enrich discussions going forward with the hopes not just to initiate revisioning our understanding of RFR policy implications but towards transforming practice as a result (John Heron \& Reason, 2008).

\section{Methodology}

Concerned with "elucidating human environments and human experiences" (Winchester \& Rofe, 2010, p. 5), my qualitative methodology sought to understand both the social structures and the individual experiences that make up RFR processes. Resulting from a social constructivist epistemology this research is also interpretive; "reject[ing] the objectivist view that meaning resides within the world independently of consciousness"(Collins, 2010, p. 38). This means I employ methods which focus on the multiplicity of human experiences, ways of knowing, and discourses which reflect these.

Understanding the importance of reflexivity in my role as researcher and acknowledging that "Meaning is something that a researcher reconstructs in a dialogue with the subjects of analysis" (Ercan \& Marsh, 2016, p. 6; Wagenaar, 2011) I employed a qualitative methodology informed by the collaborative, reflective, and active nature of cooperative inquiry. 


\section{Methods}

As Dilley remarked, "Queer theory is about inquiry rather than declaration.” (1999, p. 426). Therefore, my methods, although traditional in the qualitative form of one on one interviews are interested in and aware of the complexity of the issue (barriers to RFR) in context of the social world (dominant ways of thinking, socio-economic influences etc.). This involved semistructured interview methods with numerous actors engaged in varying aspects of the resettlement process: legal aid, charitable trusts, resettlement volunteers and services, community advocacy, and governmental decision making.

\section{Recruitment and Sampling Frame}

From preliminary conversations with practitioners in the field, it was evident both family reunification and the experiences of former refugees in the rainbow community are highly sensitive, deeply personal, and ever-evolving topics. I felt it would be inappropriate to seek out and ask for the time, emotional expenditure through vulnerability, and potential traumatisation of these community members directly. Because of this, my research focused on those involved in the advocacy, service provision, and legal/policy process and their insights. Interviews consisted of participants' expert opinions and observations, and indirect accounts relating to RFR.

Two of the six participants interviewed ended up being from refugee backgrounds themselves, and while interviews were personal in nature, they were undertaken in their capacity as advocates, activists, or employees in RFR processes. This decision, to move away from interrogation of a singular classified group (albeit diverse) and towards an overview of all actors within the system affecting that group, is conceptualised by Ramona Faith Oswald et al. (2009) as a form of queer methodology in and of itself:

"Queering methodology means giving up on the idea that we can put people in groups and then analyse some other part of their lives as if their group membership was a simple fact. Using queer theory means sampling whatever set of people or phenomena is of interest but then going beyond their so-called characteristics to study the mundane processes that go into these classifications as they relate to heteronormativity." (Oswald et al., 2009, p. 11) 
It is precisely to these "mundane processes" and "classifications" within policy that my participants were intimately connected; be it through advocacy on behalf of their community, legal and charitable support, resettlement service provisioning or in the formation of those categories themselves for policy purposes. The aim in listening to them was to look at systems rather than subjects but with an underlying "sensitivity to the complicated and multi-layered lived experiences and subjectivities of individuals" that queer influenced methods require (Valocchi, 2005, p. 767).

By interviewing participants from different, intersecting, aspects of the reunification system as a whole, I aimed to gather primary data which elucidated both the RFR structure within which former refugees are centrally situated, and the opinions and actions of actors within each of its components. These intersecting components of the RFR structure (each of which corresponds to my six participants) are illustrated in the figure below.

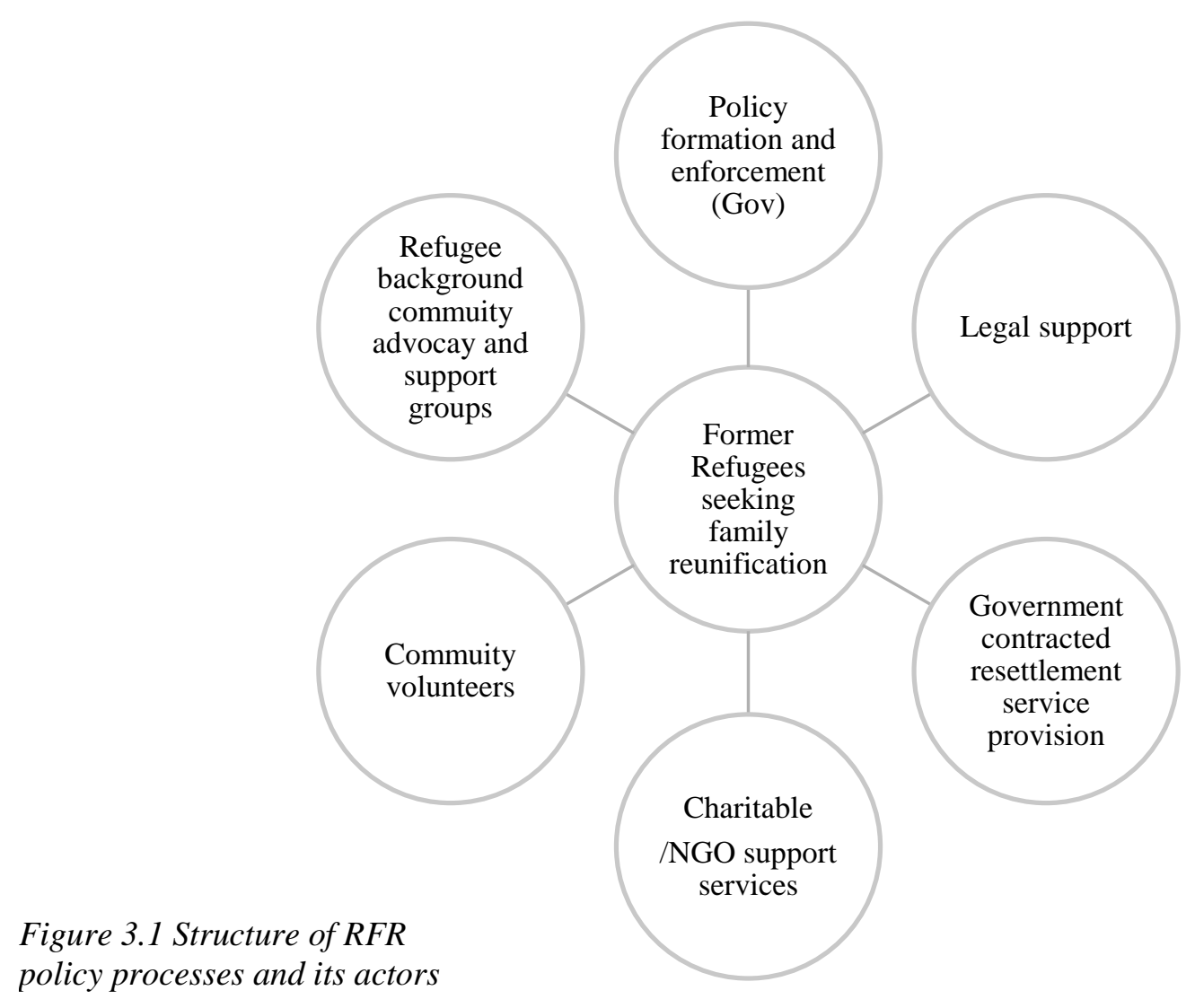


However, understanding that the lived experiences of former refugees undergoing family reunification are the centre of this structure, I stress that this research should go hand in hand with the voices of refugee background people- which must be both motivation and lead in processes of policy reform.

I employed a combination of criterion and chain ("snowball") sampling (Patton, 2002). Criterion sampling is the selection of cases or participants that meet decided upon criteria. "Snowball" sampling identifies people or cases of interest reported by others who may be involved in, or know of, similar cases; this non-probability form of sampling is considered appropriate for uncovering marginal or "difficult to find populations" (Kirby \& Hay, 1997, p. 296) such as refugee background rainbow community advocates. I began this sampling approach by contacting previous colleagues working in resettlement service provision at New Zealand Red Cross. I composed a list similar to Figure 3.1 identifying the composite parts of RFR processes, wanting at least one sample participant from each of these. My colleagues put me in contact with various participants from different components of the RFR structure. With each new interview participant came recommendations for more and a chain reaction began of interested parties. In addition, I contacted government departments, charitable trusts across the country, and friends in the former refugee community via email and phone call. Identifying and deciding who to talk to was based upon criteria of roles and experiences in the intersecting fields of refugee family reunification (as identified in Figure 3.1). 


\section{Introduction to Participants}

I have expanded Figure 3.1 to include my interview participants indicating from which component of the RFR policy structure they have come (see Figure 3.2 below). While I have deidentified all participants in this thesis due to majority request, I include here a brief introduction to each, and their relationship to RFR policy.

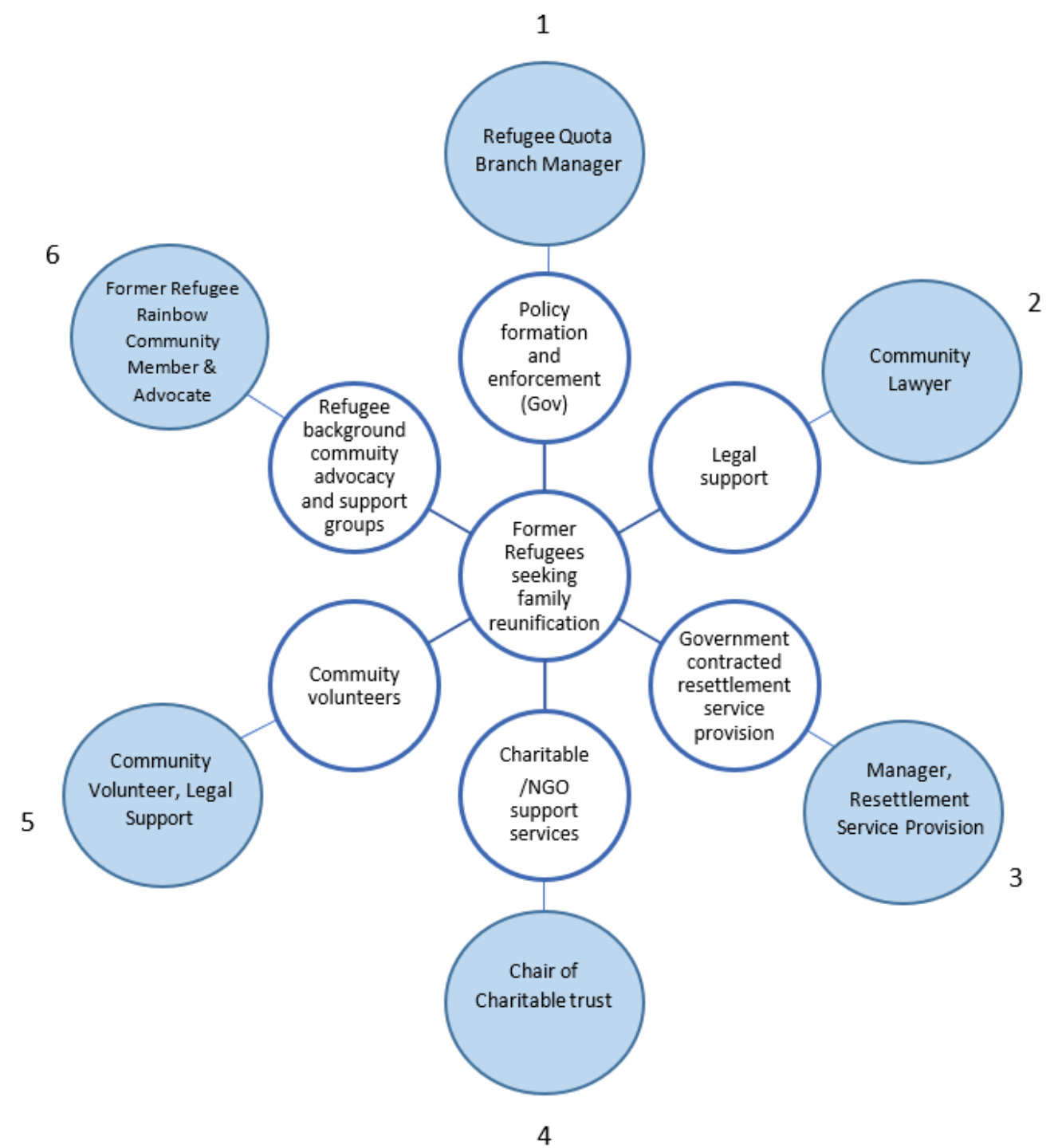

Figure 3.2: Structure of RFR policy processes, its actors, and corresponding research participants 
1. Refugee Quota Branch Manager has been engaged in refugee resettlement policy for over ten years, contributed to family reunification policy formation and he currently oversees policy processes pertaining to quota refugees with Immigration New Zealand.

2. Community Lawyer has been working in immigration law with and for refugees and asylum seekers for over a decade. She is based out of Wellington Community Law Centre and has contributed to several reports and open letters advocating for more inclusive family reunification policies.

3. Manager Resettlement Service Provision works in resettlement services with a focus on supporting arrivals via the Refugee Family Support Category pathway. He is developing a pilot programme specific to the needs of former refugees arriving via RFR.

4. Chair of Charitable Trust is based in the Manawatu region where she also sits as a city councillor for Palmerston north. She has been involved in refugee resettlement in both the UK and Aotearoa NZ and currently chairs a charitable trust which seeks to alleviate the financial barriers to those applying for RFR.

5. Community Volunteer has a background in immigration law and dedicates her time to supporting members of the former refugee community in both resettlement and in sponsorship applications for RFR.

6. Former Refugee and Rainbow Community Advocate (also referred to as Eliana when sharing their personal RFR case) is a former stateless person, originally from Colombia. They were granted asylum in Aotearoa NZ after detainment in Hong Kong on account of their passport photo not matching their gender identity. They have since been granted citizenship under exceptional circumstances and are prominent in leading advocacy campaigns for LGBTQIA+ former refugees.

The recruitment process was lengthy and took four-six months. This was in part due to the highpressure workload many in the resettlement sector face and so delays in communications and plans to connect were expected and factored into research planning. The second delay in recruitment processes came from the COVID-19 outbreak mid-way through the interview period. 
During this research an unprecedented global outbreak of the virus COVID-19 led New Zealand to call a state of national emergency and instigate a nationwide lockdown. Consequently, travel arrangements to see participants were abandoned and there were few responses to requests for phone interviews. As with most forms of widespread societal disruption (be it financial, public health or otherwise), it is those on the margins who feel the impacts most acutely. Some participants from refugee background communities who I had been in contact with to organise interviews now found themselves at home caring for children fulltime and concerned for their safety and the safety of those family members still in refugee camps or conflict zones overseas. The closure of borders and lack of information from many states on the impact of Covid-19 had rendered much of the world, and especially so the former refugees with whom I was in contact, in a state of deep anxiety. The focus for many was now on immediate priorities of attaining income support, caring for children, managing personal overwhelm. Understandably, I received apologies from participants no longer willing or able to give their time and energy to this study.

Further, in the eye of the storm of a global pandemic, community support organisations and government officials scheduled to meet with me were now channelling their time, energy, and resources into providing care, information, and formulating official response strategies.

Interviews were placed on indefinite hold. After the lockdown was lifted and New Zealand had returned to business as usual, I received contact from two community organisations and one government department offering their participation. While by this stage it was too late to include them in the scope of this research, I take their concerted effort to contact me after many months of disruption as an indication of the interest in and importance placed on this research by those in the sector. I hope that the application of queer theory to the task of refugee family reunification reform continues beyond this thesis, for there is an apparent desire for it.

\section{Interview Methods}

Interview methods lie at the core of my research in their explicit interpretivist aims "not to test hypotheses, but rather to explore people's experiences, practices and perceptions in-depth to establish [my] understanding of their understanding" (Ercan \& Marsh, 2016, p. 14). Interviews were also inspired by the collaborative standpoint of co-operative inquiry whereby I aimed to replace traditional mutually exclusive roles of researcher and subject with a cooperative 
relationship so that all involved work together as co-researchers and co-subjects (John Heron \& Reason, 2008). Drawing on participants' diverse knowledge and experiences about and within refugee family reunification I sought to conduct myself as a convener of cooperative inquiry where everyone was involved in the evolution of questions, input of individual and collective knowing, drawing of conclusions, and ideation for future actions. Thus, everyone involved could exert influence on the process. However, I acknowledge that to consider this process collaborative is to imply equal power relations between myself as researcher and interview participants. Given that this research began with me and then opened up to collaborative interview styles, I do not feel the process was a true representation of co-operative inquiry, rather it was informed by the collaborative orientation toward participant input into both process and understanding.

It is because of this collaborative orientation that I chose to disseminate an aide-memoire prior to each interview instead of following a rigorous structure of questions. This process allowed for both me and the participant to lead lines of inquiry in the interview and share ideas and stories of knowing. Disseminating this aide memoire early allowed for participants to reflect and ruminate prior to meeting and encouraged them to give feedback on the overarching research questions I shared with them, ensuring clarity and informal agreement over the focal ideas. The aidememoire provided a skeletal agenda of opportunities to discuss various questions, observations, and experiences yet retained a wide scope for participant influence. Aide-memoire prompts drew heavily from the fourfold "extended epistemology" that underpins co-inquiry. Consequently, the aide-memoire called for a mixture of personal reflection (experiential knowing), storytelling (presentational knowing), institutional knowledge (propositional knowing) and idea generation (practical knowing). Being an open conversation not all interviews gave equal weight to these forms of knowing however the prompts did encourage participants to step outside of their preferred form of enquiry to consider other ways in which they know the subject at hand. Instances where these were brushed aside or asked to be removed from the record, added value to the wider picture of manifest processes of family reunification and the universal nature of its impact upon actors involved. For example, every single participant expressed a personal affinity with the need for protecting and expanding family reunification for former refugees. Each interview came to land on the question of 'in an ideal world what would you change about the 
policy process?'. This was deliberately asked last, encouraging participants to draw from all the forms of knowing that had been unpacked during the course of the interview. Thus, if a participant tended toward one expression or another as a result of their role or background the different ways of knowing encouraged throughout earlier interview prompts would hopefully challenge their default means of response.

A primary aim of this research was to capture these multiple forms of knowing so as to challenge normative assumptions within the refugee family reunification process, thus highlighting their impact. While different participants had tended toward expressing different forms of knowing (some almost purely through experiential or presentational via storytelling others choosing to lead on propositional components of political analysis and statistics) clear and congruent themes emerged across the data set.

\section{Methods of Analysis}

Thematic analysis enabled me to organise interview findings according to their relevance to key lines of inquiry- barriers, exclusions and suggestions. These lines of inquiry were clearly stated in the aide memoire.

I then engaged with Foucauldian discourse analysis to explore the cultural and social mechanisms evident within discussions and material around policy and its subjects. Where thematic analysis allowed me to share inequalities and injustices that came to light through interview processes, FDA allowed me as a researcher to "expose how inequalities and injustices are sustained by the resilience of certain underlying normative categories." (Waitt, 2016, p. 286). Therefore, I consider FDA an apt methodological tool for the epistemological goals of queer theory, which seeks to challenge normative categories.

What Foucault brings to bear is twofold. Firstly, that considerations of discourse as it presents and constructs knowledge (or as Foucault calls them 'truths') must pay attention not just to historic or cultural origins but to the ongoing 'history of the present'. The 'history of the present' meaning the socio-political climate of the day as it stands to influence what is widely taken for granted as normative in the present, and what of this has been inherited by historic events. It is the idea that history didn't just establish a dominant knowledge, but that this process continues 
and that our present-day analysis forms part of this process. Foucault explained this in a 1984 interview: "I set out from a problem expressed in the terms current today and I try to work out its genealogy. Genealogy means that I begin my analysis from a question posed in the present" (Kritzman, 1988, p. 262). The question of barriers and exclusions in contemporary RFR policy involves tracing of its 'genealogy' back to colonial interference in Aotearoa NZ. This formed part of my sensitivity to discourse that engaged with concepts and comparisons to Te Ao Māori.

This idea of "using history as a means of critical engagement with the present" (Garland, 2014, p. 367) brings with it the second aspect through which I approach analysis, that of power. Foucault not only recognised that knowledge is unfixed, contingent, and shapes our social world and understanding but that certain knowledges are dominant as a result of power. Those with the greatest power, have the means to establish the discourse which holds certain knowledge as truth. Therefore, power is intrinsically linked with the promotion of ideas as taken for granted truth, which in turn shape our social policies and processes.

So too does Foucault (1980) recognise that power is necessary for discourses to remain resilient against other knowledges in its establishment of norms and categories. The resilience of discourses which categorise, holds great relevance to RFR policy which ultimately hinges on eligible and ineligible kinship categories.

\section{Resilience and Rupture: applying FDA}

Foucault considers the relationship between power and knowledge to be so inextricable, he often presents the two as 'power/knowledge' in his texts (Foucault, 1980). Understanding discourse as operating to order and present reality or 'truths' in certain ways, Foucault argues that aspects of reality ('knowledges') can be shared through a number of possible discursive frames. However, these frames can be afforded different presence and authority depending on the power relations at play. Power enables certain knowledges to be produced, known, and presented as norms or as common sense. Those with recognised or sanctioned legitimacy and authority (platform and voice) can influence and disseminate knowledges through discourse.

Paradoxically, those same power relations can be repressive, constraining what it is possible to know, or indeed articulate (Cheek, 2008; Foucault, 1980; Jørgensen \& Phillips, 2002; Waitt, 
2016). This aspect of repression or containment is especially clear when the subject position being articulated lies in contradiction to the normative explanatory discourse as produced by relations of power, and dominant thinking. In this research, 'mainstream' or hegemonic discourse is constructed or reflected through the language of RFR policy, and those who form part of its machinery and articulation. Its very normality and dominance can constrain what is possible to understand about those who occupy the subject position RFR policy seeks to address (former refugees); refugee voices do not have influence (power) over 'mainstream' discourse. In short, power relations impact the production of, or sharing of, knowledge and the ease or difficulty with which participants in this research were able to articulate certain aspects of reality, and how that reality could be different.

However just as discourses promoted by those in positions of power maintain resilience through policy and governance, societal norms and discursive structures, contradictory or alternative discourses from either the margins, or the power-less, contain knowledges which can "rupture" them momentarily (Waitt, 2016, p. 306). In paying attention to those discourses which rupture, I sought to centre what troubles the heteronormative, western ideas from which policy is established as a prompt for further inquiry. This inquiry thus forms part of a wider queer-(y)-ing of refugee resettlement in Aotearoa NZ.

Similarly, FDA gives me opportunity and motive to present those discourses which are on the margins, those which have not been afforded the same role in shaping social processes or which are dismissed on the bases of their opposition to known 'truths'. FDA aligns with my epistemological standpoint of queer theory in its attention to the resistant, rupturing, discourse of the power-less.

But what do I mean by discourse? What does this power/knowledge nexus and its influence over establishing norms look like in interview transcripts? While discourse analysis is entirely interpretivist, there is a wide body of literature that notes certain discursive techniques and their effects (Graham, 2005; Waitt, 2016). Across disciplines constructivist and Foucauldian discourse analysis has been applied to research which intersects with social processes. It has been shown that close study of rich texts reveals the subtle forms of power that are deployed by policy and institutions (and their actors) as a mechanism of social control via 'truth effects' (Foucault, 
1971). In this study, I approached my interview transcript as these rich texts, seeking to identify discursive structures. These included strategies to impose or defend 'norms' often by grounding meaning in binary opposition (woman/man, them/us, extended/immediate), or deploying different knowledge-making practices (such as eyewitness accounts or industry statistics) for effect.

The process of my Foucauldian-inspired discourse analysis found its roots in intuition. During conversations I noticed patterns of speech, phrases of significance or the presence of an overall message or worldview. At the time, the accompaniment of nonverbal communication such as eye rolls, gesticulation, or eager head nods was as crucial to this messaging as the words themselves. I was also conscious of the various power afforded to each participant on a daily basis, for example, those speaking from a community advocacy or voluntary perspective drew on far more experiential ways of knowing while those in government or service provision often spoke immediately with an air of authority on the topic at hand. I took notes on these observations during and after interviews.

Using transcriptions as a rich text, I went through and coded first according to examples of barriers, exclusions and suggestions. I took inspiration from Waitt and Warren's (2008) use of category labels to interpret transcripts of surfers: context, practices, attitudes and emotions. I went through and highlighted that which related to practices, experiences, and emotions. I further studied participants' illustrative stories for words which implied a positive or negative judgement such as "ridiculous", "unfair", or "reasonable" to examine the impacts of power on process. Through re-reading and coding transcripts I became aware of hesitations and moments where participants struggled to articulate certain experiences or frustrations, I made a note of these also for further exploration.

After this initial coding process, I noted down the three key discourses around ideas of family which stood out and began to identify the deployment of discursive structures in promotion or resistance of them. Finally, I considered what was not being said. Some participants eluded to personal views which were not representative of their professional role and so held back in sharing further or excused their choice of words. Others benefitted from the power that comes with positions of management or tenured experience and were well versed in the "privileged 
discourse" (Foucault, 1972) around refugee families and reunification capacities in Aotearoa NZ. According to Foucault, silence around a particular topic is a mechanism of social power within established structures (Waitt, 2016, p. 308). I speculate further on topics of silence and hesitation in my analysis of findings.

\section{Ethics and Representation: Queer Infused, Collaboratively Inspired}

\section{Doing research}

Prior to recruitment I applied for, and was granted, ethical consent by the University Human Ethics Committee (application number 0000028065). Interviews took place in a range of environments, often I met participants at workplaces or local cafés. Three interviews took place over Zoom and Skype call during Aotearoa NZ's lockdown period. Interviews were recorded and transcribed verbatim. Prior to recording I discussed consent and process with each participant giving them the option of reviewing transcriptions and electing for de-identification in the final thesis. Some participants met with me for coffee to discuss their thoughts on the research project prior to becoming interview participants, this further enhanced the collaborative nature of my interview methods as, in the 'official' interview there was more of a sense of mutual input into questions and themes explored. Koha was not part of my ethics application however I did purchase/provide refreshments to two participants as compensation for their time and contributions.

\section{On "straddling in ambiguity"}

Conducting research about an experience which I have not lived, I am mindful of both my positionality in differing experiences, ethnicities and privilege. I am also aware of my position as being complicit in research approaches stemming from the neoliberal institutional context of western academia and the historic colonial continuities of such research (England, 2010; Tuhiwai Smith, 2012). Development research, in recognition of researcher positionality, commonly discusses the insider/outsider dichotomy in relation to the issue or subject being explored (Crabtree, 2019). However, adopting a queer theory stance in my approach to research means resisting the idea of the insider/outsider binary, acknowledging that: 
"In interpretative and emancipatory research paradigms, a researcher can

reproduce dominant modernist representations by restricting their own

complexity to a binary identification as an insider or outsider." (Manning, 2009, p. 3).

Therefore, I took inspiration from several queer and feminist theorists who seek to blur the line between the insider/outsider dichotomy. While I believe it is important to acknowledge my subjectivities, I recognise that in this research process I also "oscillate" between insider and outsider roles (Tang, 2007, p. 13). In "working the hyphen" (Fine, 1998, p. 130) between self and other I am "signifying both being hesitant or embracing of the roles participants might have allocated for me...[having] the agency to switch in between roles if necessary or to remain straddling in ambiguity" Tang (2007) (cited in Manning, 2009, p. 3).

As a tauiwi cisgender white woman who has worked in refugee resettlement in Aotearoa NZ, I was perceived by participants in a multitude of ways. Some viewed me as distant researcher, others as colleague (although they did not know me personally), others still as friend or ally. Most assumed I would share their position/views on the basis of my background, or what parts of my background with which they resonated. I found myself making this switch between roles in interview processes, often beginning as researcher and revealing more of myself as being connected to their industry or their activism throughout the conversation. This process of oscillation was contingent on rapport built within the interview process, so too was it contingent on the role allocated for me through participants perceptions of the co-inquiry process.

\section{On What Becomes of An Ethic Of Care}

Taking into account a feminist ethic of care, which sees ethics within practice as "not so much an activity but a way of relating to others" (Held, 2006; McEwan \& Goodman, 2010, p. 1), I conducted research in a manner cognisant of the vicarious traumatisation that can occur for those working in this sector. Feminist 'care ethics' (Popke, 2006, p. 506) challenge the notion that emotion, care and consideration of welfare are restricted to the "space of the private" (McEwan $\&$ Goodman, 2010, p. 1) or indeed the space of formalised institutional processes. Instead, it is viewed as an ongoing relational state of being. Considering care as a state of being sensitised me 
to the connections many of my participants have with the care work in which they engage in resettlement spaces. I understood that asking participants to discuss instances where they may not have been able to achieve the desired outcome for clients who are former refugees, or where they may have encountered confronting accounts of refugeehood and related potential or perceived short fallings in policy, needed to be done with care and consent, and required appropriate debriefing most likely through existing structures within their organisations or community groups.

I ensured participants understood they could request recording stopped at any time, dissemination of aide memoirs and encouragement of input enabled participants to outline any areas they did not want to discuss. Four out of the six transcripts I draw from were reviewed in full at the request of participants, I contacted all participants prior to publication with a list of the quotes used for their final approval. Three participants have requested to see how their contributions fit within the findings of this research and will receive a follow up report and copy of this thesis if they wish.

\section{Analysis, Writing, and Representation}

A further aspect of my positionality I reflect critically on is the ethics of naming and representation. While I contacted participants to clarify the terms by which I refer to them, I still felt that this decision lay largely with myself as author and in hindsight would want to ask participants to determine their own title/name to be used in the presentation of findings rather than offering suggestions for approval or changes. Further, enhanced somewhat by the use of FDA, representation of participant voices was a delicate ethical balance. Referring to journal notes I made immediately after each interview and recognising transcripts in the context of thematic analysis helped me to ground my interpretations of participant meaning from transcripts, in the experience of conversation at the time.

As I presented these discourses, which rang through different participant interactions, overlapping at times, and contradicting at others, it was important to foreground my own contextual subjectivity in undertaking analysis of participant transcripts. FDA analysis presented in this thesis is, inevitably, a product of my chosen lens of queer theory, and its attention to 
power and exclusions. It is also a product of my affinity to post-colonial thought and positionality as a tauiwi resident in Aotearoa NZ engaged in the ongoing unlearning of decolonisation. Discursive findings analysed intentionally draw links between the exclusion of refugee rights to family and dominant belief systems of Eurocentric heteronormativity whilst allowing space for consideration of what needs further research attention.

In an effort to disavow any claims to objectivity, I have reproduced and included my original annotations of excerpts analysed in these chapters. The visual prompt of my own annotations across the transcript excerpts is to contextualise analysis as a manifestation of what I intuited in these interactions, and later interpreted as I sought to challenge and de-construct normative discourse. While different in intent and nature, I took inspiration for this practice from James Burford's work as a queer theorist exploring experiences of men who have sex with men (MSM) in Thailand. In this work, Burford (2010) fills the margins of his writing with "graffiti" as a means to consciously reflect his positioning as a "queersearcher" and to highlight the margins as a space for resistant movements. In including my annotations in my own work, I too aim to disrupt the dominant scholarly form of a thesis with "subversive strategies of resistance to status quo" (Burford, 2010, p. 18). It is my hope that the images of my annotations interrupt ideas of finality or impartiality in the analysis presented and embody the epistemological stance of queer theory. My analysis here is interpretivist, and ever changing, expanding. The use of raw annotations is as Burford's graffiti: a symbolic "quer(y)ing [of] the ontological assumptions of positivist research by registering more than one claim to truthful re-presentation" (Burford, 2010, p. 18).

Where Burford sought to draw attention to marginality and resistance as a manifestation of the aims of queer theory, I seek instead to "expose how inequalities and injustices are sustained by the resilience of certain underlying normative categories" by quite literally highlighting discursive mechanisms that reveal, "maintain, or rupture" ideas of family within RFR policy processes (Waitt, 2016, p. 289). 


\section{Limitations}

There were a number of limitations to this research, largely relating to a lack of pre-existing data on former refugee members of the rainbow community. Similarly, the services I interacted with which form part of RFR processes tended to work primarily with quota refugees. This means that analysis does not comprehensively represent convention refugee experiences. However, I argue that this limited number of convention refugees seeking out RFR services is reflective of more general policy bias towards those who arrive via the quota pathway. My participants spoke to this point in interviews and I elaborate further on this issue in chapters four and five. I have already discussed the ways in which this research was merely inspired by cooperative inquiry. Ideally the production of the initial key lines of inquiry would have taken place in a collaborative group context, that I chose to initially develop this topic individually limited its collaborative scope.

\section{On Partiality and Oversight}

I aimed for my results to be a product of the interaction between researcher and participants. As a researcher, I viewed myself as a participant in a collective process of the gathering and interpretation of discursive and qualitative information while being mindful and open about my positionality and its impression on my inevitable research interpretations.

This partiality also extends to the connectedness of myself as a researcher to those interviewed. While I may not have known my participants personally prior to interviews, the similarities in cultural and socio-economic background and experience I shared with many of them left open the risk of inadvertent blind spots within this work. This potential for oversight came from both the limited number of participants from refugee backgrounds and from participant assumptions of shared institutional knowledge meaning details omitted from interview answers.

Finally, while it was a conscious decision to interview participants from a refugee background only if they were engaged in the structure of RFR policy or processes (most likely through advocacy or community action), the lack of refugee voice is worth critical consideration. I am critical of this for two reasons: firstly, because it does nothing to challenge the marginalisation of refugee voices from processes which directly affect them, such as policy review. Secondly because the low proportion of former refugee participants in this thesis highlights the dominance 
of tauiwi New Zealanders who have not experienced refugeehood in positions of power, which directly affect former refugee opportunities for reunification. While I do believe it is crucial to, as I have done, work with people in the system and processes of RFR I seek to inquire about. I envisage future research seeking to provide a balance of perspectives by focusing exclusively on former refugee opinions.

\section{Conclusion}

In applying interpretive methodological approaches to the gathering and analysis of qualitative information, I engaged in an interactive, cooperative, and participative subject researcher relationship. Interviewing six participants, each from a different component of the RFR policy process (structure) I sought to capture multiple forms of knowing to challenge normative assumptions that underpin RFR. Disseminating an aide memoire prior to semi-structured interviews allowed for participant input into the content of interview inquiry and prompted the expression of experiential, propositional, presentational, and practical ways of knowing. Thematic analysis revealed clear and congruent themes across transcripts identifying barriers and exclusions within RFR policy and processes. Foucauldian discourse analyses deepened my understanding of these by revealing the core ideas embedded within policy, and the power structures which uphold such ideas as norms. FDA further enabled me to embody my conceptual framework of marginality through the centring of queer subjects. It achieved this by highlighting the discourses of, and around, people who challenge the status-quo and therefore further challenge perceptions of RFR policy in its effectiveness and appropriateness to the needs of the people it exists to support. Reflecting on my methods revealed limitations in the research, specifically the need for more refugee background participants and a more exhaustive collaborative approach (from proposal to publication). The findings of thematic analysis and then FDA are shared in the following chapters. 


\section{Chapter Four}

Theme 1: Barriers

\section{What are the common/key barriers to refugees successfully engaging in family reunification processes (from application to settlement)?}

\section{Presenting Thematic Analysis}

Thematic findings are divided into the two chapters, this being the first. Each presents the key themes emerging from participant information. Themes are organised according to the core questions I set out to address and their respective focus, these being: general barriers and exclusions of those who trouble hetero-western norms. I return to policy recommendations in chapter eight. Information collected was reviewed to identify the themes and major ideas evident in participant transcripts that pertained to these research questions. This process of thematic analysis revealed multiple subjects across the data set with significant overlap from different participants. Many of these themes echo those which have featured already in policy review papers, advocacy pleas, and academic research. In presenting thematic analysis here, I seek to engage with previous studies noting content similarities from across the literature on family reunification and refugeehood in Aotearoa NZ. Additional discursive analysis and findings are explored in subsequent chapters.

Both these chapters provide an overview of themes discussed as they relate to the question at hand (barriers or exclusions), before providing select examples from the participant interviews. Each theme is then further organised according to policy or process aspects. While mindful that

these are interrelated, the use of policy and process labels here allows me to present participant responses in a way which reflects the many components of refugee family reunification (RFR) from application through to resettlement experiences.

\section{Overview}

Conversations with participants took place in the context of a shared foundational understanding of some key barriers, which were referenced throughout interviews. These barriers, also noted in my context chapter, are well documented in literature and have been a centre point for RFR 
advocacy in recent years (Amnesty International, 2019; Choummanivong et al., 2014; Johnstone, 2018; Mahony et al., 2017). Among these barriers, the limited number of places available for former refugees to arrive via the family support category pathway came up frequently. Despite recent quota increases to 1500 per year, the number of available places through tier one (T1) of the RFSC pathway continued to sit at 300. This had remained unchanged since 2003 until the announcement of the 2020 Wellbeing budget shortly after these interviews took place. Included in this announcement was the commitment to increase RFR numbers to 600 to reflect the wider quota increase. However, the lamentably small proportion of places to those arriving via quota pathways remains the same. Further, the closure of tier two (T2) was a notable barrier, limiting not only if but who could be eligible for sponsorship.

In addition to numbers, barriers to quota refugees utilising the refugee family support pathway were limited to who could be brought over to join them (as previously outlined in Figures 1-3) and whether or not those persons had been declared by them offshore prior to their own resettlement. For those wishing to sponsor a family member to join them via the refugee family support category (RFSC) pathway, there were significantly more barriers discussed. The majority of RFSC related barriers pertained to accessibility (place numbers and legal support) and extensive bureaucratic and financial demands on former refugee sponsors (housing, savings and evidence provision).

Additionally, with quota refugee family reunification the defined terms of 'immediate' family meant that many former quota refugees who wish to bring additional family members or close relatives who do not meet the criteria were also seeking applications through RFSC. Convention refugees, not having the quota family reunification pathway available to them are reliant solely on the RFSC pathway to be reunited with family members, rendering them with comparatively little choice as to with whom they may be reunited and when. In light of this, one participant referred to the convention refugee experience compared with their own experience as a quota refugee as "Convention refugees are like second class refugees. Yeah. They, most of the things that that are you would give it for granted to people like me are not given to them." (Former Refugee, pers. comms., 2020). The limitation of convention status refugees to only RFSC 
pathways was seen as emblematic of a wider systemic prejudice against those who arrive via asylum-seeking means.

Finally, a number of barriers were discussed in relation to resettlement post reunification for former refugees arriving via the refugee family support category. Most participants noted the impact this has on refugee sponsors, given the expectations on them to provide and the complexities of navigating social support systems with residency status granted via RFSC as opposed to via UNHCR official quota status. These themes are picked up further in the exploration of exclusions within FR policy and process.

\section{Policy: Quota Reunification Pathway and RFSC Tier One}

\section{Non-declaration:}

Non declaration of family members in offshore interviews with UNHCR and Immigration New Zealand, was discussed at great length in the majority of interviews. If a quota refugee does not declare their siblings or parents during these interviews, which usually takes place in refugee camps, later applications for family members to join them in New Zealand are dismissed or considered fraudulent. Reports as to whether refugee applicants are made appropriately aware of these consequences varied across participants, with those in the community sector expressing scepticism at how well this is communicated at the time. All participants who were involved with legal support, be it through a voluntary support capacity, as community lawyers, or as a charitable support trust, were emphatic in their response to questions around the non-declaration issue, using language of 'impossibility' and often raising the issue unprompted and early on in the piece:

\footnotetext{
"Yeah, it's just about impossible. If you refuse to. If you don't-I shouldn't say 'refuse'. If you are trying to protect, for example, your family members because you are suspicious of the interpreter or you're just really nervous. Yep. It becomes just about impossible later on to apply to bring them here. So, if you
} 
don't declare your children or partner. It is absolutely impossible to bring them here through refugee quota. There's just no chance."

(Community Lawyer)

"In the past we've tried to fix up reasons why other people haven't declared and they're [INZ] really. They can be quite hard-line and say 'we're going to revoke your residence now because you didn't declare'yeah it can be quite punitive then at that point. So. And nobody knows that when entering..."

(Lawyer and Community Volunteer)

Participants noted the lack of consideration given to power dynamics at play within an offshore interview context. It was noted often that in the context of fleeing, many refugees are in heightened states of stress and anxiety and understandably hesitant to give away knowledge that could potentially be used to locate or harm a loved one. Participants illustrated their points with client stories:

"We've had people who when I first started, we had an Iraqi woman. This is back before Syria became the way it is now. So she had fled Iraq to Syria and she hadn't declared her sons to the interpreter because they were supposed to be doing military service and they hadn't done it or something like I think it was the case. And she was really suspicious of the interpreters. So she didn't declare them and then that meant that she couldn't apply to bring them here at all. And INZ just take such a hard line and they're kind of like, 'it doesn't matter what your reasons are we're going to take it as a character issue and it proves that something, it proves something'."

(Community Lawyer)

"and telling people that you've got people... 'here are these people go find them', like you do not do that! You do not do that."

(Community Volunteer) 
These stories raised also the complex nature of a refugee journey as one which may not necessarily sit within the bounds of INZ eligibility criteria without some significant contextual understanding. One participant shared a current case where gang warfare, domestic violence and coercion had led a woman to have had multiple partners, believing that her second partner had been killed by her third partner. She had since settled as a solo mum in New Zealand. On discovering her second partner was still alive, she was undergoing applications for reunification:

"Um it's just, I just can't even imagine it. So she never declared the second partner who was father of her, one of her children, because the gang of the third partner who had forced her into a relationship said 'you're never mentioning them, these are my children now, you never speak of him as their family'so yeah now we've had to fix that with immigration and say you know actually she's discovered that he's still alive, and she still loves him. And can we bring him?

How's that process been? Working with INZ is there some understanding?

Well this is what we're just doing late in the piece because I don't have a lot of trust that yeah what they will do in that situation."

\section{(Community Volunteer-Legal Support)}

Participants were quick to point out how frequently they spend time working on cases of nondeclaration and the associated grievances for former refugees seeking family reunification: "Non-declaration is something [others] and I have to work on all the time." (Community Volunteer-Legal Support, pers. comm., 2020).

It is therefore unsurprising that this issue has been closely examined in previous studies. In 2009 a Wellington-based discussion document produced collaboratively by four key refugee resettlement services made explicit recommendations for "an amnesty period to allow refugees to come forward safely to disclose historic mistakes in the recording of identity or family details, and have these corrected.'(Changemakers Refugee Forum, 2009, p. 37). Participants with whom 
I discussed this did not seem to think adequate allowance has since been made for safe disclosure of historic mistakes in the recording of family details. Two of these participants were involved in the referenced report ten years ago and felt that these recommendations had not been taken seriously.

\section{Policy: Tier two}

\section{Closure:}

The closure of tier two, regardless of its bureaucratic necessity due to application overwhelm, is a cause for much distress for many former refugees. T2 allowed former refugees who already have an immediate family member with them to sponsor 'extended' family. The significant role of grandparents, aunts and uncles and other family members in the lives and kinship expressions of former refugees is only acknowledged through T2 of the RFSC pathway. As discussed in chapter one, the closure of this category for the foreseeable future has left many families separated indefinitely. Further, the limited number of registration places and lengthy backlog of applications for processing means that even those who have registered to apply are left with many questions and uncertainty. Eliana, a participant, community advocate, and former refugee seeking reunification with her mother via the RFSC pathway describes the impact of this uncertainty on her life and the frustration of not knowing if reunification will ever be possible. (Eliana is applying to bring her mother to NZ via the T2 RFSC category, having used her opportunity for quota reunification to ensure her partner can stay in NZ with her, T2 is her only remaining option):

"Which is constantly closed! I refreshed the page constantly...This is my

schedule every day, I wake up in the morning, I open my my, my computer and

I have my screen in my computer like the first, when I open the browser, it is

the first thing it shows when I open the browser is not Google. It's a page of immigration stating if it's still in a T1 or if it's being changed to T2. I mean, I've been doing this since October last year. Every day, every day to check if there's change because there is not, no one notifies you... This is the current 
state of my situation. Because I have papers, I have all the documents ready to

go. Yeah, I have document with signatures from justice of the peace, all

everything, all ready to go. But it's just, you know, a very unfair system."

\section{(Eliana)}

The closure of $\mathrm{T} 2$ is symptomatic of a more significant issue within family reunification via RFSC, that of demand. In 2007 RFSC came into effect to replace the previous 'ballot' system and, in theory, was preferable to the previous randomised system. RFSC ensured registrations to sponsor family went into a queue with a two-tiered system (T1 identified by a higher level of need such as being alone in New Zealand or a sole carer). With only 300 places available through RFSC and application processes taking at least two to three years (Changemakers Refugee Forum, 2009; M. Williams, 2016) many former refugees find themselves waiting to be drawn from an ever-growing queue for a category which is now closed until 2025 (Immigration New Zealand, pers. Comms., 2020). The, now decade old, 2009 discussion paper on RFR claimed the adequacy of the policy needed to be reviewed "due to the length of the queue" (Changemakers Refugee Forum, 2009, p. 21). Since the publication of that paper, the refugee quota allowance has increased from 750 places, in 2018 to 1,000 places and again in 2020 to 1,500. Meanwhile, at the time of writing, the number of available places under RFSC had remained at 300 (Gray, 2008; Office of the Minister of Immigration, 2018).

However, participant frustrations with T2 extended beyond the known barriers of numbers and access. Time delays as a result of system overwhelm and eligibility limitations were referenced by numerous participants as significant barriers. Participants with involvement in legal processes and support were most vocal on these matters.

\section{Who can sponsor under T2:}

There were a number of issues raised relating to who was eligible to be sponsored under T2. The first was the limited scope of who could be sponsored. While T2 offered former refugees who already had family members with them in New Zealand opportunity to apply to sponsor further 
family to join them, the scope of who is eligible is limited and leaves many families having to make "impossible" (Community Lawyer, pers. Comms., 2020) decisions about who to sponsor.

If a person has been reunited with a partner under quota reunification and now wishes to apply for a grandparent or niece or nephew, this is unavailable to them regardless of the nature of relationship shared with that family member (for example if a person was raised alongside their cousin and had a sibling-like relationship for all intents and purposes- this would not be granted under T2 criteria). A lack of choice marks the refugee experience from processes of fleeing, separation of family and friends, and socio-political and social circumstances beyond their control or predictions. Further, the impact of limited choice and autonomy prevents former refugees engaging in various factors influencing New Zealand's desired resettlement outcomes of belonging, participation, and inclusion (Strategic Social Policy Group, 2008).These outcomes hinge on whether or not former refugees have access to, choices over, and resources for engaging in activities of work, education and community (Strategic Social Policy Group, 2008), this is recognized in the recent redesign of community resettlement frameworks (MBIE, 2019).

The psychosocial benefits of reunited families and their flow on impact for these outcomes has been well documented and were also discussed by participants in this research (Choummanivong et al., 2014; Refugee Family Reunification Trust, 2020; UNHCR, 2001b). When these opportunities become marked by difficult choices about which family member to bring, and the burden of guilt therein, resettlement outcomes are arguably less likely as this further exacerbates the sense that one has knowingly left loved ones behind (Poole \& Wise Group (N.Z.). Te Pou o te Whakaaro Nui., 2010)

"There's a really limited group that can sponsor as well. It's only parent, adult child or adult sibling... they can't, with T1 you can do aunts and uncles and other people. So if the person that they wanted to sponsor changes their mind. That's it, you can't substitute someone else. So you've wasted the opportunity. If the person dies, you can substitute someone else."

(Community Volunteer-Legal Support) 
Further, lawyers interviewed drew attention to the lack of adaptability to context and shifting relationships in policy for $\mathrm{T} 2$ which left former refugees who were fortunate enough to have registered when $\mathrm{T} 2$ was open, now unable to be reunited with anyone:

While some participants mentioned that this was a system their clients had become accustomed to, all participants lamented that policy placed some in this position.

\section{Time delays impacting on eligibility:}

The issue of choice is magnified somewhat by the risk that during the time delay between registration in the RFSC T2 queue and opportunity to lodge an application for sponsorship, life continues to unfold for diasporic families:

But the other issue is that the dependent children...So say you've got someone here sponsoring their brother and brother's wife and their children. The children have to be under the age of 25 and they have to be dependent. So they can't be working independently. They can't be married or have their own child. And so, you know,.

Surely, all of that can happen in that time of application, especially at that age?

I know it might take three years from when you put your registration in to when the application is pulled from the queue. And then it means that some of those older children will get left off the application. But if their application had been drawn sooner, they might have been able to be included."

(Community Lawyer)

Further issues of dependency were raised with participants giving examples of arranged marriages or independent employment (to mitigate poverty) taking place during the four to five years wait for T2 availability. Two participants raised the issue of pregnancy and its gendered implications for eligibility. One participant remarked on how frequently she saw this become a barrier: 
But what happens if a 20-year-old daughter gets pregnant? And it happens all the time. And then they become, the reality is that they become more dependent and they need their parents more than ever. But. under immigration policy, they become independent and they're not allowed to come and we've had that happen so many times!

(Community Lawyer)

The gender bias inherent within a policy stipulation which cannot affect fathers in the same way aside, the fact that this policy "completely overlooks the additional needs of pregnancy and new motherhood" (Kindon, pers. comms., 2020) undermines the very purpose of family reunification which is to aid resettlement and reduce distress of separation.

Knowledge of the myriad of barriers associated with $\mathrm{T} 2$, from closure, to time delays, to reduced eligibility criteria was discussed as something which greatly impacted lives and choices of former refugees seeking to sponsor family members:

One other thing I would say is that the nature of the refugee experience disrupts relationships, such that people will leave a spouse or partner because they don't know. I've come across a number saying 'I'm not going to enter any relationship until I've .. so I can be tier one'. So yeah that's probably the big thing. And yesterday I was going through with a client and my brain was saying 'if only you had not entered the relationship with your partner, your sister would be eligible to come and be with you but now we're just lodging his application so now you've cut out the possibility to bring your sister but you didn't know'. Because it'll now be tier two.

(Community volunteer-legal support)

And when it comes to accidental pregnancy. It's a really it's actually a really perverse policy because it puts, you know, these kids in, well, do I have to have an abortion to preserve my mum's status as a sponsor? you know, if I or the additional guilt, you know, an accidental pregnancy in some families, it's so 
shameful then the additional shame of derailing an application because it's like at any stage of the sponsorship process. If that happens, it can make the whole application fall over. So it's a really crazy situation.

\section{(Community Lawyer)}

The impact of this awareness of barriers and the role it plays in refugee lives, choices, and presentations of self, is further explored in the following discursive analysis chapters.

While critiques of time delays and consequent eligibility as a dependent in RFSC processes are not new (Changemakers Refugee Forum, 2009; Department of Labour (DoL), 2004; M. Williams, 2016), the focus on how they impact sponsors and their family members overseas is here different from the prevailing literature. Both the 2009 policy discussion paper and a 2004 extended research project into refugee voices noted the extensive impact of time delays on mental health of former refugees undergoing RFR processes. This impact on mental wellbeing is largely attributed to awareness of continuing threat and suffering in refugee camps, origin countries, or loved ones' ongoing experiences of fleeing (Changemakers Refugee Forum, 2009; Department of Labour (DoL), 2004). The effect of this trauma is well documented and discussed in earlier chapters (Choummanivong et al., 2014). Participants in this study maintained that these impacts continue today, often describing the changes in physical health and wellbeing that went alongside participants' experiences.

However, beyond recognition that INZ's policy “falls short of UNHCR's broader recommended approach, based on 'dependency' including emotionally, physically or economically dependent relatives" (Mahony et al., 2017, p. 5), the specific examples of dependency categorisation are not discussed at length in the literature. Neither is the position many current and potential former refugees find themselves in to make choices about relationships both overseas and in New Zealand for the sake of their own or loved ones' eligibility status. Both these issues offer a perspective of impact beyond the obvious external factors that motivate the fleeing of refugees to resettlement countries. What these themes highlight is the direct impact of policy and process on hindering resettlement and trauma recovery, magnifying situations of status precarity and 
consequently driving former refugees into positions of difficult choice, poor health and relationship loss.

\section{Process: Requirements of applicants}

\section{Bureaucratic demands}

All participants acknowledged the consistent issues of lacking documentation, expectations of evidence to be produced in support of an application, and the need for advocacy to contextualise FR applications:

Some of the other issues I think that come up in and the fact that INZ

officers... When they, when they are processing these applications, quite often, they just don't take into account why people might not have documentation. You know, we have to explain over and over again. 'This person is from Eritrea. They had to leave immediately. They didn't have time to collect their birth certificate!' and things like that. It's just so frustrating.

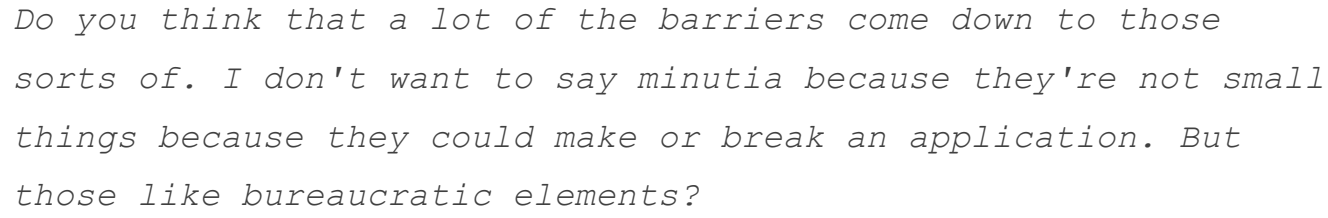

Yeah. Yeah. There's massive bureaucratic. Yeah. And things like sometimes we have clients come to us and they're partway through the process and they've just made so many mistakes along the way that we have to try and correct. Yeah.

(Community Lawyer)

The issue of documentation raised by participants here echoes that discussed in previous studies. A 2004 study spoke with 74 established refugees applying for family reunification, only half of these individuals had been successful, with the most common reason for unsuccessful applications being lack of documentation and incorrectly completed applications (Department of Labour (DoL), 2004). A later 2016 council brief from the NZ Law Society outlined the 
complexity of family reunification applications, reiterating these issues and the necessary assistance required to meet such bureaucratic demands (M. Williams, 2016).

INZ expressed in interview that there was some discretionary understanding in place for lacking documentation. This tended to entail alternative forms of evidence gathering such as DNA testing or additional and extensive processes to obtain legal documentation of marriage or adoption. However, the emotional (and at times relational) impact of these bureaucratic barriers and processes on former refugees was referenced frequently (and is explored further in following discussions of exclusions):

I think that proving, proving of self is already a very integral but difficult part of the refugee journey for people that come through the quota to New Zealand. And so they have a very difficult interview with UNHCR. And then they also have a series of interviews with Immigration New Zealand. So I think that their having to prove [themselves] is an incredibly hard part of the refugee journey for quota folks. And then for family, if they have also [a] refugee journey themselves, then they will also experience some of that.

(Resettlement Service Provider)

\section{Lack of legal aid in $N Z$}

With such demands for evidence and understanding of legal systems and processes in mind, conversations frequently turned to the lack of legal aid available. Community lawyers discussed the lack of funding for this service, and the necessity of their service to former refugees:

Immigration is really difficult. It's a difficult process to navigate even when you're relatively educated and English is your first language. And so, a client whose English might be really limited... Who maybe had very little education is just impossible and they can't do it without an advocate, but there's no legal aid available so they can't go to a lawyer. That's a massive, massive problem 
that we've got. So unless you've got a community law centre who's got the ability and resources and capacity to assist you, it's really, really difficult.

(Community Lawyer)

Acknowledging this difficult process, participants from resettlement service providers outlined the gaps that accessible legal support filled and noted the Wellington region was unique in its ability to provide such services to former refugees in the region. However, even in regions such as Wellington where community law centres were resourced appropriately to provide legal support, often the funding received through community law posed difficulties for working with former refugees where support could range from a quick explainer session with an interpreter, to an extensive case and application process:

Because community law center's funding requirements are that we have to see a certain amount of clients every year. And we can only count each client once. So if we see a client for half an hour, that's of, say, the same value as working on an application for 80 hours. So we have these real tensions...

... But legal aid would cost like out of the overall legal aid budget... it would be such a tiny amount, but it would just mean that people could you know, it's an access to justice issue.

(Community Lawyer)

Participants shared their thoughts on the necessity of legal support in accessing and using the RFSC. Community lawyers shared that this oftentimes included the refugee quota reunification pathway (despite INZs commitment to immediately action these cases) as information and support was scarce for newly resettled refugees:

So what we find is a lot of people have come through Mangare. They lose contact with refugee quota branch and they might have started the process there, but they need help continuing it here. Sometimes IQB need a prompt to remember to keep working on that process. And it's... various issues that come up that an advocate needs to be involved in. (Community Lawyer) 
A report out of Nelson highlighted the issue of under-resourced support and lacking legal aid reflecting what participants anecdotally shared of their colleagues and connections in different regional resettlement centres. This report (based primarily on interviews with Nelson Community Law Centre clients) surmised that, "The prospect of interacting directly with Immigration New Zealand is intimidating and, in fact, Immigration New Zealand itself presents so many barriers to clients that its own advice is for people to access legal help." (Keeble, 2017, p. 2). The continued barrier of lacking legal aid for former refugees seeking family reunification in Aotearoa NZ is a decades-old issue that continues to hinder access to justice, despite the widening of policy in both number and design under the drive for greater accessibility. Arguably, this simultaneous need for, and definitive lack of legal aid for former refugees in Aotearoa NZ is symptomatic of policy processes which have not given due consideration to the complex circumstances of third country resettlement; circumstances involving the "separate but related stressors" on former refugees which are well documented in both domestic and international literature (Keeble, 2017, p. 2).

\section{Expectations of sponsor: housing and financial savings required}

Amidst these stressors of resettlement, be they financial, relational or emotional, lodging an application to sponsor family members to join requires meeting ever expanding requirements for evidence of housing provision and financial savings- enough to support the family members who will be arriving through RFSC. Input into this research included contacts at the Refugee Family Reunification Trust in Wellington who shared that their very organisation grew out of a dire need to support applicants in meeting the extensive and financially burdensome demands of INZ ${ }^{2}$. Initially, this was in provision of adequate savings or flight costs, more recently however it has

2 The Wellington Refugee Family Reunification Trust offered input into this research sharing with me the barriers and exclusions they perceived to be most important. Although they declined to participate in a recorded interview, much of what was discussed echoed the key themes outlined here. 
come to focus on the housing requirements of applicant sponsors under RFSC. Participants from resettlement service provision, legal support and community voluntary roles all remarked upon the increasingly growing requirements of sponsors to provide adequate housing. These comments are aptly represented in what one community lawyer had to say:

The other big barrier is the fact that refugees have to provide housing for their family members to arrive... and I get it, I get why that is in place. But it's so hard.

... And I think what we found was it used to be... It used to be just the housing policy or the housing requirements should just tick a few boxes and say 'yes I'll provide housing. We'll worry about that later'. And now it's like, 'show us you've got a house. Shows how you gonna pay the rent, show us the savings sitting in your bank account'. And there was a client who had about 30 grand saved and possibly more money may have been more than 30 and they were declined and told 'your plan's not good enough'.

I was like, I could not house my family if I needed it to house my parents, like I wouldn't be able to do that! So.

(Community Lawyer)

What also became clear is that the rigorous expectations around housing varied from case to case, this was largely attributed to INZ officers having differing understandings and interpretations of what can reasonably be expected of a sponsor:

How does that work? Is it just a financial proof or do they have to already have a change of house?

Sometimes. This is the problem. INZ want to see the house sitting there empty, with the lease. And so, you know, that's impossible. And it's such... and then and then it might take... If they get approved. It might take months for the family to get here. So you could have a house empty for six months. And so we're kind of refusing to do that. But we have had, but then it comes back to 
inexperienced case officers, because some of the more experienced reasonable ones who are like 'of course, it's ridiculous'. But then you've got very, new, very young who just I just feel like I haven't actually just... Just haven't thought about the practical side of things.

(Community Lawyer)

Likewise, one former refugee interviewed expressed their own anguish at what was expected of them in applying to bring their mother here under T2 of the RFSC:

That system! They want me to have one hundred and fifty thousand dollars so I can sponsor my mum in other category. Even as a professional scientist I wouldn't be able to have the funds.

Probably we all won't be able to you know to have that, that sort of salary. You know the families are human rights. It's not something that you can pay, and that you, that only the very rich people have can have the right for. And it's just nothing. I mean, \$150,000, with that amount of money, you can't... I mean.. like, one hundred and fifty thousand?!

(Eliana)

A mixture of bewilderment and outrage was followed swiftly by questions as to whether this was an underhand means of ensuring former refugees could not bring family members through T2. I could not give an answer to this in conversation, but the more salient point here is the message being sent through such rigorous expectations of sponsors. That of unwelcome, of active barriers with underlying motivations, as opposed to passive oversights in the design of policy systems and processes.

Following discussion of housing and financial requirements conversations often led to the evergrowing role of volunteers, resettlement services, and lawyers to play advocate for former refugees in expressing to official bodies, such as INZ, the context of those whom these policies are impacting and their reasonable capacities in meeting the requirements of an RFSC 
application. That the policy was set to require so much of sponsors that almost every case necessitated justification and advocacy, was evidently wearing thin on participants.

\section{Process: provision for resettlement}

This requirement for advocacy, in the case of former refugee families reunited through the refugee family support category, continues beyond applications granted and through to resettlement within the community. Speaking with a pilot programme from a key service provider (one which receives government funding contracts for the provision of resettlement services) the role of filling the gaps in understanding through mainstream government social development provision is sizeable:

As I say, the reason that I'm passionate about it is because it's very uncommon area for most social service providers to be working in so they don't understand the rights and responsibilities of the refugee family support category. And that often leads to quite a lot of the necessity of advocacy just to get the legal entitlements for these migrants and then the financials space that's looking at opening bank accounts, getting IRD numbers and getting Work and Income entitlements and those all three of those areas take quite a bit of advocacy. So that's part of the reason that I'm passionate about it. It's not kind of settled in the same way. It's not well understood in the same way that quota work is.

\section{(Resettlement Service Provider)}

The theme of advocacy on behalf of former refugees to highlight the unreasonable nature of policy and process requirements, and or to explain and contextualise former refugees' rights and entitlements to those administering social services or assessing immigration applications, reoccurred throughout interviews. It is also necessary to be mindful that both this research and its participant base takes place in a resettlement region that stands anomalous from the rest of Aotearoa NZ in its resource and capacity for legal and resettlement support for family 
reunification cases. That many regions, such as that reported in Nelson Bays, are unable to offer such levels of advocacy or legal support, leaves me questioning how many RFSC applications or work and income support registrations go rejected and unchallenged with former refugees feeling out of options and distressed. The grief and disillusionment of this is expressed clearly by one participant I spoke with:

So how wonderful it would be to have my mum next to me here. You know, I would look after her, but I can't. Because New Zealand has taken that right out of me, you know. Yeah. I think what I was thinking is that it's a right that I have for granted. It's not a right. It's not a right. It can't be granted because now you, you need to be a very special person to be able to, to have family in New Zealand if you're a refugee, you just can't expect. Yeah. So I think that I what I what I think I have to say about that. It's just sad.

(Eliana)

\section{Conclusion}

The general barriers explored in this chapter highlight implicit exclusions through omitting to consider, and at times contributing further, to the structural and logistical challenges former refugees face. Barriers such as time delays impacting on eligibility hinge on gendered experiences of marriage and pregnancy, this disproportionately impacts women transforming an issue of processing time, into a gendered exclusion. Similarly, refusal of applications based on non-declaration highlight inattention to issues of power in policy formation, exemplified by lacking consideration for the experience of flee, and the context of fear within which offshore interviews take place. Although many barriers present as bureaucratic or logistical, a perspective of marginality brings to light the way in which these barriers operate as a mechanism of exclusion. The following chapter seeks to explore overt exclusions of those who trouble heterowestern norms. 


\section{Chapter Five}

\section{Theme 2: Exclusions}

\section{In what ways is NZ's family reunification policy and its associated processes exclusionary to those who 'trouble' hetero/western norms?}

\section{Overview}

Participants were no strangers to the exclusionary aspects of FR policy. Many spent the majority of their work seeking to advocate for, or break the news of exclusion to, former refugees with whom they worked or shared community. I did not seek to define exclusion with participants, allowing them to speak freely of what their own interpretations of exclusion in practice might be in the context of FR. Many of the responses aligned with Estevill's (previously explored) definition of social exclusion as:

\footnotetext{
"an accumulation of confluent processes [which]...distances and places persons, groups, communities and territories in a position of inferiority in relation to centers of power, resources and prevailing values." (Estivill, 2003, p. 19)
}

I therefore consider social exclusion in the context of RFR to be anything which contributes to not just a complete shutting out of a person from policy and processes, but rather an absence of a person's ability to access the full benefits of them. In this context, the centers of power are Immigration New Zealand, the resources and prevailing values manifest in expectations of the sponsor, and the ideologies on which policy was (perhaps unconsciously) written. The latter means that areas of exclusion hinge predominantly upon the issue of narrow definitions of family within policy. From these narrow definitions come the forced choice between family members, the inflexibility around who can sponsor whom, and the use of DNA testing to determine familial relationships.

When I set out to do this research, I included numerous questions around the experiences of LGBTQIA+ refugees who were engaging with family reunification. Two things quickly became evident; first that this was not something many of my participants encountered but that this may 
be in large part attributed to perceived appropriacy and accessibility of the policy pathway. Second, was that family models which trouble the hetero-western 'norm' of the nuclear family stretch far beyond those from the rainbow community. Though this was known at the outset of my research, the limitations of reunification policy on such family groupings was not. In fact, almost all the cases that participants discussed involved a struggle to justify the importance of familial relations which did not fit the policy-determined definitions of family. In troubling these 'norms' former refugee families are consistently queer(y)ing the notion of a "New Zealand definition of family" as one refugee quota branch manager referred to it.

What became clear, was that these 'norms', promulgated by policy specifications, were rarely represented in refugee background families, thereby either actively excluding RFSC applicants by rendering them ineligible, or implicitly sending them a message that their family did not fit the acceptable norm in New Zealand. Many participants, myself included, noted the contradictions of this norm citing formation and understandings of whanau in Te Ao Māori and the importance of identifying the continued influence of settler colonial state history on governance and policy in Aotearoa NZ (this is discussed further in chapter six). The theme of defining New Zealand family through structures of refugee reunification policy and its implications is picked up again in discussion chapters six and seven.

In an effort to tease out some of these challenges and contradictions, this chapter outlines the themes of exclusion beginning first with the instance of customary adoption. It then looks to the role of policy definitions in excluding family members and the need to recognize cultural impacts and implications of leaving dependent family members behind. I then present the stories participants shared to highlight the issues of prescribing hierarchies of closeness to family relationships and the consequent lack of flexibility on who can sponsor. Following that, I present the matter of DNA testing which was raised by all participants involved in the legal application process and issues raised around the necessity, accuracy and impact of testing. Finally, I discuss exclusions specific to former refugees from the rainbow community seeking to engage in family reunification. It should be noted that this (as with most themes touched on in participant responses) is an area which requires further, in-depth research. The prevalence of "I don't 
knows" throughout my interviews was revelatory of the marginalised position in which queer refugees find themselves when it comes to formalised processes and policies.

\title{
Policy: Exclusions in Regard to Narrow Definitions of Family
}

\section{Forced choice on which family members to bring}

While both quota and family support category reunification pathways allow for numerous family relationship forms, the policy requires that the sponsor living in New Zealand (or principal applicant) may only include their 'immediate' family, defined as partner and dependent children. This means that any alternate family set up, particularly interdependent family groupings such as siblings living together raising their children or a parent with an adult child and grandchildren, is not accommodated (Changemakers Refugee Forum, 2009).

Participants were quick to point out that the intersection of the policies that government is setting forth around immediate family (based on a hetero-western nuclear model) combined with the cultural and familial norms of former refugees seeking reunification, places sponsors in the unbearable position of choosing between family members:

\begin{abstract}
But I think that there's the big question there, who do they choose to bring?
Because at that point you're making a call on priority, and I think in terms of the policy, it should be broad enough to allow for any of your family members to come.
\end{abstract}

(Community Volunteer/Legal Support)

\section{Cultural appropriacy of leaving dependent family members behind}

Participants shared illustrative stories of families who had had to decide who to sponsor. Issues often arose out of who was determined to be 'dependent' and who was considered 'immediate'. Issues of dependency, namely how someone can be classed as an adult dependent child under T2, 
permeated conversations around barriers as already discussed but the issue of dependent elders, not considered immediate family under the policy, was a cause of great anxiety and oftentimes further separation of families.

The context of refugee journeys, be it due to war, oppression, or genocide often instigates shifts in dependency between and across family groupings and relationships increase in their so-called immediacy according to experiences of flee (Rousseau et al., 2004; H. A. Williams, 1990). The definitions of immediate family and prescribed (almost always biological) relationships within that work to exclude crucial kinship relationships that may have formed or been sustained through years long experiences of endurance through trauma in home countries and again within refugee camps:

Let me say this. There's all kinds of arrangements that happen when people are fleeing war and living in refugee camps. And I've seen some really sad situations of groups of people that have been living together for years. They end up being separated because they don't fit the criteria. And that happens in refugee family support category as well. So we have application that we've been working on for years and years and it involves an adult sponsor here. She's sponsoring her uncle, the uncle's wife and their children. But part of that family group is the uncle's wife's elderly mother. And so everyone else is eligible to come, but they'll be leaving the grandma behind. And... And she's very dependent. But because she's an adult, she's not considered to be one of the dependents. But she absolutely is.

(Community Lawyer)

Participants seemingly had no shortage of client stories where this had been the case, in most instances examples involved loyalties to dependent elders and family groupings that would not be classed as immediate family under policy:

And so we have had another application in the same situation, basically, and they decided not to go ahead. And it was a really difficult decision for the sponsor here because he was sponsoring his sister and her husband and they 
had. I think it was I was either eight or 10 children and again, the elderly mother. And he was weighing up. He was like 'all those children would get these education opportunities if they come to New Zealand' and they were in Somalia. And he said, he had to make this call. But in the end, it was his sister who was like 'I can't leave my mum'. So, they decided against it.

(Community Lawyer)

So, it is called refugee family reunification, but it quite often ends up with people, families being separated from each other and having to make terrible decisions.

(Community Lawyer)

Cultural accountabilities to dependent families back home also factored heavily in decisions (forced by policy as they may be) over which family members to bring. Again, this further divided families as duties of care appeared to take precedence over personal relationship preferences or emotional need. One participant, reflecting on her own perspectives and the lived experiences of refugee background community members she works with, underlined the western nuclear family perspective from which policy is written:

and it interests me from my experience that people have already made that decision from a long time ago and I wonder how much that decision is not theirs alone. Whereas it's interesting from a western perspective I feel like that would be my decision to pick a sibling but I think the way those families work as a wider family group they go 'this person is struggling so it doesn't matter if you wanna pick someone else'. [...]

which is also interesting because you're looking at dynamic of like what is a cultural norm for how a family operates, we don't write policy from that perspective so were not incorporating that into our understandings.

(Community Volunteer and legal support) 


\section{Hierarchies of prescribed relationships impacting who can sponsor}

Participants expressed through both their institutional knowledge and through illustrative stories of refugee background clients and friends, that the cultural appropriacy of leaving dependent family members behind is not considered in the current policy apparatus. It seems apparent that oversights such as this are a result of assumptions about family units and a supposed inherent hierarchy of prescribed relationships. These oversights can lead to two forms of exclusion: the first is ineligibility for some former refugees to apply to sponsor family under T1. The second is the idea that family members who are alive and fall within the definition of 'immediate' but who may be estranged from the sponsor take precedence over family members where there has been a longstanding kinship relationship.

Policy stipulations, based on Eurocentric ideas of genetic closeness as a precursor to dependency, come to prevent instances of family reunification. This stood out as particularly salient in the following example of an ongoing case application shared by a participant:

It doesn't come up very often but we do have some clients who are eligible for tier one, but they don't actually have anyone alive who fits into the group of people they can sponsor. It's just really sad. I've got one client solo mum here. She doesn't have, her parents are dead, her children are all here and they're dependent. She doesn't have any siblings or aunties and uncles because many family members were killed. She's from the Congo. And so the one family member that she'd like to sponsor is her second cousin. They were living together in the refugee camp. She's not allowed sponsor her because she's not within the group of acceptable family members you are allowed to sponsor. But she's got no one else. There's just got no one.

We've written and said she she's she's an eligible sponsor, but she doesn't have anyone to sponsor. Can you make an exception and allow her to bring her cousin, or second cousin? And they've said no.

(Community Lawyer) 
What was particularly interesting about this story is that it both encompassed the prescribed hierarchies of relationships within family set ups and highlighted the Eurocentric concepts of family members defined through their levels of separation biologically, rather than their involvement in the wellbeing, dependency and close emotional kinship loyalties. The story continued:

And...it's really interesting because we applied initially because she wanted to sponsor... she called her her niece because she's a bit younger. And we spent months working on this application before we realised that that she wasn't a niece. But but it comes back to what we think about family and what is a niece and what's a cousin or second cousin, because we had to get right down into who's related like, you know, we had to do this whole whakapapa to figure out where this niece sat in it. But it's, it's very similar to Māori culture here with, you know, everyone is your cousin or you know your auntie, your uncle. And just there's whole concepts around you know, this this particular definition we put on uncles and aunties and cousins.

That's such a telling example. Yeah. Especially if they've been living together as family in refugee camps. Literally they've been separated. They were together. Yeah. It really is a family reunification situation that you're seeing disrupted isn't it?

Totally. Totally. And I do think I think that she does have one brother alive, but she's got no way of contacting him well she she doesn't know if he's dead or alive. She doesn't know where he is, she's had no contact with him for years. But INZ would allow her to sponsor him if she could find him, but not the more 'distant' relative that actually she [wants to join her].

It's just, you know, going back to your idea of a family, it is focusing more on the situation of the person here again and what they need and who they need.

(Community Lawyer) 
Critiques of this western-centric idea of family can be found across multiple academic disciplines, particularly in Anthropology. I found the centrality of family definitions and ideologies within these findings, and their relevance to explorations of exclusion, led me to engage a great deal with Critical Kinship Studies. Given that this research was inductive in nature, and that queer theory is by definition an interdisciplinary approach, I seek here to further explore what critical kinship can bring to bear for my analysis of RFR from a queer theory perspective in later discussion chapters.

The expansion of dependency and family ties as a direct result of migration and conflict is widely understood in the field of migration studies and the reported expertise from resettlement organisations such as those interviewed in this research (Choummanivong et al., 2014; Department of Labour (DoL), 2004; Gray, 2008; Refugee Family Reunification Trust, 2020; Rousseau et al., 2004); so too is the necessity of extended family to resettlement and acculturation experiences for former refugees (Tingvold et al., 2012).

This expansion of dependency ties as a result of displacement is evident in the above case example. Despite being a former refugee with no living relatives and therefore qualifying under T1, this applicant was denied reunification with her niece, largely because an assessment of need does not take place. There is no discretion within policy for the inevitable impact of displacement on family ties and the shifting nature of kinship relationships that would be considered 'immediate'. This leads in many cases such as the above to result in further separation and grief, despite the very existence of RFSC and quota reunification being to aid resettlement and trauma recovery.

Not knowing if family members are dead or alive creates further implications for nondeclaration, as discussed. The all-but-zero tolerance on non-declaration for those people who may later find out about eligible family members can work to further enhance separation and the trauma therein. It can also exclude people seeking reunification under these circumstances. 


\section{Customary adoption}

When prompted to discuss instances where participants had encountered issues as a result of nonnuclear family set ups, the first issue that frequently surfaced was that of customary adoption. Customary adoption refers to when a child has been raised by someone other than their biological parent as opposed to adoption as granted by the court; adoption in many cultures not requiring juridical proceedings to be recognised as legitimate. Refugee Quota Branch maintained there was a necessarily growing understanding of, and discretion used for, cases of customary adoption which was a positive step towards the inclusion of non -normative family structures. Participants from resettlement provision and legal support corroborated this perspective. However, the legal requirements for customary adoption to be recognised or legitimated by INZ was a subject of much frustration for those participants engaged in legal support services.

The first of the issues these participants raised was the need for customarily adoptive parents to undergo legal adoption processes. These are time intensive and complex given limited access to birth records and documentation in many cases. Moreover, participants mentioned these intensive processes also applied for family members who have become guardians of younger siblings or relatives in the event of a parent's death. These family members often have to legally adopt siblings in order to remain a family unit through resettlement and reunification:

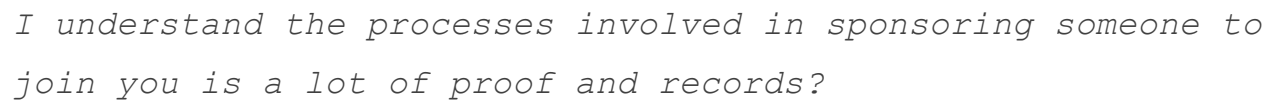

And actual legal adoption so that's some of the things that [my colleague] has had to to do and I had one or two where we would have to get an older sibling, the eldest to legally adopt the youngest to be able to bring them in as family. Or if it's the husband or, so I think in families that are war torn any families that are left behind you just scoop them up and bring them so there's been more flexibility but it's still kind of allowing that to fit the policy...

\section{(Community Volunteer/ Legal Support)}

While the allowance for these processes to assist families to meet policy requirements is generous, the policy requirements themselves often cause delays or are costly and converge with 
other barriers such as lack of access to legal aid. When combined, they cause a great strain on all involved.

Participants spoke of varying experiences with INZ around understanding and discretion regarding customary adoption. While some relayed stories of successful pleas on behalf of clients, a common theme was the lack of consistency across different INZ officers dealing with customary adoption cases (which in turn impacted opportunities for former refugees seeking reunification):

Ifind that Refugee Quota Branch are much more open to understanding the situations that lead to adoptions that aren't textbook because they're working with refugees all the time. I find the teams that work on refugee family support category, quite often the officers are very young and very inexperienced and it's like it's, you know, just just even getting them to open their minds to how customary adoption might work can be very difficult and very frustrating. (Community Lawyer)

Attention to the differing understandings around customary adoption was noticed in part due to the fact that such cases are "super common" (Community Volunteer, pers. Comms., 2020) and so participants had a breadth of experience across multiple INZ interactions from which to draw. When discussing customary adoption with refugee quota branch, one manager, who had also been involved in the policy formation process, outlined the risks of not requiring rigorous legal processes:

I have seen an instance when a young girl was brought, as, you know, as adopted by a family here and then and after that, that the girl arrived in New Zealand, she said 'when is my mother coming to New Zealand?' In our records show that she had no mother and she was adopted by by an aunty who raised her. And then even in conversations with her, we realised that it actually was a planned scheme, that the child would be brought to New Zealand because we maintained very strongly to that... We are signatory to the U.N. Convention and protection of Rights of the children. Yeah. So when in this instance we look 
at the best interest of the child, which meant that we needed to bring the mother to reunify with the child, whereas the adults who were involved in this were referred for fraud because they committed technically... So it's that's why I say it becomes very, very complex situation. That's why we are quite careful when we look at the definition of what is an adopted child. And so, yeah, I have encountered once a situation of, you know, child manipulation. Yeah. I won't call it any stronger than that.

\section{(INZ Quota Branch Manager)}

This example is important in recognizing the potential for people to be fraudulent, but also in highlighting the nuance of desperation that drives such a scenario. Perhaps if family reunification cases were known to be more reliable, accessible, and quota intake were higher, then attempts to work around the system in such a way as the above example depicts would not be necessary. Further, this participant has been deeply involved in both formation and execution of refugee family reunification policy for over a decade. In this time he recalled only one instance of what was referred to as "child manipulation" and agreed that this had been with consent of the parents, albeit fraudulent under the law, and recognised the context of desperation within which these decisions had been made.

The complex processes of legitimating customary adoption, even when it has become clear through interviews with highly trained officers and secondary sources of evidence that familial relationships are patent, works to further complicate processes for nonnuclear families, i.e. those who trouble hetero-western norms. It is clear that, with sufficient legal support (aid), and if families are fortunate enough to have access to necessary documentation or records from their countries of origin (difficult in times of war or instances of political asylum), customary adoption can be recognized and supported in reunification policy. However, the numerous barriers and stressors provoked and enhanced by this process were considered unnecessary and exclusionary by the participants interviewed in this research. 


\section{Process: DNA Testing}

In instances where family members are not adopted there are still numerous issues in relation to requirements around proving eligibility for family reunification, most notably the use of DNA testing and its effects in excluding non-normative family set ups. Since around 2001 INZ has offered refugees DNA testing as a means of verifying family relations in the absence of other forms of evidence such as birth certificates (Changemakers Refugee Forum, 2009). While this process is officially optional, for many former refugees seeking reunification with family, it becomes their only viable 'choice' in the absence of further required documentation or evidence. One participant spoke at length about the communities this policy affects most:

When we have people who don't have a birth certificate and don't have any way of proving that they're related to their family members, they can undergo DNA testing. So somebody, you can choose not to...And INZ is not supposed to hold that against you. But what they would do is say, well, we just don't have evidence that you're related. It's a real problem for people coming from, well, obviously, anywhere where they have not been able to take the birth certificates with them. But in Myanmar birth certificates aren't issued when a child is born, particularly in rural areas. So people just don't have birth certificates.

People don't really have a choice like. And most people just agree to it automatically because they're so desperate to get their family here. And then what I find interesting is kind of like, well, you know, if if they were out to mislead INZ, they wouldn't agree to DNA testing, you know. So the fact that they agreed to it straight away is a sign that they truly believe these people to be family members.

(Community Lawyer)

DNA testing as a tool for immigration processes is widely used in refugee reunification globally, yet comes with strict guidelines under UNHCR to be "resorted to only after all other types of proof have been examined" (UNHCR, 2008, p. 7). Comprehensive literature reviews and qualitative research raise social legal and ethical concerns around the use of DNA testing. Issues 
of cultural exclusion, furthering family trauma, double standards for considering familial relations legitimate, and privacy concerns are consistent across the literature (Barata et al., 2015; Granados Moreno et al., 2017). These issues were reiterated by participants in this New Zealand based study, and calls from the 2009 discussion paper on RFR policy for a review of DNA testing policy went unheeded (Changemakers Refugee Forum, 2009).

A perhaps less tangible aspect of DNA testing and its exclusionary impact is that of strained choice. While DNA testing is always 'voluntary' and INZ go to great lengths to point this out (including in interviews conducted for this research), the likelihood and fear of cases being thrown out on the grounds of lacking evidence if a former refugee does not consent to DNA testing works to strongarm applicants into invasive processes. Policy maintains that a refusal of testing options cannot negatively impact a case. However, in a structure where, without apt documentation, DNA testing is the only viable means of providing appropriate evidence for eligibility, a refusal to undergo testing tends to jeopardise sponsorship cases. Further, for those who cannot afford the legal and logistical support required to undergo these processes, or for those for whom their religious beliefs cannot allow for it, the consequences of not undergoing testing (being unable to fulfil requests for sufficient evidence) often renders them excluded from reunification outcomes.

While INZ policy around DNA testing procedures includes required counselling opportunities and sensitivity on behalf of immigration officers towards negative results and its impact on families, participants interviewed had not seen any instances of this support and were concerned about the further trauma caused by DNA testing processes:

And so what we've seen in so many cases is people who genuinely thought that they were biologically related to each other aren't, which just is like setting off a bomb in the family!. It's so awful.

And the reality is that for women in refugee situations, they might not know who the father is ..that you know sexual assault... People sometimes, have to you know like in refugee camps... That's a currency to get enough food or money to survive. (Community Lawyer) 
Their concern reiterates those recorded in discussion papers almost ten years ago (Changemakers Refugee Forum, 2009) and in international literature (Barata et al., 2015; Granados Moreno et al., 2017). The lack of sensitivity around context, and impact of a negative DNA result was found by one community lawyer to be particularly disturbing. She recalled a case in point involving a dependent nephew:

....and anyway, this DNA testing and they can't prove any link between the sister and her nephew. So she thought he's her biological nephew through her brother. Yes. We can't ask what's happened. We can only assume that the mum has at some point.. Yep. And but we don't know. We can only speculate. And so this this kid their nephew is a teenager. And so we're arguing that. I mean he's been part of the family for years. He was adopted when he was like four or six, been with them for over 10 years. Like lived as a family. And they're now saying you're not part of that family group. And that's been going on for a really long time...

...But I mean we've had to argue the tests aren't reliable to try and establish that kind of relationship. But also, you know, I think a stronger argument is that actually, that's family.

(Community Lawyer)

Appeals, advocacy pleas, reports and articles have documented issues with inaccuracy of DNA testing (Barata et al., 2015; M. Williams, 2016). However, participants in this research emphasises the need to address lacking recognition of nonnuclear family units in RFR (something which DNA testing undermines). So too do they stress the need for policy to recognise and accommodate for the impact of refugee experiences upon the family unit. Debates around the accuracy of and existence of DNA testing procedures were secondary to the belief that INZ needed to exercise greater understanding in their processes of verifying familial relationships, ideally designing processes that did not back former refugees into a corner of undergoing testing that could be, and often is, later used as a punitive tool to "impugn an applicant's good character" (Changemakers Refugee Forum, 2009, p. 37). 


\section{LGBTQIA＋ Discrimination}

In undertaking this research, I was acutely aware of the silence surrounding refugee background members of the rainbow community in Aotearoa NZ resettlement discussions and research, particularly in regard to family reunification. While numerous family set ups work to trouble western heteronormative ideas of the (nuclear) family, the LGBTQIA+ community sits at the heart of marginalised family set ups. The 'double marginality' of rainbow community former refugees often yields exclusions from both third country resettlement experiences and traditional support systems and resources (Buscher, 2011; Randazzo, 2005). The opportunities and experiences of LGBTQIA+ former refugees engaging in RFR is therefore an apt perspective from which to examine policy which exists to support the marginalised. I therefore also asked participants specifically about their interactions with LGBTQIA+ experiences in the context of discussing family reunification.

Exclusion of former refugees in the rainbow community seemed to be, by in large, unintentional oversights of considerations in policy and process. During interviews with refugee quota branch, the will to include LGBTQIA+ families in policy was evident. However, it became clear, firstly that oversights in policy and process, overt or nuanced, can be a cause of much distress adding to the cumulative struggles of refugee background members of the rainbow community from application to resettlement. Second, these oversights and exclusions indicate there is a great need for further research and education specifically focused on LGBTQIA+ former refuges' experiences, and needs.

\section{Policy: Language and terms}

When it comes to the terminology of family under international human rights law, the UNHCR Commentary to the Additional Protocols of the Geneva Conventions of 1949: concludes "all those who consider themselves and are considered by each other, to be part of a family, and who wish to live together, are deemed to belong to that family." (UNHCR, 2001a, p. 5). This same document explicitly maintains that family members can include "less closely related relatives, or even unrelated persons, belonging to it because of a shared life or emotional ties" (UNHCR, 
2001a, p. 5). In terms of RFR policy in New Zealand, family groupings are inclusive of any gender identity or relationship with immediate family using language of 'partner' and T1 offering a wider grouping of family relations (albeit in the absence of gender-neutral nouns for aunts and uncles/nephews and nieces in the English language). However, one participant noted the scope for more inclusive language on Immigration New Zealand's website and accompanying print sources. This was reported as particularly significant given the context of heightened anxiety clients often come to her in when seeking legal or peer support around RFR. She recommended that explicitly stating that all forms of relationship and gender identities are welcome would signal inclusivity at the earliest stages of family reunification applications:

I mean one thing I was thinking about is the language used doesn't reflect the breadth of the rainbow community. So. Say I'm sitting with someone and they're like 'I'd like to bring my partner'for example just looking at the policy (and the human rights law sits behind it so there should be a sense of no discrimination... within that) but what actually is written on the immigration new Zealand instructions is 'you are entitled to bring your spouse, partner' and then they've said 'that can be same sex, civil union or defacto' ...but it'd be better to say that just includes.. I don't know you'd probably have to ask communities how they would like that to be worded so that when someone like me works with anyone I can say to them here you're entitled to bring your partner whoever that partner is ... because like 'same-sex' is pretty, its still missing people..

(Community Volunteer and Legal Support)

\section{Process: INZ officers and assessments can be insensitive/ignorant}

All participants noted that in some cultures and contexts members of the rainbow community have found themselves in positions of perpetual precarity given that identifying as LGBTQIA+ is formally illegal or considered culturally reprehensible. Therefore, former refugees seeking reunification with a partner or family member can be hesitant to ask about their options for fear 
that disclosing their gender identity, sexuality or relationship status might compromise their applications for reunification, or even risk their personal safety. Three participants (one from personal experience and two from their professional backgrounds in community law) remarked that this contextual understanding was absent in interactions with INZ officers.

I note here as my participants also did, that INZ employs numerous officers of varying dispositions, training and sensitivities and so it goes without saying the experiences they drew from were not necessarily universal. However, grievances were significant and ranged from being misgendered in interactions with interviewing immigration officers to rigorous, expensive, and unnecessary requirements of trans applicants to undergo a medical assessment. These grievances, and the stories shared to illustrate them (examples included forthwith), stretched beyond family reunification processes to include convention refugees applying for residency, and tended to have their roots in bureaucratic processes that have been designed and instituted without due consideration of LGBTQIA+ experiences, relationships and needs.

Examples were given of INZ officers misgendering applicants or mistakenly 'correcting' them on their choice of pronoun. This usually came from the fact that documentation provided did not reflect a person's preferred name or gender as making such changes to official documentation is not possible in their country of origin, “... and immigration officers just being completely confused" (Community lawyer, pers. Comms., 2020). Although applicants are given opportunity to indicate how they would like to be referred to, officers were reported as tending to work with a focus on the processing of forms and documentation rather than necessarily the applicant themselves. Naturally this led to experiences where former refugees felt their gender identity was not taken seriously or understood. One example given was where an officer, seeing two genders and two names on the application, had assumed not only that the applicant mistakenly applied for themselves and a partner, but further made the heteronormative assumption that the presence of a male and female indicated partnership:

We had one trans male who you know, like his immigration application is he's asked to be referred to with the name that he uses now rather than his birth name. And the immigration officer has come back and said who is your partner? You need to provide evidence for your partner. (Community Lawyer) 
While not purposeful or malicious on behalf of the immigration officer involved, the message received through this difficult interaction was that the applicant's identity as a trans male and as a member of the rainbow community was not understood or accepted in New Zealand. As with the discussions of barriers, bureaucratic processes here work to exclude rainbow community members from applying for RFR, especially trans people. These incidences of misgendering, documentation hassles and lacking understanding are embedded within a process that has been built on heteronormative understandings of family reunification. Participants agreed that some INZ officers are compassionate towards the unique circumstanced of 'double marginality' and act to mitigate exclusions as much as possible. However such processes and the actors who enact them do not automatically hold space for needs and experiences of LGBTQIA+ applicants and therefore place "persons, groups, communities and territories in a position of inferiority in relation to centres of power, resources and prevailing values." (Estivill, 2003, p. 19).

One participant shared a further illustrative example of automated letters being sent to applicants, these letters pull a former refugee's information straight from their official documentation rather than from a case file or application. For many trans or non-binary applicants this means the name and gender pronoun printed on these letters is not correct. These seemingly innocuous byproducts of bureaucratic processes contribute further to messaging that one may be prone to exclusion as a result of their LGBTQIA+ identity troubling western hetero norms of the third country in which they wish to, or are, resettling.

One participant who was working in resettlement provision recognised this intersection of exclusions from representative documentation and mistreatment in interactions with INZ officers. Initially he suggested a preferable approach would be to place more emphasis on interview processes to put applications in context of human need and act as a reminder of the very real and significant impact they had on a person's life and safety. However, he also noted that it was his awareness of these kinds of incidences and harms within the application process for LGBTQ+ former refugees that still concerned him:

And it's kind of strange, as I mentioned to you, the transformative way that I
could see this going is that the immigration officer would go and conduct the
interview offshore right. And there would be a chance for that person to stake a 
claim not based on policy but identity. Yes. But it would also be an incredibly

challenging and potentially very hurtful process for them, too. Yeah,

particularly if the claim was denied because that's their process of not being

believed in the identity you're espousing.

(Resettlement Service Provider)

\section{Assumption of 'medical costs to state' for trans folk}

Another form of exclusion resultant of assumptions or misunderstandings of the rainbow community is in the presumption that trans family members would want to medically transition to the gender with which they identify. The consequences of this presumption are twofold. Firstly it places applicants in the difficult and further traumatising position of undergoing medical examinations. Secondly, it indicates a 'return on investment' approach to refugee resettlement and family reunification therein. One lawyer argued that these kinds of requests often meant applications had to be abandoned.

And we've had ridiculous requests around medicals and the medical issue is... And actually, any family reunification application that involves someone who's transgender, Immigration New Zealand just, they don't understand it I think and so they're, they are assuming that everyone will want to surgically transition. So they're looking at how much they're going to cost the health system.

...And so then they're asking, they're asking people to get reports from endocrinologists and psychologists....it's just ridiculous.

(Community Lawyer)

While this issue was specifically raised by only one participant, others agreed that requests for medical reports are extensive and often unnecessary. Such requests are also indicative of the "clean violence" of technocratic processes that centre economic and logistical evaluations and efficiencies without discretion for or recognition of those bodies who sit in the margins, and whom these processes most affect. 


\section{Cumulative struggles of refugee background members of rainbow community}

In discussions around former refugees within the rainbow community it became clear that many of the exclusions and barriers that came up were not unique to the process of family reunification. Former refugees who identify as LGBTQIA+ seemed to encounter a host of exclusions unique to their status. Often, this would be because former refugees in the rainbow community tend to be convention refugees, having arrived here via asylum seeking journeys and granted refugee status on arrival. One participant, who was both a member of, and advocate for the rainbow community of former refugees explained that convention refugees had little access to many of the resettlement rights and opportunities of those who arrive via UNHCR quota pathway. The issue of convention refugee exclusion from resettlement services is echoed in both qualitative research from 2013 and ongoing policy advocacy through the Asylum Seekers Equality project (Alia Bloom et al., 2013).

Participants also explained that many who do arrive seeking protections will do so because their status as LGBTQIA+ placed them in fear for their life in their home country as a result of state supported persecution of the rainbow community, hence the large representation of rainbow community convention refugees. This participant had been fortunate to arrive via the quota on compassionate grounds due to extenuating circumstances which were granted by ministerial discretion. When asked about exclusions for this community in family reunification processes, they had this to say about their position in relation to the majority of refugee background folk who are LGBTQIA+:

Yeah, I mean, I don't know many people who are. Right now that are because the only people I interact are LGBT refugees. They are different to me because they do not come under the quota refugee system. They actually came to New Zealand and they apply for asylum. They were asylum seekers here. I don't know the...

So they're convention refugees? 
Yeah. That. Convention refugees. And obviously...Convention refugees are like second class refugees. Yeah. They, most of the things that that are you would give it for granted to people like me are not given to them. So they don't, they do get residency, they don't get a visa that enables them to stay a given time.

And for instance, one of the problems is that they, that they can't even change the name and gender, some of the ID's of them. So it is really I mean, we are protecting someone because they are trans, but we are not allowing them to change names and gender because not in our law, only person can change a name when they become a PR permanent resident. Well, what happens is that we are, we are protecting someone here. But we are removing the protection by not allowing them to have an I.D. gender that recognised who they are! And it's something that can be just simply corrected. We provide enough some sort of I.D., you know? I mean, that person would surely be someone that's going to stay in maybe a whole life in New Zealand. Why we make that life so difficult for them? Okay. And it's happening right now. So I'm not so sure if they have the right to bring someone... because I understand that if I, if I don't have rights, they have less rights than me. And it's difficult for me, I'm sure way more difficult for them.

(Former Refugee Community Advocate)

The cumulative struggles for LGBTQIA+ refugees, particularly trans folk, was raised by all participants. There seemed to be a resigned helplessness among many who discussed this, perhaps because it was outside the scope of their role in relation to family reunification support or because it was something they felt never gained any traction. As unsure as many participants were on the rainbow community experience of refugee family reunification, all of them maintained that it was likely a struggle given the numerous grievances and exclusions faced by LGBTQIA+ former refugees in general. The same refugee background trans advocate shared their own experience of resettlement prior to receiving permanent residency: 
Yeah. One of the things is that the... That understanding of, "oh, you came here, shut up, you know, you, at least you're alive here", okay? Because this is kind of like they're thinking. When you complain about something being unfair, then you say, you know, "you came here from livingin that refugee camp with not having running water or toilets", (because this was my situation) "but you're complaining that you cannot change your name and gender. You know, like that's not like alife-threatening condition that should you should be complaining of". You know, Ididn't understand that when you come here and you see how others and other members of the community enjoy a life of respect for their identities, cultures, traditions. You say why I am not respected? Why I cannot be respected in the same way? And then is you always the way on you understand if a society is fair is how you feel treated, okay. So, yes, obviously no one is coming with a knife here behind me and trying to stop me at every time you know I'm in the street or somebody spits on me. I mean, all those behaviours are not necessarily behaviours of New Zealand, but. But it's I want to be treated equally. OK. And if having a name on my ID.. yeah.

People say to you when you are a refugee "you are poor or you are homeless". And I say no, I'm not poor I'm homeless. No one wants to give me a job because my name and my gender and my I.D. are different to the one I am now. No one wants to rent me a place. Right. Because who's going to rent me when my I.D. doesn't look like the person am I. You know, that they don't see things. They don't see the layers of discrimination. They just think that person doesn't want to work and is a homeless because. But it's the system that is making that person homeless and poor. Yeah.

(Former Refugee Community Advocate) 
This experience is illustrative of what many in the rainbow community feel, it is however only one amongst a myriad of diverse and multifaceted struggles within a system riddled with barriers and exclusions for those who straddle the 'double marginality' of refugeehood and belonging in the rainbow community. What both motivated the deductive beginnings of this research and what has become clear through the inductive process is the need for more research and literature which centres the experience, needs, exclusions and understandings of former refugees in the rainbow community in Aotearoa NZ, and which heeds their insight into necessary policy reform.

\section{Conclusion}

Exclusions in RFR are often intertwined with policy processes which could result in the further separation of families or the breakdown of familial relationships. These are illustrated through examples of mishandled or inappropriate DNA testing or necessitating lengthy and invasive formal adoption processes for long established customary adoption within family units.

However, the majority of discussions around exclusions within reunification policy came down to the simple truth that families are complex. Across cultures and contexts, time and again refugee background family set ups trouble hetero western norms. Be it through an absence of, or convoluted biological connection, through an unbreakable commitment to dependent elders, through unclear or unspoken paternity as a result of rape or extra-marital relations, or through the simple fact that immediate family extends often beyond that which is assumed in policy pathways. This led, in most cases, to former refugees being asked to choose between family members, essentially deciding who do (or can) they choose to give life to. The next chapter seeks to understand the dominant discourses on family which shape RFR policy and the exclusions explored here. It also highlights the discourses which counter hetero western definitions of family in Aotearoa NZ, laying the groundwork for more inclusive policy reforms. 


\section{Chapter Six: Discussion 1 \\ Dominant and Counter Discourses}

Social constructivist discourse analysis recognises the role of language in perpetuating, constructing or embedding dominant ideas and power relations. Further, discursive analysis of this nature pays attention to the historical and cultural context from which subject positions are created through discourse. In premising that different (or dominant) social understandings lead to different social actions (Foucault, 2006a), the question of what discourses enable or constrain within conversations about RFR policy or interviewees' experiences can also draw attention to previously taken-for-granted relationships of power within policy processes.

Language is understood by social constructivist discourse analysts to communicate a pre-existing psychological reality (Jørgensen \& Phillips, 2002) or from a Foucauldian perspective, widely held "truths". The language of hegemonic discourses is critical to the production of such 'truths' and their particular subject positions, in this instance 'the eligible family' or 'the eligible refugee'. What is implied, not said, or the opposite of such 'truths', i.e., alternative (or counter) discourses, however, were also important to acknowledge as they too were evident in conversations with participants.

In this chapter I identify three hegemonic discourses on family which emerged from conversations with participants: Family as 'more than'; Family as 'culturally bound/culturally ineligible'; and Family as 'culturally akin'. I notice the role of these discourses in constructing and constraining articulation of ideas of 'family' and draw analysis from both the 'what' and the 'how' of expression in regard to these discourses. Recognising the critical, observant, and at times contradictory Foucauldian concepts of discursive indicators and techniques within a 'history of the present' in Aotearoa NZ leads to discussion of relevant social theory as it pertains to these discourses and their manifestations in RFR experiences. I interweave discussion of these discourses as they relate to theories of structural violence, critical kinship, power and the historic significance of the settler colonial state.

In applying this Foucault inspired discursive analysis to the subject of family reunification, three discourses became clear. The first discourse represented the inadvertent rupture caused by a 
discourse which seeks to explain that which has been excluded by those in positions of power. This discourse, which I title 'family as more than', contextualises the need for rupture and for expansion of understanding when it comes to questioning family reunification, its subjects, objects and their constitution in discourses of differing power.

I then present two more discourses, one which I identified as dominant and the other which explicitly challenges (ruptures) the hegemonic ideas of the former. These are more intentional in their rupture as they seek to declare rather than explain. One represented that which underpins policy as it stands at the time of writing and therefore the most resilient (or 'mainstream') discourse by default of its (re)production by those in systems and positions of power: the discourse of 'family as culturally bound/culturally(in)eligible'. The other worked to rupture this, by arguing the contrary ('family as culturally akin') through the use of discursive structures of a similar nature to those it seeks to contradict. I present each of these in turn.

\section{Family as 'More Than'}

When participants sought to articulate aspects of family that were not reflected in RFR normative discourse, this process was not easy. The reoccurrence of their reaching for further explanation as to how or why a family may be the shape and form that it is led me to identify a clear thread of discourse which I call 'family as more than'. Discussing family structures which troubled norms required work, evidenced in participants circling back or diverging into expression of different ways of knowing (experiential, practical, presentational). Oftentimes, participants leant on the recollection of client stories or their own stories, long narratives of ancestry and relational history, as illustrative vignettes which might validate the emotional and experiential kinship connections they saw or had. Recollection as a means to explain took place in the form of muddled accounts, emotive language and storytelling without narrative clarity. One such example was in the explanation from a community volunteer of where customary adoption could help families who don't fit the model of family eligibility criteria: 


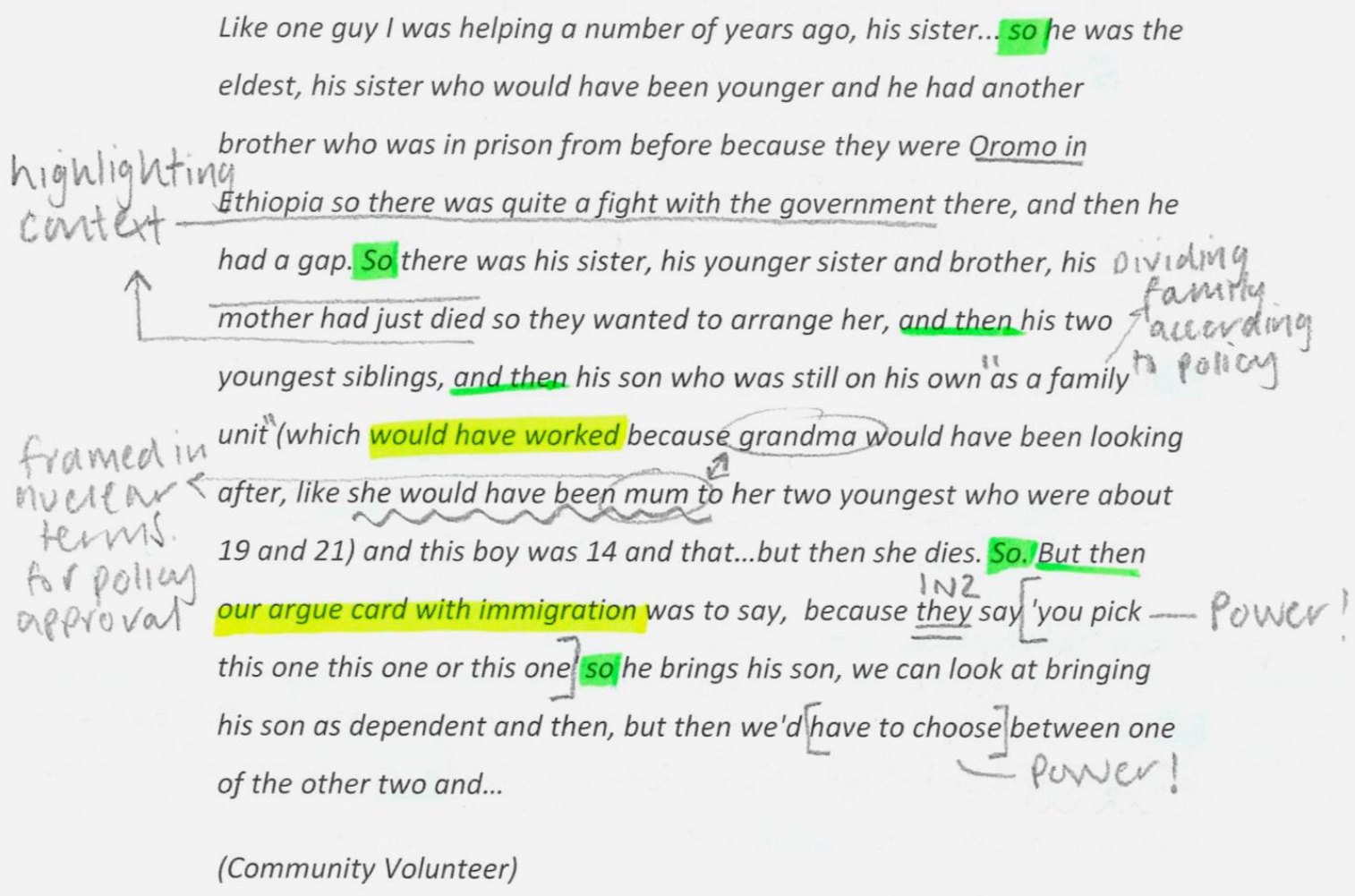

What struck me about this recollection of family experience is not so much the relationships involved or the circumstances under which separation had occurred but the ways in which these had to be explained vis a vis how they 'would have worked' if framed correctly. If the family underwent legal processes of adoption (incidentally, undermining the pre-existing relationships of accepted dependency and kinship) so as to ensure the family could be kept together then a non normative family set up could be deemed acceptable in the eyes of policy. The example reads as a sort of stream of consciousness, peppered with 'but then's' and 'and so's' stumbling over itself in its attempt to explain how a family could be deemed a family even though it troubles norms of the heteronuclear unit and structures of caregiving within that. References to age seem to be as much to contextualise the case in terms of dependency policy as to highlight the indisputability of this family's' need to stay together. What the printed transcript does not capture is the urgency with which explanations were often conveyed: Discussion of how a family could be eligible was rapid and emphatic to deliver the intrinsic message that a family should be eligible. 
Often, when recalling client kinship networks and family set ups, participants would stop and recount, apologising for their poor memory, starting over with the explanation, tracing connections. For example, a community lawyer said:

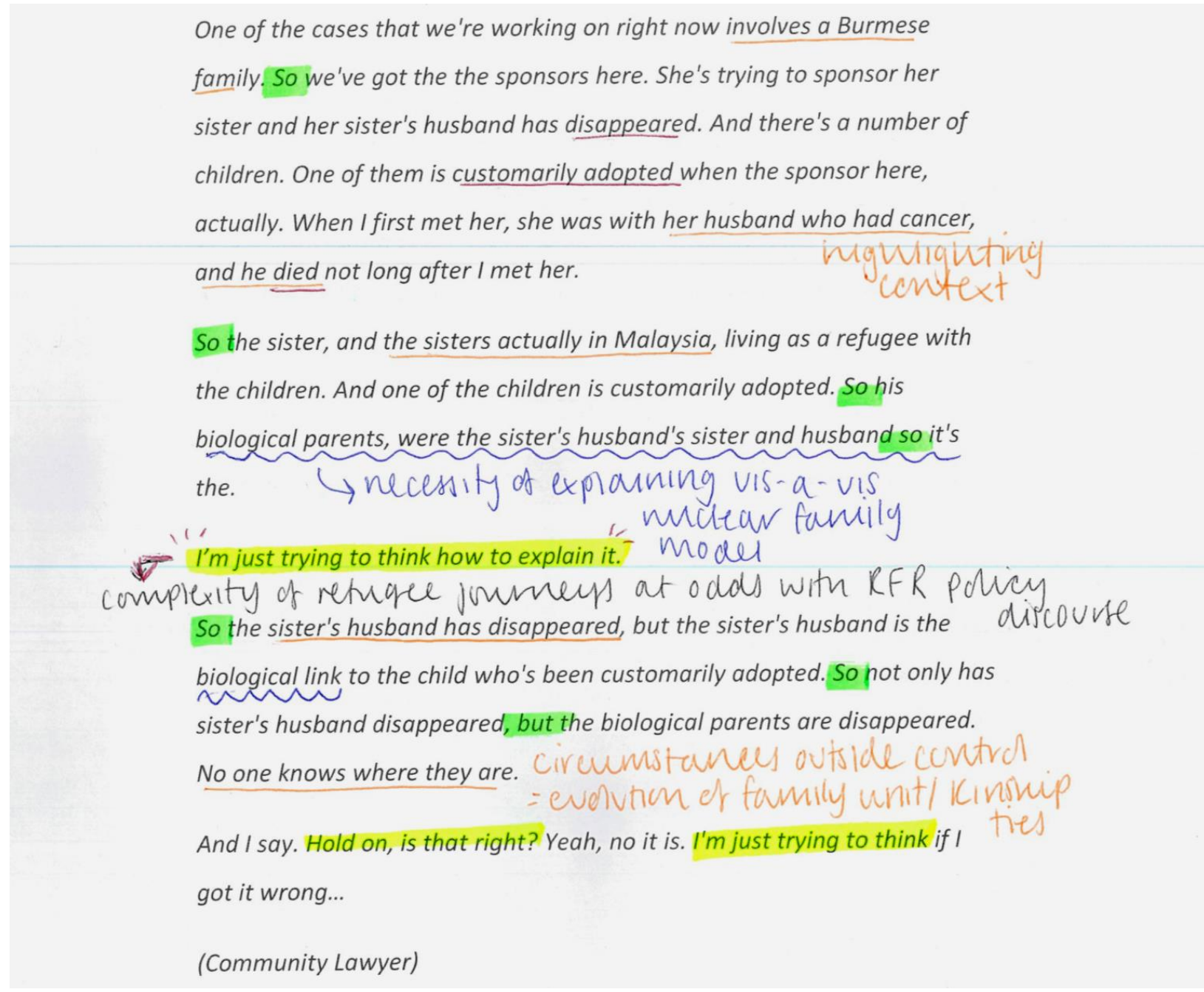

The task of constraining the evolution of family and kinship relations, through experiences of genocide or flight, into tidy case explanations designed to support RFR is difficult, even for lawyers immersed in this work and fluent in the language of policy and legality (the dominant discourse). Often it appears the person narrating still hasn't fully sorted 'the family' into a coherent, rational entity which can be presented easily, instead, there is a tangible sense of 'overflow' in these recollections, conveying a sense of people flowing out of any bounded sense 
of rationality (Sara Kindon, pers. comms., 2020). The repeated references participants made to their efforts "I'm just trying to explain it", "I'm just trying to think" are reflected also in the discourse markers of "so...". Opening remarks or sentences with "so" indicate a supposition that no statement can be made without first some relaying of context. This is important to those speaking because context illustrates the nuance of each case and aids in conveying the deeper understanding that is proving so hard to articulate in the language of policy eligibility and former refugee casework. The repeated use of "so" is observable across multiple participant transcripts. Arguably, its use extends beyond connection of thoughts and conveyance of stories. Rather, it implies connection to the before. For example, 'this relationship was impacted by this and so...', or 'this event took place and so this relationship came to be'.

I view the repeated use of "so" here as a conscious or unconscious indicator that nothing shared can be done without recognition that it is a consequence of what came before. In many ways this small repetition reflects the reality that refugee journeys are marked by impact and consequence, and that they are also complex, evolving, and non-homogenous. Such a reality is also frequently repressed by discourses of third country resettlement providers and policy processes. 'So' is in some ways an acknowledgement of the 'more than' when attempting to talk about 'family' within RFR.

Discourse is explicit and implicit in its relationship to norms here: Explicit in its content discussion of how to make family structures which trouble hetero nuclear norms work within the RFR process. Implicit in the way participants could not discuss these family structures without some form of explanation and justification. In sharing that these families shouldn't have to jump through hoops to be valid, participants also had to validate the families themselves through contribution of backstories or personal opinions on the just-ness of each case. Participants had to use the same discourse they were at odds with to express their discontent with the system. Jacques Derrida (1997) talks about there being 'nothing outside the text', in his criticisms of logocentrism- or the valorisation of words over all other forms of explanation or understanding. In doing so he infers that trying to dismantle loyalty to an idea (deconstruct ideas of 'family') is addled by the limitations of language (relational labels that determine if someone is 'uncle' or 'father' and the values of relational immediacy that are placed upon them). These participants 
reflect Derrida's observation in their struggle attempting to expand ideas of 'family' with only language available to them that has previously existed to reinforce these ideas.

Yet this discourse of 'family as more than' was clear not just in discursive markers and recollection as a means to explanation, it was identified outright by participants from all aspects of RFR policy structure:

So, she had had four partners. And you know it's the shape of people's lives don't fit. I mean its her story and not really mine to tell but...

(Community Volunteer) best explauned Mrovgh lived expenences of FRs.

$\mathrm{J}_{x}$ And he was weighing up. He was like 'all those children would get these f education opportunities if they come to New Zealand' and they were in of Somalia. And he said, he had to make this call. But in the end, it was his sister who was like 'I can't leave my mum'. $\rightarrow$ narnow detintions (Community Lawyer) of 'immealiate fumbly' = seperation or suttering

It's the family I grew up with, the family that knows who am I, the family that make me the person am I. Okay. Let me make a distinction between these two. They should not see the person I love, as the same family under the law, under that system, because this is just removing myself from who am I, from my culture and from my traditions... It doesn't, it shouldn't be that a matter of like how do you order your life like first being your family hei ravcluy $\mathcal{D}$ and then love, because that's just not fair. That shouldn't be that way. We of Kins hip
all should have the right to bring a family. Our family, the family that is

f living in those challenging conditions. You know, those the family members that that you want to you know, who share your life and experience, your. new life in New Zealand.

(Former Refugee Rainbow Community Advocate) 

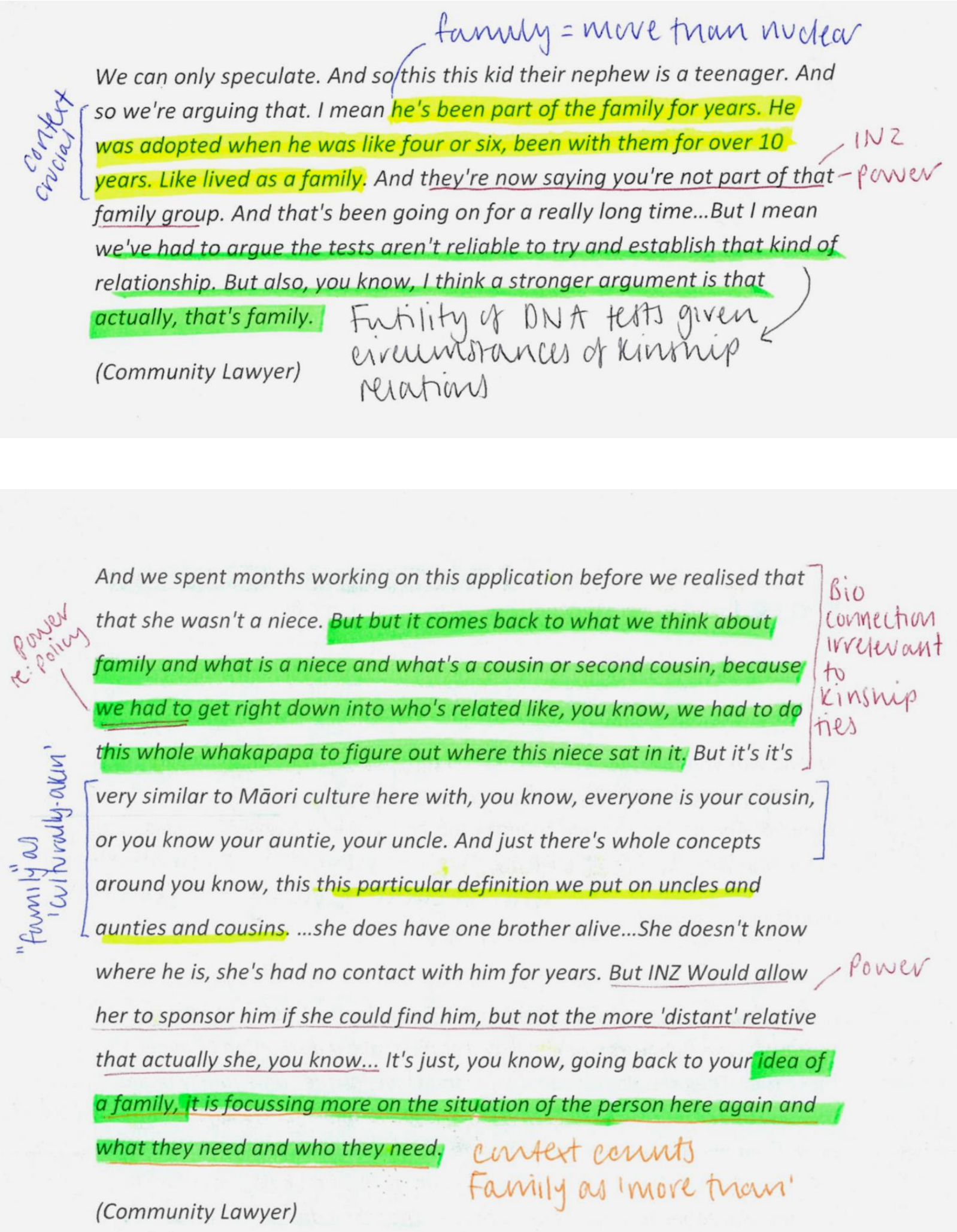
These excerpts are from discourses of family as 'more than' nuclear, 'more than' separable or distinct in accountabilities of dependency, more than partnership, more than a biological son, more than a not-actually-niece. Family as more than shared genetics or nuclear forms of dependence, where a place on the biological family tree does not correlate to relationships of dependency, kinship experience, or reunification needs.

Participants leant on their ways of knowing, their empathies and frustrations and experiences, to relay the message that families don't fit the structure of policy presumptions and prescriptions. In doing so participants conveyed with urgency the message that in fact, though former refugee families trouble these normative structures, they are justified in doing so. The fact that justification must be argued or implied is indicative of the power of norms constructed through discourse on family and its subsequent policy in New Zealand.

These discursive attempts came through as emotive language, and storytelling yet often with no narrative clarity because these lived realities contradicted the structures within which they were supposed to fit (for example, as biological son, as closest living relative, as important as a partner, as unchanged by trauma, death, flee and so on). As one participant exclaimed, "It's the shape of people's lives [that] don't fit" (Community Volunteer, pers comms, 2020).

Foucault (1994, p. 118) argues that to discover the key problem is to observe "what lies at the root of these diverse solutions [and explanations]". In this instance, the observable root is just that - diverse solutions are required for diverse subject positions (i.e., The unpredictability and impact of refugee journeys on familial structures requires policy solutions which adapt to and accommodate for this). The contradictions in themselves speak to the core issue; Families are complex, diverse in their formation and articulation. They are also nebulous by default of psycho-social-economic circumstances, which are often in flux for refugee families. Consequently, the rigidity of policy, and its subsequent discourse, stands in opposition to the subject position for whom it aims to understand and provide.

In sum, RFR policy, although claiming to exist to support former refugee families in reunification attempts, is built upon embedded ideas of family as hetero-nuclear, which serve to exclude or problematise these families' reunification attempts by positioning them as 'more than' 
nuclear or sharing close genetic proximity. That such families had to be extensively explained, advocated for and justified by the people I interviewed highlights the ways in which dominant Eurocentric discourses of family as a nuclear unit prevail, necessitating the need for a counterdiscourse of family as more than.

\section{Family as Culturally Bound/ Culturally (In)Eligible}

The second discourse I identify here is that of 'family as culturally bound or culturally (in)eligible'. I named this discourse such when reflecting on references to the hetero-nuclear family unit as "New Zealand definition of family" in interviewing a government representative (pers. Comms., 2020). The participant elaborated further:

\section{Our definition of immediate family is quite, quite defined and it is in New Zealand contexts. We do have requests from ...people out in the community about family members that this will be a completely different perception of what their immediate family member is, you know, whereas that would be extended family. \\ (Refugee Quota Branch Manager)}

Although this participant does not use the terms hetero-nuclear they do refer to the ascribed categories of 'immediate' and 'extended' within policy criteria which, as I have shown in previous chapters, are modelled off the dominant norm of hetero-nuclear family structures.

In policy the attribution of family criteria to 'New Zealand' as a whole, implies a perceived compatibility of policy stipulation and cultural norms. While the discourse of family as culturally bound is most prominently found in interviews with Refugee Quota Branch management employees, it represents the dominant discourse of family that underpins policy as it stands today, in doing so it also foregrounds the need for attention to alternative knowledges, or discourses that resist this. I have already explored one such discourse of family as 'more than', but more than what? The idea of family as culturally bound indicates an immobility and a universal acceptance of norms on which policy is premised. By producing and identifying clear 
norms, the discourse of family as culturally bound by "New Zealand contexts" works to ground meaning in binary oppositions. Culture is widely understood as including shared values (Baldwin, 2006), if the Eurocentric nuclear family unit, reified by shared genetics, is named as culturally acceptable in New Zealand then refugee background families who trouble this definition of family are then considered not so much as 'more than' but rather in opposition to these norms and values, and thus in opposition to New Zealand culture.

Applying a constructivist discursive lens to this discourse requires examining the origins of these so-called New Zealand definitions. The "historical and cultural specificity" (Burr, 1995, p. 4) of the new Zealand context underpins the power/knowledge nexus that enables this discourse of culturally accepted family forms to prevail in the machinery of government policy. I argue, the Eurocentric ontologies that arrived on Aotearoa NZ's shores with colonialists in 1840 continue to permeate ideas of family and kinship and its related policy(Durie, 2003; E Tū, 2018; Mikaere, 1994; Moewaka Barnes \& McCreanor, 2019). The discourses underpinning RFR policy can therefore be viewed as a hangover from the colonial "episteme"(Foucault, 2002) of white modernity and progress introduced through European dominated power structures in Aotearoa NZ (Healy et al., 2012; R. Walker, 2004). The dominance of Eurocentric thought in conceptions of family is not unique to New Zealand however and is widely covered in anthropologic scholarship, specifically in critical kinship studies.

Critical Kinships' emergence as a body of scholarship is notably marked by David Shneider's work "A critique of the study of kinship" (1984) in which among other arguments he outlines the promotion of the heterosexual nuclear family ( "a cultural unit which contains a husband and a wife who are the father and mother of their child or children.” (Bloch \& Schneider, 1972)) as a cultural norm, he critiques the conceptualisation of the nuclear family as the quintessential American kinship.

Schneider critiqued not just the cultural significance of the nuclear family but its inference that biological parenthood is necessary. One mechanism through which the definition of 'natural' kinship as a biological relationship is promoted is popular discourse. Schneider's analysis of such discourse and the cultural interpretations of common kinship related idioms expose the "valorisation of genetic relatedness" in western ideology (Riggs \& Peel, 2016, p. 44). One such 
example is the phrase "blood is thicker than water" in which Schneider argues that western interpretations suggest it to mean that blood relations between kin are more important than any other form of relationality, 'blood' here interpreted as referring to descendance from the same biological (genetic) ancestry. However, Schneider points out multiple historic interpretations of the phrase's origins exist, such as that the expression under scrutiny is a shortened form of 'the blood of the covenant is thicker than the water of the womb'. If this is the case this alternate interpretation contradicts the commonplace western one, here the 'water of the womb' is less important than the covenants between those who make sworn pacts with one another ('blood brothers') or those relations formed through the blood of the battlefield. Blood, in this interpretation, is a "signifier of chosen allegiance, rather than loyalty predetermined by the fact of birth." (Riggs \& Peel, 2016, p. 32)

The commonality of the western interpretation of this phrase (that blood relatives are more important or enduring) over alternate meanings discussed is, Schneider argues, symptomatic of the dominance of western origin stories in naturalising particular modes of being, or bodies of personhood. In this instance, personhood is "constituted through individuals involved in kinship relations that are founded upon genetic bonds" (Riggs \& Peel, 2016, p. 32) rendering all other forms of personhood or kinship as queer, or deviant from the 'natural' norm. The promotion of Eurocentric ideas of kinship through discourse, as exemplified by Schneider's work, is something this research pays keen attention to both in analysis of the language of policy, and discourse captured in field interviews. While Critical Kinship literature diverges from the field of Development studies it offers insight into both the dominance, critiques, and origins of Eurocentric ideas of family that prevail in the discourse of 'family as culturally bound/culturally (in)eligible'. While Critical Kinship contributes crucial criticism of Eurocentric ideas of family, applying Foucauldian inspired discourse analysis (under the critical framework of queer theory) highlights the role of language here as both a symptom and a tool of power relations and dominant discourse on the subject. Schneider's work inspires a marrying of the power/knowledge discourse analysis of Foucault with the historic specificity of Eurocentric perceptions of family within settler colonial state culture. 
Recognising the relevance of historic specificity to the power/knowledge nexus at play within this discourse of 'family as culturally bound/culturally ineligible' lays the foundation for analysis of how discourse continues to produce the subject position of former refugees as either deviant from or acceptable to the "New Zealand context" (Refugee Quota Branch Manager, pers comms, 2020. Recognising the evolution and continuation of this knowledge/power nexus and its impacts can be considered in Foucauldian terms a "history of the present" (Foucault, 1995; Rabinow \& Rose, 2003). Transcripts from interviews with refugee quota branch (the government arm of RFR policy in practice) exemplify the continuation of this discourse in upholding Eurocentric ideas of the nuclear family as part of new Zealand's cultural norm.

The idea of family definitions embedded within New Zealand cultural contexts underpinned much of my conversation with a Refugee Quota Branch manager, who identified that the definitions of family on which policy is premised is the most significant barrier to former refugees successfully engaging in family reunification processes. However, this barrier was not acknowledged as a needed area for change so much as an inevitable by-product of policy based on rational adherence to cultural context:

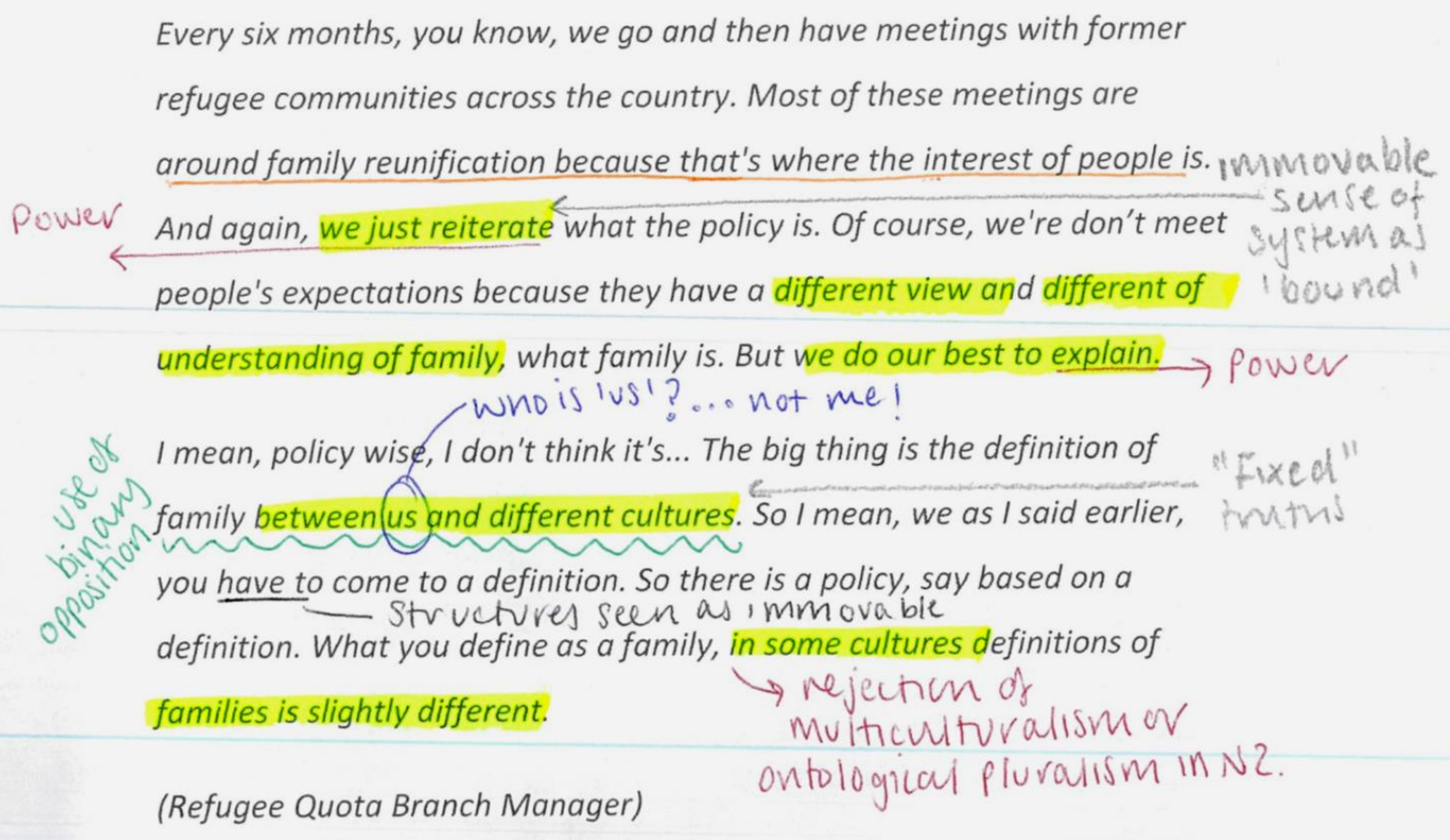


By repeatedly referring to the "different view" and "different understanding" of former refugee communities, this discourse works to ground meaning and justification in binary opposition. Ideas of family are embedded as incompatible "between us and different cultures".

Foucault talks of discursive structures as forms of social control (1971) identifying the "subtle forms of social power" (Waitt, 2016, p. 305) that constrain or naturalise ideas and practices as common sense. In repeatedly referring to difference in culture this participant enforces the idea of family conceptions as "fixed" (Foucault, 1971, p. 12) posing limits upon who may be considered (in)eligible for RFR. Conversation with refugee quota branch was peppered with identifiers of power/knowledge. I note here the use of verbs such as to "reiterate" or "explain" positioning former refugee communities as having to abide by the cultural ideas of family explained to them. This positioning also implies a "hierarchically valued dichotomy" (Waitt, 2016, pp. 304-305) of donor-recipient whereby government bodies (donors) educate former refugees (recipients) on what is acceptable to apply for under RFR policy.

The production of this subject position for refugee families, who are seeking acceptance within New Zealand has further implications in that families may be seen as troubling norms unless they perform in a way which is recognisable to authority as culturally acceptable. This performance and the internalisation of discourse therein may take place in response to produced knowledge/power for the purposes of assimilation, survival, or reunification. I explore this further in the following chapter.

Former refugees are spoken of in this interview, albeit sympathetically, as at the mercy of immovable policy and must therefore accept their subject position as produced by a discourse of difference. Foucault refers to this form of social control via discourse as "truth effects" (1980). One of these effects is the maintenance of a bureaucratic system which continues to exclude, examples of which have been highlighted already in my findings chapter. The production of these bureaucratic systems works to solidify discourse of family as culturally bound by embedding ideas of family as finite (defined by western hetero nuclear terms) in eligibility and accessibility criteria of policy. This evolves discourses which represent attitudes into policy 
process of structural violence. Such policy processes have been covered in my findings chapters, many of which are described in their capacity as bureaucratic barriers to proving or qualifying status as 'immediate' family for the purposes of RFR outcomes.

Johan Galtung first coined the term structural violence in his 1969 article 'Violence, Peace and Peace Research.' Here Galtung identifies that while violence is widely understood as having a clear subject-action-object relation (he uses an example: the husband beat the wife) structural violence instead represents incidences of social injustice where it is impossible to identify a single actor responsible for, or who commits the violence. Often times this social injustice takes the form of poverty or as Akhil Gupta refers to it "any situation in which some people are unable to achieve their capacities or capabilities to their full potential, and almost certainly if they are unable to do so to the same extent as others." (Gupta, 2012, p. 20).

In the case of RFR, this research has shown that the potential for a successful application and reunification of family hinges on good fortune of available legal support, English language skills, family units which conform to policy structure, and documentation provision by country of origin. My findings also showed that this good fortune of necessarily intersecting capabilities renders some applicants unable to achieve RFR success to the same extent as others. The barriers explored in this thesis, all of which find their origins in the attitude informed bureaucracy of the state policy and its process, can be labelled as structural violence. Violence which is impersonal, oftentimes unintentional, and yet built into the structure of power "and shows up as unequal power and consequently as unequal life chances" (Galtung, 1969, p. 171) for former refugees seeking family reunification.

Further, given that structural violence encompasses the exclusion of one from achieving their capacities or capabilities (for family reunification under policy), the barriers discussed by participants echo Amartya Sens capabilities approach, or rather his frameworks of social exclusion as explored in my review of development literature. The discourse of 'family as culturally bound' enables policy processes to be justified in their bureaucratic inflexibility around the eligibility of family relationships for reunification, and thus contributes to the perpetuation of structural violence. The Foucauldian "truth" here that family has definitive bounds is dominant by default of its being the discourse of power (government). The mechanism of this power's 
application is policy and process. I therefore argue that because policy and process here exclude former refugees from their capabilities and capacities to seek RFR (via bureaucratic barriers), RFR policy is an agent of structural violence.

Additionally, the social exclusion of LGBTQIA+ refugees from RFR processes is exacerbated by these bureaucratic means (as I have explored in findings) many of which are promoted or justified by the same discursive structures that are used to promote the 'family as culturally bound' discourse. The subtle form of violence associated with technocratic organisations and processes, referred to by De Certeau (1986) as the state's "soft violence" (Cited in Rousseau et al., 2004) adversely affects those of 'double marginality'.

In paying attention to the relationship between these effects of truth and power it is important to recognise the role of persuasion. Persuasion entails "establishing and maintaining sets of ideas, practices and attitudes as both common sense and legitimate." (Waitt, 2016, p. 304). Considering persuasion to be a form of disciplinary power, Foucault (1971, p. 12) draws attention to the deployment of different knowledge making practices and their use in reiterating and reifying dominant discourses. I include the following interview excerpt as an example:

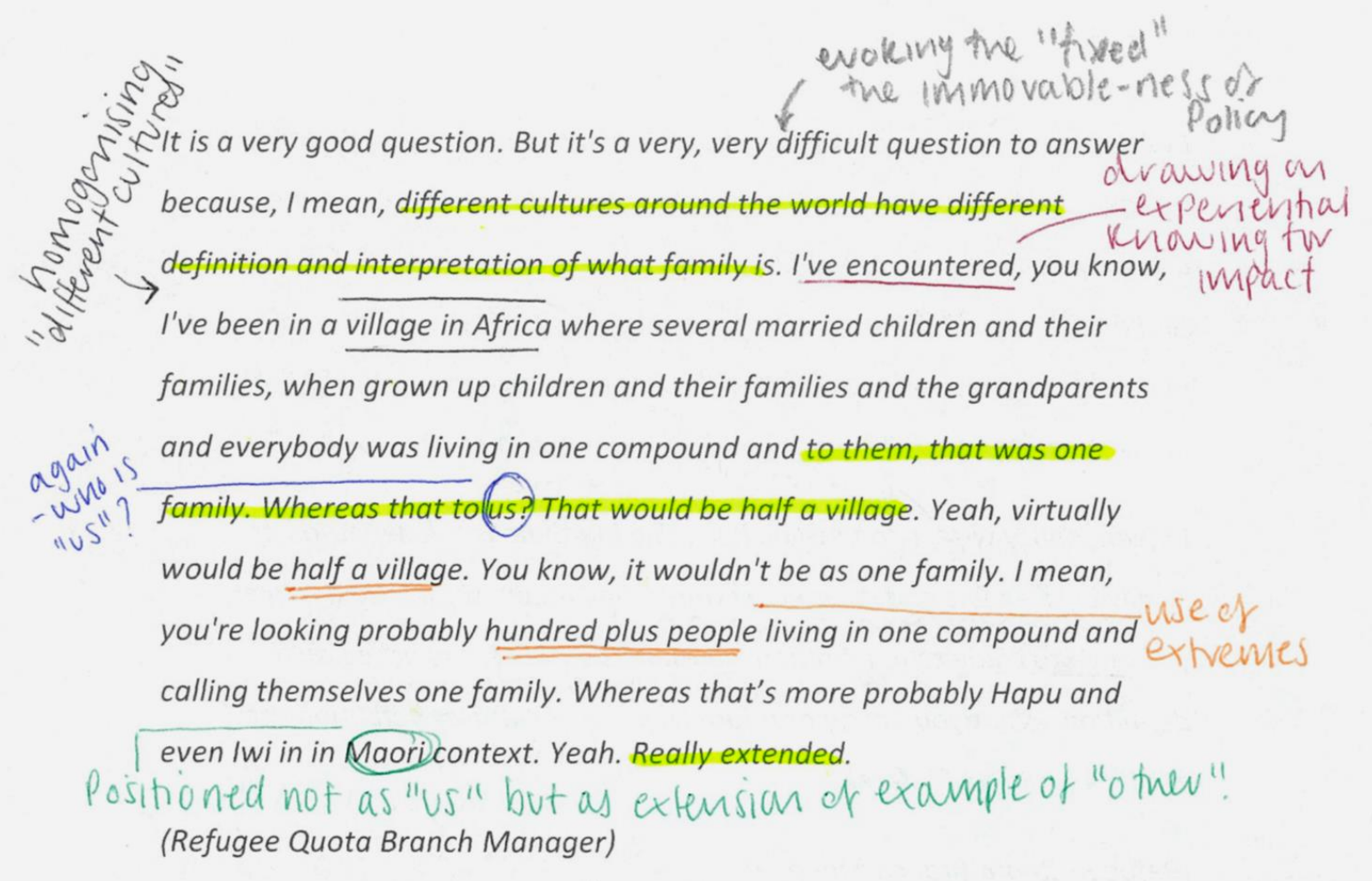


The use of anecdote here, referencing the extreme example of a village visited to highlight difference, cloaks the issue at hand (incompatible definitions of family) in language of rationality. Implied in this example is the notion that were policy to be any broader, then it would have to accommodate for the "hundred plus people". It (ironically) demarks the notion of family as tenuous and contingent on social norms, therefore necessitating that definitions remain fixed for the common-sense purpose of avoiding a 'sublime to ridiculous' evolution of policy allowances. The likelihood of one hundred plus people applying to be kept together through a single RFR application is slim to say the least but the deployment of knowledge that such size groups may identify as family serves its purpose here in situating current policy as rational in its exclusionary impact. An earlier statement from this interview carries the same sentiment declaring "you have to put some parameters" on defining family within policy "otherwise the risk of, you run into risk of becoming arbitrary in decisions" once again appealing to ideas of common sense and logistic capacity: "officers that make these decisions, they need some some guide and they need some rules on them" (Refugee Quote Branch Manager, pers. Comms., 2020).

This participant deployed a number of other knowledge making practices to reinforce the discourse of 'family as culturally bound/culturally (in)eligible': References to statistics; successes of the New Zealand government in meeting global obligations under UNHCR; and utilising further anecdotes of to establish this discourse as a rational response to contextually contingent possibilities. Deployment of knowledge in these forms served the purpose of persuasion, and therefore disciplinary power (via exclusion of former refugee bodies). It is important to note that this participant, showed personal connection to and empathy with the cause and purpose of RFR. However, the dominant discourse of family as culturally bound was so (re)produced through this interview because it was embedded within the participant's own worldview as immovable.

Similarly, within these utterances of rules, limits and rationality is the concept of risk, be it "child manipulation" or applications for a "hundred plus people" for RFR. In introducing the concept of risk, from a position of power, this discourse also legitimises a process of othering. The apparent rationality, arguably, masks fear which necessitates a discourse that justifies exclusion. That this 
participant was in a position of, or representing, power is arguably exemplary of what enables the discourse of 'family as culturally bound/(in)eligible' to prevail in the mechanisms of policy stipulation.

Finally, it is interesting to note the use of Te Ao Māori as a reference point for understanding notions of family within the African village example. Te Ao Māori here is only referenced in the context of an example of 'other', with hapu and iwi aligned with the example of an African Village and thus indirectly positioned in opposition to the so called "New Zealand definition" of family. Arguably this represents a subconscious continuance of the colonial episteme from which Eurocentric ideas of family became established as a dominant "truth" in Aotearoa NZ. This use of reference to Te Ao Māori contrasts distinctly with the third discourse I identify of 'family as culturally akin', a discourse which emerges from participants of refugee background and service provision contexts.

\section{Family as Culturally Akin}

The third discourse I identify emerging form participant transcripts is that of 'family as culturally akin'. Much like the 'family as more than' discourse this discourse works to rupture the resilient discursive structures that promote 'family as culturally bound/culturally (in)eligible'. It has been shown that dominant discourse (of family as culturally bound) situates refugee background families as other. It promotes ideas that they are too different, diverse, and situationally contingent to accommodate for. 'family as culturally bound' privileges Eurocentric heteronuclear family structures excluding all others by default. However, while this discourse is carried forward into the history of the present via the machinery of government, it is not reflected by participants from all other aspects of the RFR policy structure I interviewed.

Frequently emerging from conversations around barriers and exclusions was a resonance with Te Ao Māori, and a call for greater consideration of indigenous ontology associated with family in Aotearoa NZ. Participants identified that within Te Ao Māori lay reason upon reason for both greater understanding of refugee background familial set ups, as well as greater appreciation for ontological pluralism in RFR policy formulation. Refugee background experiences of family, in 
its different manifestations of kinship form (be it via customary adoption, precedence of relationship history over shared genetics, significance of elder care and influence, and so on) was seen as culturally analogous to concepts of, and within, whānau and hapu in Te Ao Maori.

The meaning of whannau is widely understood to be resonant with that of family structure, however it is not the same as eurocentric conceptions of family as limited to household or genetic proximity, rather it is more complex , more encompassing of relationship forms as well as spiritual, emotional and physical dimensions related to whakapapa (ancestry) (Mckenzie \& Carter, 2010; T. Walker, 2017). Whānau encapsulates numerous family structures, and is referred to often in the literature as appearing in two forms: Whakapapa whānau, referring broadly to "individuals with a shared ancestry or common line of descent"; and Kaupapa whānau, which encapsulates "individuals who may not share the same ancestor but share a common bond, such as geographical location or shared purpose" (Mckenzie \& Carter, 2010, p. 2). Scholars consider Whānau a central location of both individual and collective identity for Māori and a core component of Aotearoa NZ's cultural heritage (Cram, 2014; Moeke-Pickering, 1996; T. Walker, 2017).

In discussion of family as culturally akin, participants employed knowledge through comparison, personal account, and a complete inversion of discursive structures embedded within the discourse they sought to contradict- that of 'family as culturally bound/(in)eligible'. One such example of this inversion is the reference to the centrality of whānau in New Zealand culture by a former refugee participant: 


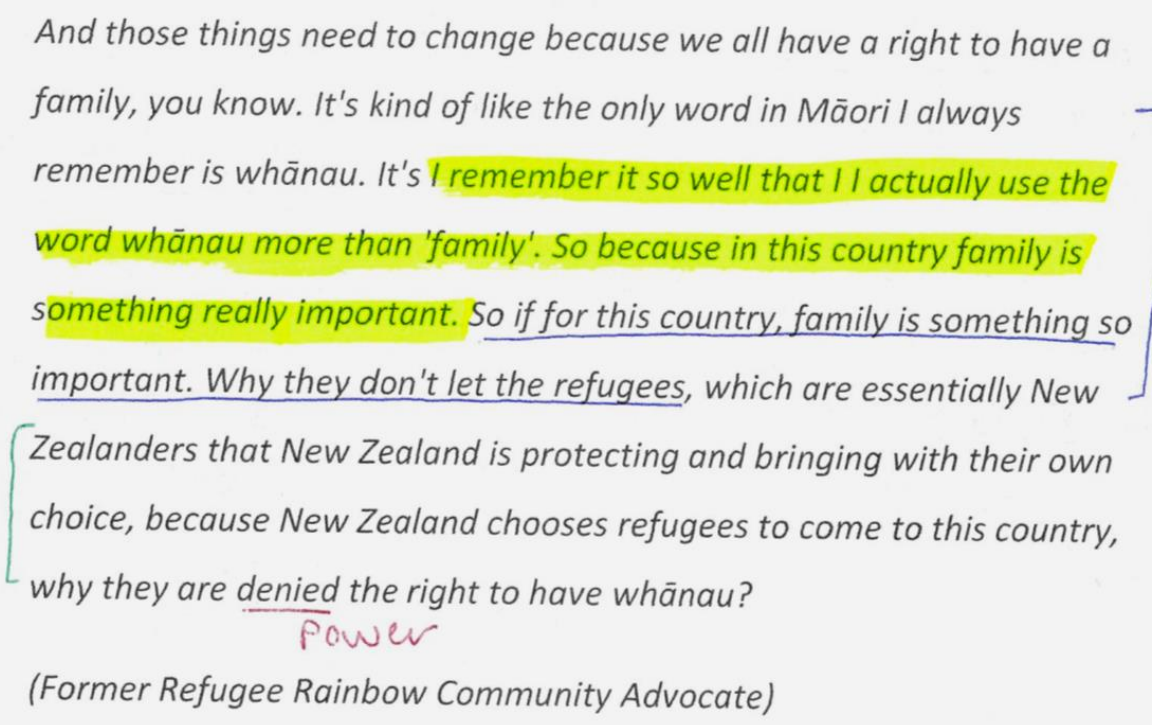

I have already shown that in the discourse of 'family as culturally bound' concepts from Te Ao Maori are only referred to for added effect to an example of an African village, an example used to add reason for not broadening definitions of family within policy. Here, quite the opposite is at play with a participant referring to the importance of whānau in Te Ao Māori, as part of New Zealand's cultural fibre, to implore broadening of definitions within policy.

The contrast of context within which participants from (structural) power and participants from the margins employ reference points from Māori ontology is arguably representative of wider power relations within Aotearoa NZ. A participant from government policy formation and implementation represents a discourse which finds reason and common sense in sticking to western hetero-nuclear ideas of family as a "New Zealand definition" and basis for policy (Pers. Comms., 2020). Conversely a refugee background participant engaged in grassroots community advocacy represents a discourse which finds reason and common sense in sticking to the inclusive cultural concepts of Te Ao Māori such as whānau, as a basis for policy, "because in this country family is something really important" ( Pers. Comms., 2020). With attention to the history of the present in Aotearoa NZ, I interpret here that those who speak from the margins, recognise one another and find resonance in their struggles for legitimacy in the policy of a settler colonial state. 
In a similar vein, I observe that those who speak for the margins straddle two discourses for the purpose of rupture. Take for example these conversation excerpts with a pakeha lawyer engaged in supporting former refugees through RFR cases:

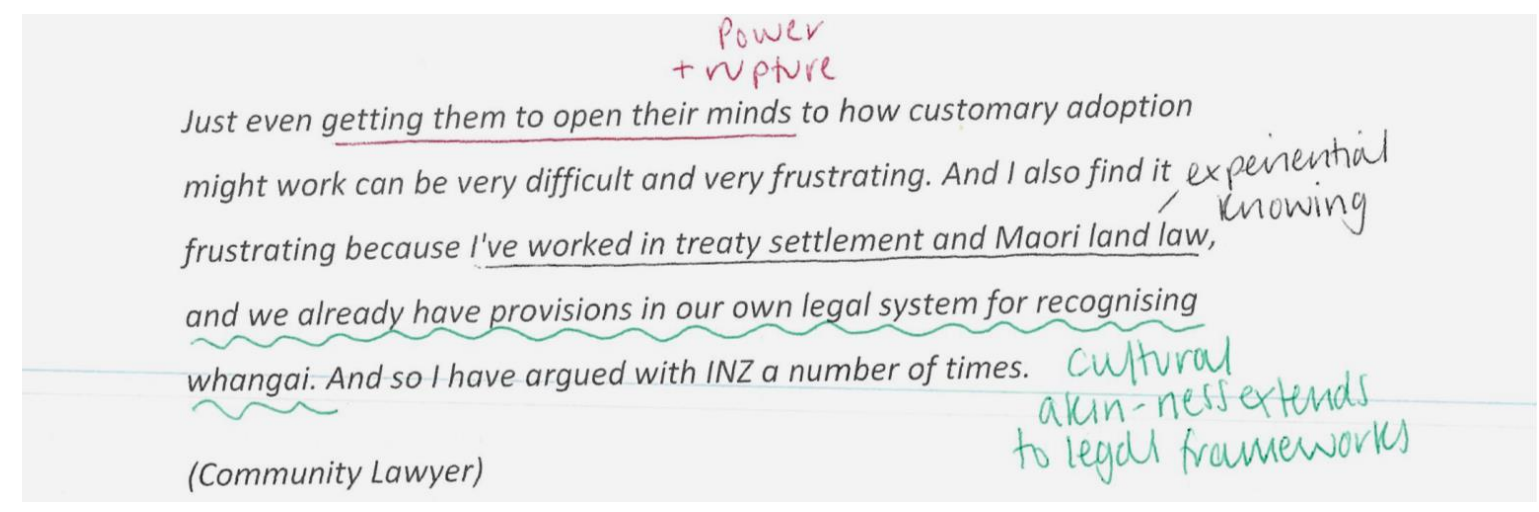

Completely. Yeah. And you know, because of working in Māori land law, I

know that whāngai can succeed to Mãori land provided the rest of the

whānau agree. So usually with Māori land, you can only succeed to it if

you're in a group that's called the preferred class of alienees and they need

to be related to the person who dies. And so you cannot leave your land to

anyone outside this preferred class of alienees. You can't leave it to a

pākeha. And so it usually has, the preferred class of alienees is if you've got

children, that's them. And if you don't, then it goes to your siblings. So you

know, so it stays within this family group. But you can leave it to whāngai.

And no one DNA tests the whanau to make sure that they're still within

that...

No. Of course not because...

But can you imagine if we did that? like...

It'd just be awful! ditterence

similarity

in

Yeah. But we're still. But we're doing it. To Former Refugees. by policy

(Community Lawyer) 
References to Te Ao Māori concepts were employed here to infer that broadening concepts of family within policy was aligned with New Zealand's culture. This participant maintained, through chosen examples and drawing on institutional knowledge, that multiple forms of kinship could be considered family within the legal frameworks from which dominant discourses emerge, and thus promoted discourse of 'family as culturally akin'.

In addition to drawing attention to cultural similarities of customary adoption processes this community lawyer made the point that family is culturally akin through an appeal to the same discursive structures of common-sense employed by government participants. By drawing on institutional knowledge of legal policy she subverts the dominant discourse this language usually upholds.

In stating comparison like this she highlights both the potential and the disparity of current policy processes to DNA test former refugees. Rather than using an example from a different continent to exemplify insurmountable other-ness of family (such as in the African example used to produce discourse of 'family as culturally bound(in)eligible'), this participant uses an example from the Aotearoa NZ context to highlight the ways in which our legal system holds space for diverse family forms, therefore producing the discourse of 'family as culturally akin' to promote ideas of policy potential/disparity.

While Foucault discusses the use of discursive structure in sustaining 'truth' as something which is only executed by those in power, this example somewhat contradicts the idea that discursive structures as "rule-bound sets of statements...impose limits on what gives meaning to concepts" (Waitt, 2016, p. 304). The 'family as culturally akin' discourse is one which ruptures dominant discourse (that family is culturally bound) produced by structures of power. This rupture is achieved by use of those same rule-bound statements that emerge from western rational thought (that broadening policy is possible because it has been achieved in the same legal framework elsewhere). Perhaps this contradiction is only possible because the participant at hand is speaking from a position of a Pākehā New Zealander embedded already in, and fluent in, the language of structures of power. That she speaks on behalf of those in the margins, but is fluent in the language of operational power, enables her to subvert mainstream discursive structures for the effect of rupture. The power/knowledge nexus is still at play but subverted somewhat for the 
purposes of allyship with those marginalised bodies and their troubling of norms. This contradiction of form undermines the social control found in discourse of 'family as culturally bound/(in)eligible' and its "truth effects" (Foucault, 1980) currently manifested in rigid policy definitions.

A second way in which this discourse of 'family as culturally akin' ruptures ideas of immovable definitions of family within policy as "truth" is in what Foucault terms "problematisation" (1994). The role of critical thought is to "disturb" or query "the naturalness, the taken for granted character of everyday life" revealing it to be the "contingent product" of historic power, law and process (Rabinow \& Rose, 2003, p. 13). Foucault, however, brings new analysis to critical thought in his recognition of that which lies in plain sight. In his conceptualisation of Problematisation, Foucault maintains that which remains on the surface is the most profound thought (Rabinow \& Rose, 2003, p. 14). When participants pay credence to the settler-colonial state history of Aotearoa NZ by recognising the ontology of whānau and the fought for legal frameworks which support this, I argue that problematisation has already formed. That references to Te Ao Māori reoccur "in plain sight" (through transcripts of lawyers, community volunteers, and former refugee experience, either via institutional or embedded knowledge), problematises dominant discourse of family as culturally bound/(in)eligible.

Problematisation is to Foucault "the ensemble of discursive and non- discursive practices that make something enter into the play of true and false and constitute it as an object of thought (whether in the form of moral reflection, scientific knowledge, political analysis, etc).'(Foucault in Rabinow \& Rose, 2003, pp. 12-13). In this instance, ideas and consequent discourses of 'family as...' are entering into play of true and false. Foucault maintains that to problematise something requires that something prior "must have happened to have made it uncertain, to have made it lose its familiarity, or to have provoked a certain number of difficulties around it" (Foucault, 1994, p. 389). As participants gave examples of similarities between family conceptions in Aotearoa NZ from Te Ao Māori, citing changes in legal recognition of this, they ruptured discourse of a "New Zealand context" (Immigration New Zealand, 2020, pers comms) as one which centres inherently Eurocentric hetero-nuclear family models. Thus, this discourse of 'family as culturally akin' begins to de familiarise Eurocentric ideas as part of new Zealand's 
cultural orientation and throw into question the dominant discourse of 'family as culturally bound/(in)eligible'.

Problematisation such as this achieves the Foucauldian difference of thought that "attempts to change the way in which a situation is apprehended...from seeing it as a given to seeing it as a question" (Rabinow \& Rose, 2003, p. 14). In this way problematisation is similar to the aims of queer theory in seeking not to answer or inform but to interrogate the production of norms by exposing that which lies in plain sight yet gets excluded often from discourse as a result of power, law and process. I therefore argue, when participants point to the impact of colonial power on the production of and "effects" of "truths" (Foucault, 1980) by pointing out that which lies in plain sight (Te Ao Māori familial structures) they are queer(y)ing discourse, problematising ideas of 'family as culturally bound'.

The relationship between discourse inherited from (and arguably upheld by) colonial power structures and the role of queer theory in illuminating the production of subject positions throughout histories of colonial oppression is longstanding. As already touched on in my review of the literature, Ilan Kapoor (2015) explores this in depth in his discussion of the 'Queer Third World'. By constructing, through the discourse of colonisation, the third world as "perverse, abnormal and passive... backward, effete, even effeminate.” (Kapoor, 2015, p. 1612) western power has justified intervention and the establishment of societal structures which bolster the neoliberal agenda, such as the nuclear family as an economic unit (explored further below).

In reconstructing non hetero-nuclear ideas of family as culturally akin this discourse is similar to Kapoor's queer third world in that it "destabilises domination and the power of the status quo" (2015, p. 1612). Kapoor discusses the similarities of 'queer' and 'third world' in much the same way that this discourse draws attention to the similarities between the Māori experience and that of former refugees when it comes to recognition within policy on family needs and norms:

"Both arise from a history of subjugation, attempting to resist and destabilise domination and the power of the status quo. Both operate from the margins, questioning normalising power mechanisms and social order, while upholding 
a deviant, non-conformist and non-assimilationist politics."(Kapoor, 2015, p. 1612)

In centring examples which queer(y) discursive structures used to promote the hetero-nuclear western family as a norm (and thus render anything else as deviant), the discourse of "family as culturally akin' works to resist the "enduring legacies" of "colonial queering" (Kapoor, 2015) lauded at both the 'third world' (from which the majority of refugees hail) and at indigenous Aotearoa NZ. In doing so, this discourse reminds us of what Jaques Lacan (1973) considers the "real" -the limit of any discursive system. For queer theorist Lee Edelmen, inspired by Lacan, this "real" is reached only by attention to the gaps and contradictions in heteronormative discourse and an embracing of that which antagonises social norms (Edelman, 2004). In a settler colonial state where norms have been imposed through Eurocentric imperial rule, decolonising ideas of the status quo is a form of queer(y)ing the history of the present. This queer(y)ing is achieved by a recognition of indigeneity, or Tikanga, as first law of the land, and in the case of supporting former refugee families who trouble the hetero-norm, as a path to justice.

It is, of course, pertinent to note that none of my participants identified as tangata whenua. The ideas of cultural resonance they present are those which are observable to an outsider's perspective. While participants (myself included), by default of their positionality as tauiwi, do not have authority to declare a stance on refugee background families from a Māori perspective, that they chose to identify resonances between cultures speaks to the perceptions and experiences of manaakitanga and kotahitanga impressed upon them from Te Ao Māori. Experiences which stand in contrast to those spoken of interactions with RFR processes and administrative bodies of government.

However, ideas of akin-ness between the Māori experience and that of former refugees presented by participants in this study is echoed in progressive literature from Māori scholars as a basis for social and structural change in immigration policies. As my participant who spoke from the margin of refugeehood and the rainbow community found resonance in the encompassing nature of whānau and te reo Māori more generally, so too do Māori scholars identify resonances in the struggle for ontological pluralism in Aotearoa NZ's immigration policy. Tahu Kukutai and Arama Rata note the "yawning hole" of indigenous peoples perspectives as a result of their exclusion 
from policy making and research related to immigration (Kukutai \& Rata, 2017, p. 27) and the significant backlash faced by Māori who challenge the state's approach to immigration ${ }^{3}$.

They continue, from a recognition of colonial relationships with immigration, to outline a treaty based model of manākitanga for immigration policy more generally. This model not only recognises Tikanga as first law of the land but would uphold the promise in the treaty of Waitangi of tino rangitiritanga in its creating space for the self determination of mana whenua through their ability to decide on immigration policy. Kukutai and Rata's model focuses on what a manifestation of manākitanga could look like in policy. They draw on examples of family reunification and increased quota numbers as a result of valuing whakapapa relationships, care, and respect as fundamentals of immigration systems.

The discourse of refugee policy given by Kukutai and Arama, as shaped by a Te Ao Māori perspective, focuses on holistic wellbeing, hospitality and the self determination of indigenous peoples. It draws on the akin-ness of journeying across oceans and the lived understanding of the need for "constitutional arrangements that better suit our diverse citizenry" (2017, p. 44). This discourse of adaptation together, is unsurprisingly wholly in contradiction to the barriers and exclusions of Eurocentric policy stipulations carried through from the episteme of colonialism in Aotearoa NZ.

Historians too have recognised the role of discourse in responding to, resisting and re-enforcing the colonial 'episteme' of Aotearoa New Zealand as it underpins migration policy. Ann

\footnotetext{
3 " As co-leader of the Maori Party, Tariana Turia faced significant backlash in 2007 when she advocated for the Treaty of Waitangi to be at the heart of immigration reform (http://www.scoop.co.nz/stories/PA0708/500302.htm). In 2011 Margaret Mutu was widely condemned in the mainstream media when she called for a restriction on the immigration of white migrants from countries with histories of white supremacy and racial oppression, notably South Africa (http://www.stuff.co.nz/auckland/local-news/5561230/Curb-white-immigrants-academic)" (Kukutai \& Rata, 2017)
} 
Beaglehole (2009) in her analysis of government discourse on refugee intake posits the following:

"the possible connection between the idealisation of the humanitarian record in relation to refugees and the colonial legacy, suggesting that the former might serve the purpose of assuaging liberal guilt over the real record of exploitation of Maori” (2009, p. 119).

She goes on to unpack the ways in which New Zealand offers comparatively little in UNHCR resettlement placements on the global stage. What the findings from my participants' shared knowledges reveal is that not only are discourses of Aotearoa NZ as a humanitarian leader in resettlement geo-politics undermined by figures and experiences of exclusion; they are also hypocritical in their attempts to assuage colonial guilt as those same policies being lauded in the public-political domain as humanitarian, are exclusionary as a result of underlying eurocentrism in how family is defined and rendered (in)eligible. Discourses of family as 'more than', and as 'culturally akin', not only rupture policy discourse of family as 'culturally bound/(in)eligible' but also wider geo-political discourses of Aotearoa NZ as a humanitarian role model in the refugee resettlement space.

\section{Conclusion}

Gordon Waitt notes in his writings on Foucauldian approaches, that dominant discourses, upheld via discursive structures, are not as fixed as they appear due to their being "embedded within different social networks" (2016, p. 306). This research sought to gain insight from representations of all aspects of the RFR Policy structure, from refugee background advocates, to service provisions (both independently funded, and state funded), to policy formation and implementation. While the participant base was small, the breadth of discourse was not. I have identified three discourses emerging from interview transcripts. Government participants represented the discourse of 'family as culturally bound' and the discursive structures that portray this as common-sense. However, in legal service provision, charitable support, and refugee background experience, participants identified contradictions within this discourse and 
its policy, appealing to a discourse of rupture. In many regards 'Family as culturally akin' is an extension of 'family as more than' in that it appeals to the reality of lived experience as a basis for compassionate and adequate policy stipulation. However, 'family as culturally akin' is also somewhat decolonial in nature, seeking recognition for authentic reference to New Zealand cultural understanding of family, not as a Eurocentric import but as its enduring indigenous ontology. In chapter eight I explore how the dominant discourse of 'family as culturally bound/ineligible' explored in this chapter, operates to discipline former refugees seeking RFR as an exertion of biopower. 


\section{Chapter Seven: Discussion 2}

\section{Limits of Agency and Discourse}

FDA discussion in this chapter considers the relationship between discourse and governmentality, noticing language which dismisses or limits, and the agency of those who adopt and invert this same language (leveraged most often against them) for purposes of strategy and survival. It is hoped that through these observations I can further elucidate how social frameworks of RFR policy exacerbate disparities in the resettlement experience. Finally, I speculate on the unspoken, hesitations, pauses and movement in interviewees' speech to attend to the discourse of silence recognised by Foucault, and the grappling for language that takes place when articulating the unfamiliar, or envisioning the "not yet" (Petersen \& Henning, 2018, p. 1) of social justice.

\section{Governmentality, biopower, and its Subversions in Relation to RFR Policy Discussion}

Having identified dominant and counter discourses on the family, through the application of FDA, it has become clear that a discourse's position as either dominant or counter is contingent on historically-situated power. However, Foucault's interest in power/knowledge and the role of discourse therein extends beyond the observational. Foucault theorised that power and its discourses becomes a technology through which governance takes place. Coining the term "governmentality", Foucault referred to "the conduct of conduct" - that which encompasses the mechanisms of not just governing others but "governing the self" (Foucault (1979) in Lemke, 2002, p. 51). Discourses produced by those in power, Foucault argued, can be disseminated to the effect of ensuring certain cultural norms by which the individual will adhere to for the purposes of inclusion and acceptance within the collective. He considered this a form of "governmentality" whereby the political state plays an indirect hand in disciplining the personal (Foucault, 2008). 
The disciplining of the personal (or in the case of RFR specifically, 'the family') is also a facet of what Foucault termed 'biopower'. Rabinow and Rose summarise this concept as the following:

"Biopower names and groups together these concerns with the management of the phenomena that characterize groups of living human beings. It relates the exercise of this form of power to varying conceptions of the nature of human individuals and collectivities, their apparently biological variability - race, fertility, gender, constitution - and the ways in which these characteristics can be shaped, managed and selected in order to achieve political objectives" (Rabinow \& Rose, 2003, p. 5)

The relationship between governmentality and dominant discourses of 'family as culturally bound/culturally (in)eligible' is a form of biopower. Much like Bentham's panopticon (a prison designed around a central watchtower so that inmates do not know if or when they are being watched), the principal idea here is self-surveillance. While resettlement and cultural integration are not parallel to Bentham's prison analogy, the idea that nonadherence to state-promoted norms entails consequences (rejected applications, social exclusion, perceived deviance) leads refugee families to engage in a form of self-surveillance, adopting the subject position which policy dictates. In the case of RFR, self-surveillance manifests in numerous ways, notably in former refugees' acceptance of the classification of certain family members over others as "immediate" and therefore eligible, regardless of actual arrangements of 'closeness' across kinship relations (because any family is better than none). It may also look like an adult child abstaining from bringing a partner to join via quota family reunification to ensure a parent, on whom they depend, may join them in resettlement. Participants who spoke of casework with former refugees shared examples of the impacts of governmentality on refugee background families hopeful to engage successfully in RFR. These have been explored in chapters four and five and will be drawn from later in this analysis.

Governmentality in the realm of RFR involves social surveillance via normalisation of certain family forms (and consequently positioning others as marginal or deviant). I have already shown current discourses render compositions of families as culturally bound, and the Eurocentric valorisation of genetic connection takes precedence over other culturally-contingent factors of 
kinship relations (and forming the basis for processes such as DNA testing). Language such as "immediate family" within policy here works as leverage for control and power. However, the language of participant responses in interviews also revealed the distribution of power.

Highlighting these power relations in the spirit of Foucault and queer theory, I argue is in itself a form of rupture. It lays bare the means by which social policy frameworks provide a foundation for inequalities and social exclusion.

In this chapter I explore both the manifestation of governmentality through RFR policy and the ways in which former refugees and their allies in service provision seek to resist it. Recognising that dominant discourse and policy stipulations create a subject position of the eligible family as hetero-nuclear, I explore how applicants to RFR perform this in order to be granted approval as a sponsor for loved ones. Next, I consider the ways in which former refugees, as marginalised people, can adopt various discourses in order to obtain RFR, even when those discourses contradict their beliefs about family. I finish with a speculation on my participants' struggle to articulate the needs of rainbow community former refugees and the limitations of current discourse in challenging the heteronormative status-quo and its inherent harm of LGBTQIA+ people seeking RFR.

Throughout participant interviews, Immigration New Zealand were referred to in such a way that rendered discussion of advocacy, or explanation of the refugee family as 'more than' futile: 


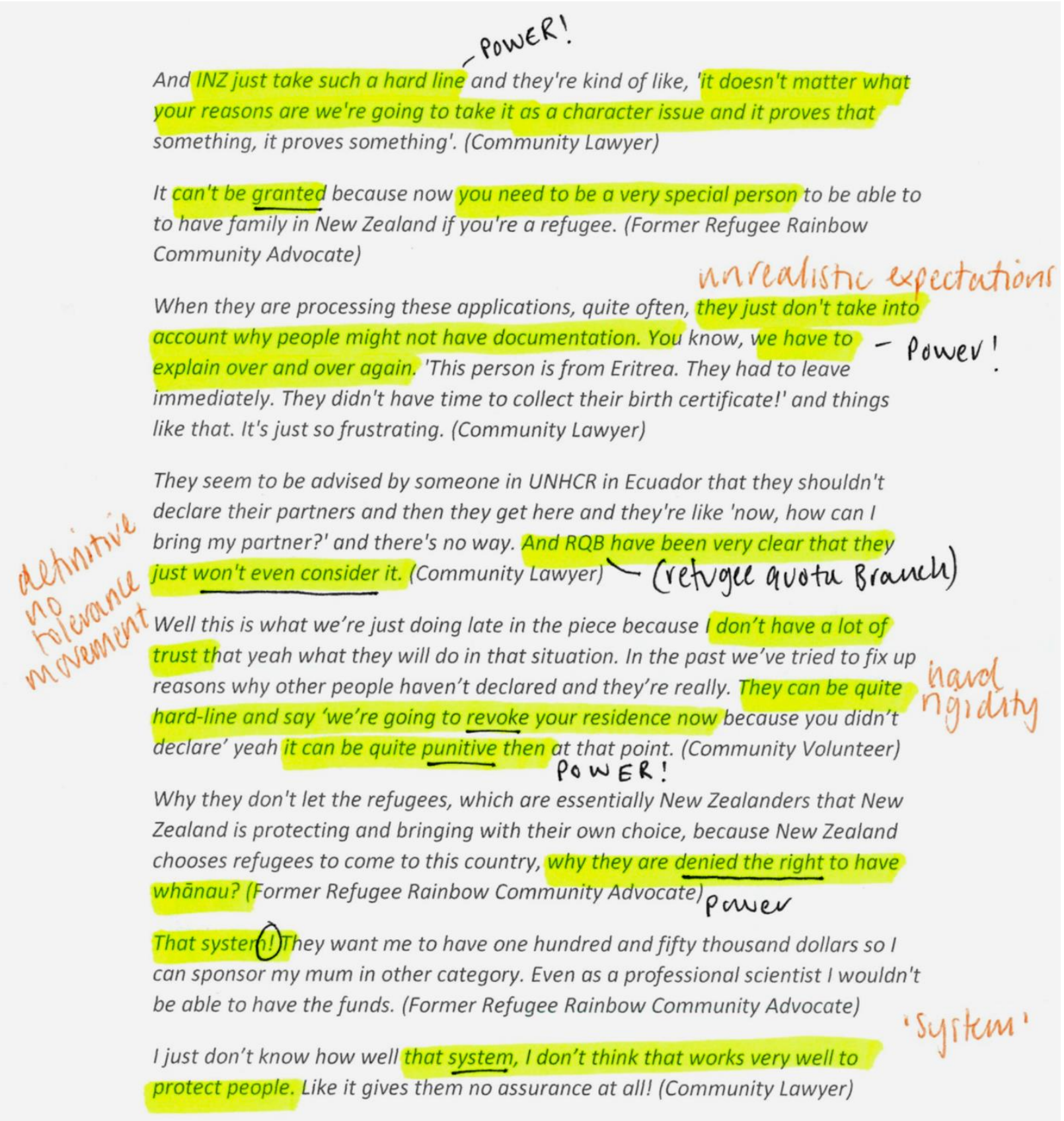

The finality of Immigration New Zealand's decision-making power over was noted. Such power was exercised through policy stipulation and individual case appeals. The rejection of opportunities to be reflexive in approaches to conduct was empirical in highlighting power relations in the structure of RFR and its associated discourses. I argue that the combined impact of resilient Eurocentric discourse that family is culturally bound or ineligible, and the enforcement of policy via bureaucratic mechanisms that stems from this power is an extension of 
the structural violence already discussed. It works to encourage the self-disciplining of former refugee families who then strive to adhere to Eurocentric hetero-western norms and narratives of 'the family'.

Contributions of critical kinship and gender studies expand upon Foucault's conceptualisation that the discipline of the family is critically important to the socio-economic political goals of the state. Foucault theorises that the western nuclear family unit operates as a 'cell' of individuals which forms part of the disciplinary apparatus of the state. Presentations of kinship and family are promoted as norms, in this instance through ideas of acceptable relational roles of labour or reproduction, to achieve the wider (neoliberal) goals of the state. Given the discourses and findings of this research it is not unreasonable to suggest that RFR policy seeks to maintain this status quo under the guise of "New Zealand definitions" (Refugee Quota Branch Manager, pers comms, 2020).

'The family', as defined in hetero-nuclear terms, here becomes the apparatus of state power (Foucault, 2006b), one which arguably serves a neo-colonial capitalist economic agenda. Problematising the western nuclear definition of family (through discourses of rupture) encourages consideration of the deployment of state power, offering critical perspective of the role of policy in its inadvertent maintenance of this status quo.

Understanding that power-produced-discourses instigate self-surveillance of former refugee families for the benefit of economic and political will, it is important then to pay attention to their impacts and subversions. What emerged from participant interviews was not a relinquishing of self and desire to powerful discourses of refutation, but rather a response to use this creation of a subject position in order to achieve the long-term goals of family reunification. This took two forms, first as a performance of a particular understanding of the subject position (however inaccurate it may be) for the purposes of rendering oneself and one's family 'eligible' under policy stipulations. The second as employing the discourses which seek to undermine one's subject position in order to exercise agency, understood in the literature as "strategic essentialism". I look at each of these in turn. 


\section{Resistance as Performer: Utilising Constructed Subject Positions for RFR Goals}

What has been demonstrated through both my thematic and discursive analysis are the ways in which institutional processes of RFR legitimate or don't legitimate ways of being and knowing (such as customary adoption versus legal adoption, or genetic relatives versus cultural kinship relations). This de/legitimisation is largely achieved through the production of a particular subject position (i.e. eligible immediate family). Participants I interviewed who were involved in RFR case support, be it as volunteers or to provide legal services, shared examples of where this position had to be performed in a way which was recognisable to Immigration New Zealand (INZ) in order to be considered for RFR. I present here two examples, each highlighting a different aspect of this performance of this subject position for the purposes of successful applications for RFR.

The first example highlights governmentality manifest and takes the form of a community volunteer reflecting on a case she supported:

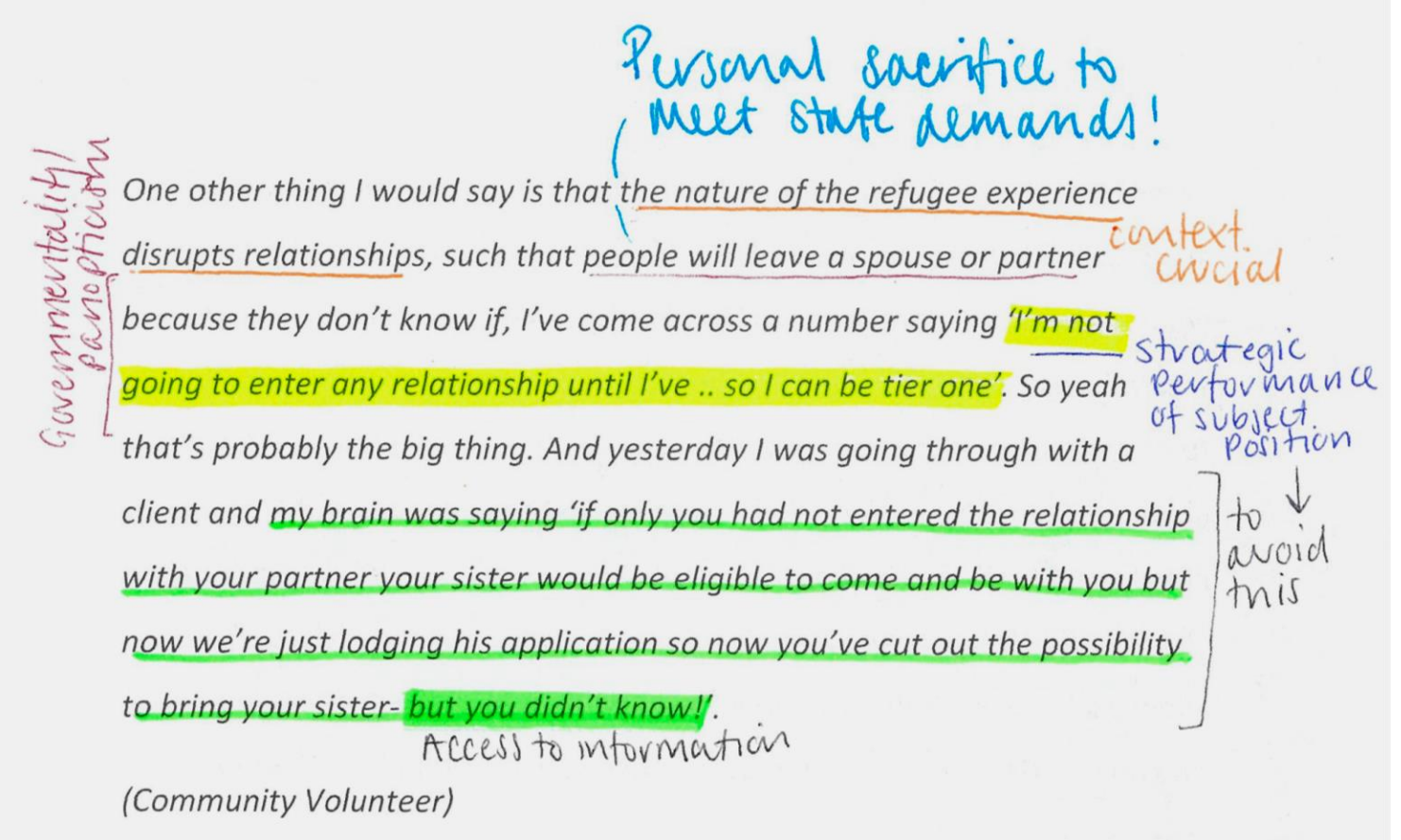

The self-disciplining of former refugees to restrain from fundamental aspects of life in resettlement (partnerships and relationships) in order to remain eligible for family reunification 
in the eyes of the state is, I argue, governmentality in action. State stipulations for RFR drive many former refugees to sacrifice engaging in certain kinship relations, this manifestation of biopower undermines the purposes of RFR in supporting wellbeing in resettlement as it impacts upon the emotional wellbeing and familial support structures of former refugees. However, for some, the approach employed by former refugees to navigate disclosure for their own ends is a reclamation of agency within a system of structural violence.

This second example works to highlight the tenacity of former refugees engaging with a policy scheme that seeks to limit and discipline their true or "real" (Edelman, 2004; Lacan, 1973) subject position:

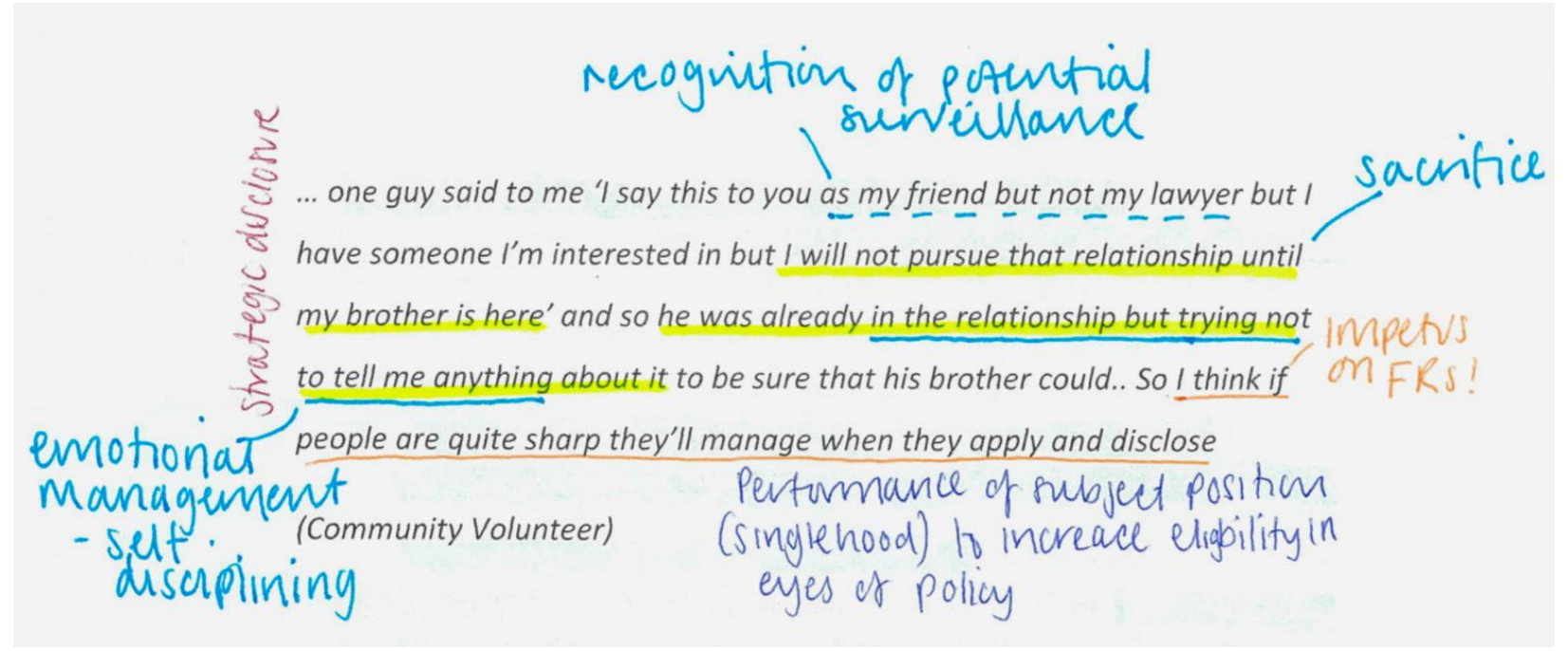

The use of strategy in when to disclose relationships here, through the performance of singlehood, represents a counter approach to adherence. Where this person's adherence to policy stipulations meant either loss of relationship or rejection of reunification with their brother, their strategic disclosure to the community volunteer instead offered the opportunity to mitigate both these eventualities. To work with the INZ system in such a way as this former refugee did is a form of gainful protest, where overt protest in and of itself would not yield any results. The adoption of policy stipulations, and performance of appropriate subject position, is a form of resisting the governmentality inherent within them and in doing so exercising agency. 


\section{Resistance as Polyglot: Finding Agency Through Multiple Contradictory Discourses and Strategic Essentialism.}

While performing the role of eligible family as constructed through discourse enables some former refugees and their advocates to find agency in advantageously navigating policy stipulations, one former refugee participant found agency in traversing multiple discourses for the purpose of personal and political ends. I referred in interview notes to this former refugee's ability to adopt multiple discourses much like a polyglot can adopt multiple languages. In the process of discussing RFR with a participant engaged in the application process, I observed the strategic adoption of an essentialist discourse of eligible refugee family (that is one which centres on genetic connection and immediate-ness of relationship as it pertains to the nuclear model) for the purposes of seeking reunification approval.

Gayatri Chakravorty Spivak, a post-colonial feminist philosopher, examined the strategic adoption of essentialist discourses by those these same discourses misrepresented; 'the subaltern'. Recognising this process as a technique to achieve political and personal ends, she coined the term “strategic essentialism”. In posing the question 'can the subaltern speak?' Spivak was critical of western research into colonial subjects and its 'logocentric assumptions', which produce inherently restricted writing, built on the study of only one part of the total experience (Bhagwat \& Arekar, 2018; Spivak, 1988). This criticism posited that within western structures, the experience and agency of the subaltern cannot be recognised by those outside of it. However, by identifying the use of strategic essentialism by subaltern subjects Spivak exposed their agency within these same structures. In doing so she articulated the phenomenon by which a "strategy of representation" takes place through the process of "adopting an essentialist position with respect to identity categories, or as Spivak calls them, "masterwords" (such as woman, worker, nation, or the subaltern), in order to mobilize a collective consciousness for achieving a set of chosen political ends" (Pande, 2017, p. 1; Spivak, 1993). Strategic essentialism, to Spivak, was a means by which the subaltern could be heard. 


\section{To exemplify this use of multiple discourses for strategic effect, I include here a lengthy excerpt}

\section{with annotations:}

I think it's very important that we allow a refugee to to connect with the

family that they got, that they call family. That this is a very important family as issue for me. One of the only, maybe, persons that I have a good

connection from my life and from my actual family you know my actual

family is my mum. But, you know, in all this journey to being here in New

Zealand. And I met someone... And he's my partner, OK? And I marry him. And it's a family I choose. It's not a family that is my family by blood.

And the policy that the the the system in New Zealand is, it creates a

differentiation in which someone that is not actually my actual like family

of blood. It's replaced my actual family that I believe I have a right to have,

you know. And the policy says that I'm eligible, or a former refugee quota refugee, they have the right to bring someone from the immediate family, like including brothers or a mother. ... Because I can't live in Colombia. Colombia is not a country which is viable for me in any single way.

Especially because my condition is, my condition as a trans person, as an intersex person, is something that is constantly challenged. ...So it is very, very difficult for me to imagine that I would never be able to, to be with my Farmily as biological mum again, $O K$, because she's living in Colombia and I can't travel back to Colombia. I would love to, but I don't have a passport from that country.

Kinship thes have deepeved through ...And she doesn't even know me. My mum doesn't even know who l am. Procets of She doesn't know how I look like now. I mean, we've been having some retcthemenł conversations over the phone. But, you know, it's very sad just to imagine that I would never be able to, or actually SHE would never be able to, to know me, to meet me for the person I am now, because at the time I left my country, I was presenting myself in a masculine version of myself. And this is the last time I saw my mum. And she's been with me the whole

journey. And she does love me for every way I am, OK? She's really identity listened. And it took her a long time to understand, you know? Yeah, but love me for the way am I.

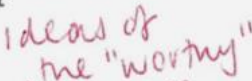

And I've been trying now to apply for. Find ways to make my mum. You $\downarrow$ refugel
know, to live with my mum now. Especially now with the successful life I'm (s-patcl et ul, 20i7) starting to have as a scientist. You know, I want to help. I want to help my family be with me. I want to enjoy, you know, I'm working on, in a company that is so supportive of me. I would be so happy to have my mum and and to share, you know, my life with her, to be able to live with her and to spend time with her. But I can't because the policy only allows one present to be with me and the person that I actually met, it's not my family. It's not a family member that is as a family in the sense of someone that shares my blood with my bloodline. - appeals to family as (Former Refugee and Rainbow Community Advocate)

$$
\text { 'cuiturally bound' Aia }
$$

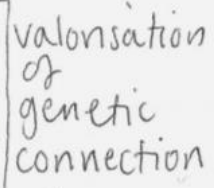


Earlier discussions with this participant had centred on the 'family as culturally akin' discourse, particularly in the context of discussing recognition of kinship relations for their rainbow community peers (see chapter six). However, when we came to discuss this participant's specific case, they employed the ideas embedded within dominant western essentialist discourse of family as biological in order to highlight the injustice of not being able to sponsor their mother to join them. Similarly they employed identity markers of the 'eligible refugee' in the eyes of their host society; one who contributes to economic growth and expresses gratitude at the opportunity given to them (Moulin, 2012; Schwöbel-Patel \& Ozkaramanli, 2017).

I highlight in this excerpt both the discourse of family as kinship choice ('more than') and the discourse of family as valorised by shared genetics. Both were employed here for the purposes of explaining how RFR policy excludes and obstructs reunification for many former refugee applicants including the participant speaking. What emerged from this example is the means by which discourses of rupture go hand in hand with the strategic employment of dominant discourses for the purposes of overall gain.

Spivak noted that the adoption of a subject position created through dominant discourse is "strategic" due to its self-consciousness. It recognises the "constitutive paradox," (Spivak, 1996, p. 214) of employing essentialist discourses for the purposes of political/personal purchase. In this case, the participant's referrel to their mother as "my blood" invoked the sense of rights and obligations that have been attributed to genetically-defined family through dominant heterowestern discourse of the nuclear family. This worked to frame their RFR application in the discursive structures of rationalisation and logic that have been deployed to establish discourses of 'family as culturally bound/(in)eligible'. The result was that strategic essentialism was embodied by the participants leveraging of discourse embedded within RFR policy for the purposes of achieving reunification, which had simultaneously been deemed ineligible under that same policy.

This participant's use of strategic essentialism was a subversion of governmentality worth noting. I argue that it is so effective because former refugees understand dominant and marginalised discourses of settler-colonial Aotearoa-New Zealand as well as understanding their own positionality as having refugee status and the value of their cultural lens on examining the 
different discourses at play. Homi Bhabha (Bhabha, 2012, p. 292) termed this positionality of being "in-between" as "hybrid space". Hybrid space recognises the knowledges and selfawareness of those engaging in strategic essentialism as a product of constructivist discourses which establish their available subject positions as either colonial or marginalised. As a former refugee resettled in Aotearoa NZ, this participant was able to recognise the marginalisation of indigenous conceptualisations of family (hence their contributions to 'family as culturally akin' discourse), the marginalisation of themselves as a body which troubles norms (hence their expression of 'family as more than' discourse), and the resilience of colonial discourses which dominate immigration policy (hence their adoption of 'family as culturally bound' discursive structures of justified biological kinship). The ability to bridge those discourses, and find agency to deploy all three, is a result of their existence in hybrid space, or as Spivak called it a "negotiated postcolonial positionality" (Spivak (1990) in Pande, 2017, p. 2).

Acknowledging the tensions in using multiple and seemingly contradictory discourses is an acknowledgment of the agency of former refugees. This excerpt from participant interviews represents the agency of those in the margins who recognise discourse as a "transactional" tool whereby stable, dominant essentialist ideas (of family and refugee identity) are accepted in exchange for political mobilisation or personal/communal interest (Spivak, 1988). In this instance the "scrupulously visible "political interest" (Spivak, 1996, p. 205) of this participant's use of strategic essentialism is reunification with their mother in addition to having been reunited with their partner.

It is, however, also important to note here that these discourses are being deployed to exercise agency in resistance to a structure of double bind. This participant, like most former refugees, as well as prior reunification claimants, engaging in RFR, was forced to choose with whom they may be reunited (see chapters four and five). In this case, they had already undergone quota RFR processes to be with their partner in Aotearoa NZ. Under current policy and with T2 closed, they were then not eligible to bring anyone else to live with them. Thus, even for former refugees who successfully leverage strategic essentialism for the purposes of RFR, they are positioned as both omnipotent (they can choose to save another) and impotent (they have to adhere to particular rules and can't save everyone) (Kindon, Pers.Comms., 2020). The use of strategic essentialism, 
while an exercise of agency, is always simultaneously bounded by the limits of policy and forced choice therein.

Structural violence is also at work through the positioning of the most socially excluded, former refugees, as the ones who have to choose - who have to be strategic. The leveraging of this hybrid space and adoption of the master (dominant) discourse to exercise agency is affective yet confined still to the scope of policy stipulations. In this sense, this participant is moving beyond binaries of colonial/dominant or marginalised subject to something ambivalent in between.

In choosing to 'do' Foucault inspired discourse analysis I was explicit in my desire to pay attention to power relations, and discursive contradictions. Spivak's theory of strategic essentialism enabled me to highlight the power not just of dominant discourse, but of those marginalised by it. In employing discourses of power, former refugees are exercising agency in achieving RFR goals and consequently shifting power relations between themselves and that which renders them marginal (the state via policy). However, this returns me to Spivak's question of whether the subaltern can speak. While agency is present in the use of strategic essentialism, I argue it is bounded by both immovable policy stipulations and thier requirement that former refugees to adopt the master discourse (family as culturally bound, or genetically defined) in order to be heard. Spivak highlights the flaws in western, poststructuralist or postcolonial critiques (and more generally, western research) in its either granting "very expressive subjectivity" to the subject position of the oppressed, or in arguing for a "total unrepresentability of the marginalized subject" (Spivak, 1996, p. 219). I share here discursive analysis of that which comes from a hybrid space (a position of refugeehood, of community advocacy, and personal need) in the hopes of mitigating this 'either/or' of western scholarship, which Spivak critiques, by recognising the agency of those who advocate for themselves from the margins, and who subvert the governmentality inherent in RFR policy. The ambivalence as to whether this agency is fully realised- subalternity fully heard, is indicative of the pervasiveness of governmentality and the structural violence of power and process (policy) which upholds it.

In considering the voice of the subaltern, within a structurally violent system of RFR, I argue the contradictions are illuminating. While former refugees can speak using the dominant or master discourse in attempts to achieve RFR, these actions come at a cost. They cannot be heard from 
their own position (family as more than, family as culturally akin) and have that received as authentic. Additionally, they are forced to choose between family members. The state effectively displaces responsibility for determining the value of others' lives onto the former refugee. This responsibility comes with many costs: financial costs of applications; emotional costs of weighing up love with duty, need and chance of success; and cultural costs around understanding of being a good mother, daughter, sister etc. Such responsibilities are individualised further reinforcing the neoliberal/neo colonial agenda. "Hegemony is reasserted through the body (and heart) of the former refugee" (Kindon, Pers. Comms., 2020).

\section{Speculation on Silence: Hesitations, Margins and the 'Not Yet' of Justice for Rainbow Community Former Refugees.}

I have thus far focused largely on those discourses that could be articulated, what they infer and who they impact through their material effects. In doing so I have reviewed the constructivist nature of dominant discourses as a means to understand the history of the present in Aotearoa NZ as it relates to refugee family reunification policy. However, this history of the present is as much understood by what remains silent or unfinished. Foucault drew attention to the notion of privileged discourse; that is how discourses which are most dominant also operate to silence different understandings or experiences of the world (Waitt, 2016, p. 308). This relationship between privileged discourse and silence has already been considered in relation to the two discourses which counter the 'family as culturally bound/(in)eligible' discourse shaping policy above ideas of 'family as more than' or 'culturally akin'. However, even within these counter discourses, there are further silences to be attended to. By attending to these silences I am able to explore what is still 'normal' within these counter discourses and embody the aims of queer theory by centring what is marginal and/or silent even within that which ruptures.

For instance all three of these discourses still encapsulate heteronormative/heterosexual kinship relationships (be they genetic or not, or "immediate" in the eyes of policy or not). In doing so, even though they may not be dominant, these discourses remain privileged over other potential 
discourses that would explicitly and exclusively focus on rainbow families, or as yet are impossible to imagine or utter.

It was also notable in conversations with participants who were cis gendered or heterosexual for example that when these conversations turned to discussions of LGBTQIA+ exclusions, they became hesitant and their sentences often went unfinished. Largely responses were met with statements of "I don't know" and "that's a good question". Communication also became nonverbal in expressions of support for raising the topic with eager nods and murmurs of "yes, yes, totally" yet when I asked participants to elaborate and tell me why this was such a crucial lens through which to look at reunification processes, they had few or no words; transcripts become littered with ellipses and run on sentences.

I interpret their hesitations and silences as reaching for the as yet ineffable, reflective of the "not yet" discourse referred to by Burford, (2010) and Weems (2001, p. 7) as it pertains to social justice for the refugee background rainbow community. I posit that participants' inability or hesitation to articulate these issues revealed the margins of our current societal understanding within the margins of language. The struggle of the most marginalised requires language beyond pre-existing discourses be they resilient or recent, rupturing or governing.

A queer analysis also recognises these silences as evidence of biopower, that is, the governing of acceptable presentations of family through policy stipulations and the preferences of neocolonial heteropatriarchal sexuality within that. An inability to articulate the specifics of rainbow community exclusion, even within recognition of its importance to policy reform, not only points to the exclusion itself but to the fact that 'there is nothing outside the text' (Derrida, 1997) colonial systems of biopower have embedded within these discourses a predisposition to the heteronorm. Further, the valorisation of genetic connectedness in conceptions and definitions of family (listed as 'immediate' in the eyes of policy and proven with the processes of DNA testing) in RFR policy is reflective of the biopolitics of state governmentality in New Zealand. As critical kinship challenges the emphasis on biological definitions of family, queer theory challenges the power structures which uphold and benefit from such. 
Patrick Dilley recognises and documents the role of queer theory and queer researchers in bringing forward queer discourses thus far. In its attentiveness to the margins, queer theory acts as a visionary for this 'not yet' to which I have alluded; as Dilley articulates, the role of queer theory across disciplines and in qualitative research is still "under construction" (Dilley, 1999, p. 1). The pauses and hesitations within my participants' utterances are to me a collective breath; a moment of recognition before the construction of new discourses. They are a signifier that LGBTQIA+ former refugee's experiences are currently beyond many mainstream service provider/policy maker/researcher comprehensions, and yet need to be woven into the construction of future discourses of social justice and resettlement. It is 'the moment before' the reflexivity of "pausing, moving" as Foucault did in his later works (Rabinow \& Rose, 2003, p.

16) for the purposes of rendering visible that which has been silenced and excluded within RFR processes.

These silences highlight to me as a researcher, beyond any information given or knowledge shared, the necessity of further research which queer(ies) refugee family reunification policy in Aotearoa NZ with the explicit intent of improving it for members of the rainbow community. It is also worth noting that if these most marginalised people are catered for, other issues raised earlier by non-queer participants are also likely to be addressed (through changes such as expanding definitions of family and doing away with DNA testing processes therein). In this way, approaches to RFR through a framework of marginality benefits all; in that what is good for the margins is good for the centre.

\section{Conclusion}

In this chapter I have built upon my identification of three counter discourses that emerged in relation to family and its definitions within RFR Policy. I have also explored the relationship between these discourses and power afforded to those who employ them as means to govern (control), or resist. I have acknowledged the structural violence inherent in policy founded on discourses of family as narrowly defined, as hetero-normative, as 'culturally bound' to western, 
colonial histories of the present. I have also acknowledged the agency found in the strategic leveraging of these counter discourses by my participants for the purposes of reunification gains.

In discussing discourses of rupture, namely that which recognise Te Ao Māori as a basis for RFR Policy critique, it becomes clear that decolonisation of government policy extends to RFR and that those which trouble western norms, immigrant or indigenous, in their conception of family are still rendered culturally (in)eligible in policy and governance discourse. In embedding my discussion in Foucault inspired discursive analysis I have been able to explicate how the production of a particular subject position, via discursive structures, can render former refugee families ineligible, or excluded from RFR processes. So too have I been able to push beyond counter discourses, applying the lens of queer theory to speculate on the hesitations and silences in participant responses and their presence as a call to action for further research which centres the former refugee rainbow community.

The question then looking forward is how to produce a realistic subject position for former refugees seeking family reunification in Aotearoa NZ; how to centre those knowledges which are represented in the counter discourses of rupture when engaging in policy reform. Queer theory is an interpretive way of bringing to bear ways of being and knowing and working with them in a politico-ethical way to disrupt ideas of norms embedded within society and its functions (policy). I therefore argue, the work I've undertaken in this thesis to highlight both dominant and counter discourses, as well as the limits of the latter, begins a necessary process of queer(y)ing the foundational conceptions of refugee families within RFR policy in Aotearoa NZ. There is much more to be done. 


\section{Chapter Eight: Conclusion and Recommendations for Policy Reform}

The impetus to engage in research about refugee family reunification in Aotearoa New Zealand came in part from a resonance with post-development theory and its criticisms of development studies in neglecting to focus on issues of social justice in so called 'developed' countries. Heeding this, I considered Aotearoa NZ a site for development research given its systemic inequities, colonial history and commitments to global development goals. I began this thesis by locating refugee resettlement within development scholarship. I did so through a comprehensive review of both rights-based development approaches and theories of marginality and exclusion. Recognising literature on the bodies which are frequently excluded from initiatives and research around these goals, I have furthered the case for queer theory in development and its application to the study of refugee resettlement more generally.

This thesis has considered refugee family reunification policy in Aotearoa NZ from the perspective of marginality. I have paid attention to the influence of Eurocentric heteronormativity on conceptions of (the nuclear) family within policy, and the consequent exclusions of those who trouble these norms from successfully reuniting with their families. Through one on one interviews with six participants from different aspects of the RFR process, this research has documented the myriad barriers and exclusions within RFR policy.

Adopting a queer stance, I asked the following questions:

- What are the common/key barriers to refugees successfully engaging in family reunification processes (from app to settlement)?

- In what ways is NZ's family reunification policy and its associated processes exclusionary to those who 'trouble' hetero/western norms?

- What are the subsequent priorities for policy reform?

Discursive analysis and discussion informed by a queer theory has asserted that many of these barriers and exclusions hinge upon power relations between former refugees and the state, and the manifestation of structural violence therein. So too has Foucauldian discourse analysis (FDA) revealed the dominant discourse of the Eurocentric western heteropatriarchal nuclear family as 
normative. In engaging with FDA I have also highlighted the counter discourses of 'family as more than' and 'family as culturally akin', these discourses have been centred in discussions which seek to challenge dominant norms and in doing so address the exclusion of queer subjects from RFR.

The questions I began with were operational however my use of FDA and the queer orientation of this research produced more questions about strategy, power and knowledge. Through my exploration of discourses on 'the family' as they pertained to RFR, I unpacked the role of power in promoting certain discourses or norms and asked in what ways former refugees who trouble hetero-western norms (the subaltern) are able to employ voice and agency to counter the dominant discourses which marginalise them. As this thesis moved from deductive to inductive what became apparent is the foundational role discourse plays in establishing norms, and the consequent impacts for policy.

By way of conclusion, I here summarise my key thematic findings in relation to my original operational questions around barriers and exclusions, and the subsequent discussion that arose from FDA in this thesis. I then share policy recommendations that emerged from participant interviews by way of looking ahead to policy reform. I share these recommendations from participants as a working through of my orientation to collaborative inquiry. I consider that bringing participants' voices directly into my conclusion is a way to further queer the usual soleauthor authority of a conclusions chapter. Following these participant recommendations, I acknowledge the limitations of this work and point to further research. Last, I share some thoughts on the academic form and my pursuit of the authentic dissertation, and finish with some final reflections. 


\section{Barriers}

I have summarised the barriers documented through participant interviews in Figure 8.1 below:

\begin{tabular}{|c|c|c|}
\hline Policy & Process & Impact \\
\hline $\begin{array}{l}\text { Non-declaration in offshore } \\
\text { interviews }\end{array}$ & & $\begin{array}{l}\text { Later applications for RFR dismissed, actions } \\
\text { considered fraudulent }\end{array}$ \\
\hline T2 Closure & & Families separated indefinitely. \\
\hline \multirow[t]{5}{*}{ Eligibility to sponsor under T2 } & & $\begin{array}{l}\text { Cannot apply for reunification of non 'immediate' } \\
\text { family members (anyone other than parent, sibling, } \\
\text { or adult child) regardless of circumstance. If } \\
\text { applicant has multiple siblings, they must choose } \\
\text { only one. }\end{array}$ \\
\hline & $\begin{array}{l}\text { Time delays in processing } \\
\text { applications impacting on } \\
\text { eligibility (up to three years). }\end{array}$ & $\begin{array}{l}\text { If a dependent child gets married or pregnant or } \\
\text { ages over } \underline{\underline{25}} \text { they are no longer classed as } \\
\text { dependent and therefore are now ineligible. }\end{array}$ \\
\hline & $\begin{array}{l}\text { Bureaucratic demands for } \\
\text { documentation and evidence }\end{array}$ & $\begin{array}{l}\text { Lacking documentation (even if inaccessible to gain } \\
\text { from the country of flee) means applications are } \\
\text { rejected. }\end{array}$ \\
\hline & $\begin{array}{l}\text { Lack of legal aid in Aotearoa } \\
\text { NZ }\end{array}$ & $\begin{array}{l}\text { Without support, applications do not meet } \\
\text { requirements and get rejected. }\end{array}$ \\
\hline & $\begin{array}{l}\text { Expectations of sponsor: } \\
\text { housing and financial savings }\end{array}$ & $\begin{array}{l}\text { Requirements of sponsor to show they have } \\
\text { obtained (in some instances) housing leases and to } \\
\text { have over } \$ 15,000 \text { in savings. }\end{array}$ \\
\hline
\end{tabular}

Figure 8.1 Barriers to RFR

Barriers ranged from not enough place numbers to meet demand and a lack of accessible legal support to extensive and impracticable financial and bureaucratic demands of former refugee applicants such as housing, savings and evidence provision. Further, when my participants spoke of barriers in policy and barriers in process to refugees successfully engaging in RFR, they did so from the mutual understanding that these are situated within a context of immense resilience on behalf of former refugees. The fact that the specifics covered here stand alone as evident and embedded barriers to successfully engaging in family reunification, and as barriers that promulgate issues of "access to justice" is worth consideration (Community Lawyer, pers. 
Comms., 2020). Add to this the foundational circumstance of those seeking refuge in Aotearoa $\mathrm{NZ}$, and the myriad experiences of inequality and trauma therein, and a reunification process riddled with issues of access, understanding, and expectations beyond possibility for many becomes more than a cause for review, but rather a "cause of deep suffering" (Keeble, 2017, p. 2). In this sense barriers identified were not only mechanisms of further marginalisation (e.g. requiring legal and financial means which former refugees did not have access to), but mechanisms of structural violence (leaving former refugees traumatised through guilt over loved ones left behind, rejected applications and punitive responses to non-declaration).

\section{Exclusions}

I have summarised the exclusions documented throughout participant interviews in Figure 8.2: 


\begin{tabular}{|c|c|c|c|}
\hline Policy & Process & LGBTQIA+Specific & Impact \\
\hline $\begin{array}{l}\text { Forced choice on which } \\
\text { family members to bring } \\
\text { vis RFSC pathway }\end{array}$ & & & $\begin{array}{l}\text { Connot opply for reunificotion of non } \\
\text { 'immediate' fomily members (anyone } \\
\text { other than parent, sibling, or adult } \\
\text { child) regardless of circumstance. If } \\
\text { applicant has multiple siblings, they } \\
\text { must choose only one. }\end{array}$ \\
\hline $\begin{array}{l}\text { Ignores cultural } \\
\text { appropriacy of leaving } \\
\text { family members behind }\end{array}$ & & & $\begin{array}{l}\text { Fomilies may choose to stay in home } \\
\text { country ot risk to their own (ond their } \\
\text { families) lives if RFR requires them to } \\
\text { leave dependent elders behind. }\end{array}$ \\
\hline $\begin{array}{l}\text { Hierarchies of prescribed } \\
\text { relationships }\end{array}$ & & & $\begin{array}{l}\text { If on opplicant is estranged from a more } \\
\text { 'immediate' relative and wishes to } \\
\text { sponsor an extended family member } \\
\text { instead (soy a niece over o brother) they } \\
\text { cannot. }\end{array}$ \\
\hline \multirow[t]{6}{*}{$\begin{array}{l}\text { Customary adoption } \\
\text { - Only recognised via } \\
\text { parents undergoing legal } \\
\text { process of adoption } \\
\text { - Varying understanding } \\
\text { of INZ case officers lead to } \\
\text { unequal outcomes }\end{array}$} & & & $\begin{array}{l}\text { Expensive and complicoted to source } \\
\text { documentation necessary for } \\
\text { customorily adoptive parents to be } \\
\text { recognised through Aoteoroa } N Z \text { legal } \\
\text { systems. Applications rejected. }\end{array}$ \\
\hline & $\begin{array}{l}\text { DNA } \\
\text { testing }\end{array}$ & & $\begin{array}{l}\text { Breach of cultural beliefs ond values } \\
\text { Forced choice-can horm case if not } \\
\text { followed through on } \\
\text { Reveals shocking news to family } \\
\text { members, can cause families to be torn } \\
\text { apart. } \\
\text { Limited to no evidence of counselling or } \\
\text { debrief support in the aftermath }\end{array}$ \\
\hline & & $\begin{array}{l}\text { Heteronormative } \\
\text { language and terms }\end{array}$ & $\begin{array}{l}\text { May leave some } L G B T Q I A+\text { refugees to } \\
\text { believe they are not eligible. }\end{array}$ \\
\hline & & $\begin{array}{l}\text { Insensitive//gnorant INZ } \\
\text { officers and assessors }\end{array}$ & $\begin{array}{l}\text { Misgendering and emphasis on } \\
\text { paperwork rigour forces refugees to use } \\
\text { previous names/identities }\end{array}$ \\
\hline & & $\begin{array}{l}\text { Assumption of medical } \\
\text { costs to state for trans } \\
\text { people }\end{array}$ & $\begin{array}{l}\text { Applications rejected on this bosis even } \\
\text { when applicant explicitly states no } \\
\text { interest in medically transitioning. } \\
\text { Applicant sent to numerous and } \\
\text { expensive medical assessments } \\
\text { (endocrinologists and psychologists). }\end{array}$ \\
\hline & & $\begin{array}{l}\text { Double marginality and } \\
\text { lack of support for } \\
\text { disclosure }\end{array}$ & $\begin{array}{l}\text { Former refugees made to feel } \\
\text { unwelcome or ineligible through } \\
\text { cumulotive processes of intense RFR } \\
\text { application interrogation and societal } \\
\text { marginalisation. }\end{array}$ \\
\hline
\end{tabular}

Figure 8.2: Exclusions in RFR policy and process 
Most exclusions were a result of policy formed around definitions of 'immediate family' as parent, child and sibling. Such examples were: former refugees having to leave dependent elders behind, or risk their lives to stay with them; potential sponsors not being allowed to apply for reunification with extended family members on the grounds that they had a 'closer' relative despite them being estranged; a lack of understanding or acceptance of customary adoption without undergoing extensive legal processes. Many participants reported former refugees felt strong-armed into the disruptive and invasive processes of DNA testing out of fear for their application being rejected. I drew attention to the inherent structural violence these exclusions exhibit. FDA further highlighted the leveraging of dominant discourses to justify definitions and stipulations within policy around 'immediate' family.

Through asking in what ways those which trouble heteronormative ideas of family are excluded I also sought to specifically ask about the experiences of rainbow community refugees seeking RFR. What became clear was that this is an area in need of further research, and a community which my participants widely understood to be most harmed by RFR processes. Literature widely acknowledges the growing global awareness of queer refugees and sexuality as a basis for claims to asylum, many third countries offering resettlement recognise this now. As the tide turns on approaches to queer refugees, the exclusions discussed in this thesis present the need to apply a framework of marginality to a review of policy processes in order to abolish the structural violence currently experienced by LGBTQIA+ former refugees seeking RFR.

This deepening understanding of LGBTQIA+ marginalisation within rights-based resettlement approaches, while hopeful, possibly presents a scenario where queer refugee rights, and their ability to bring family, will be eased more quickly than those people who are not LGBTQIA+ but who still don't conform to the norms promulgated by dominant discourses of the family. Perhaps in this sense, non-normative sexuality may be embraced before non-normative 'culture' or 'ethnicity'. I suggest there is value in further research to understand and dismantle the dominant discourse of Eurocentric hetero-patriarchal nuclear families, recognising this discourse as symptomatic of lingering racism, even if ideas around normative gender and sexuality are shifting. 


\section{Heteronormativity, The Neo-Liberal Agenda, and the 'Truth Effects' of Colonial Power}

My discursive analysis contextualised thematic findings by identifying the discourses which establish or undermine (reinforce or rupture) current RFR policy and its implementation. Applying a Foucauldian lens to participant interview transcripts, I identified three discourses emerging in relation to family. These were "family as more than" "family as culturally akin" "family as culturally bound/ineligible". The latter being the dominant discourse. Through considering these discourses and from whom they are spoken I have highlighted both the role of RFR policy as a disciplinarian instrument of state power, and the discourses which challenge (rupture) this.

Through recognition of discursive structures, interwoven with ideas of biopower, governmentality and colonial influence on the 'history of the present' in Aotearoa NZ, I have argued that the master discourse of "family as culturally bound/ineligible" is promulgated by those in positions of power to justify, rather than deny, exclusionary policy. I reason this process to be a hangover from the colonial 'episteme' of Aotearoa NZ's past and one which continues to subjugate structures of family within Te Ao Māori and refugee background communities through the establishment of a Eurocentric heteronormative status quo. In doing so, I have acknowledged the resonance found (and articulated) between refugee background and indigenous conceptions of family, noting the ways in which the marginalised speak for one another and lamenting that although they rupture, they do not overrule the discursive privilege of state power- the dominant discourse.

I considered the establishment and maintenance of normative nuclear family structures via RFR policy stipulations and dominant discourse to be a form of biopower. Critical kinship lends observations to this discussion about the valorisation of genetic relationship within conceptions of family, and the neo-liberal agenda of defining 'nuclear' kinship through western scientific discourse. Inspired by Spivak's question as to whether the subaltern can speak, I considered the strategic leveraging of this essentialist discourse by a former refugee participant in attempts to subvert or navigate the exclusions inherent within its application to their RFR case. I recognised that the forms of resistance that take place within this system (be it through strategic essentialism or the performance of a particular subject position) while effective, are still bound by the limits 
of discourse and its policy. The policy still forces choice, instigates the separation of families, and oftentimes demands the subjugation of a former refugee's body to medical scrutiny through DNA testing or gender categorisation. Manoeuvring a former refugee's reunification case through these hoops successfully, while an exercise of agency, is not without stress and loss.

The mechanisms of this establishment and maintenance of heteronormative family structures are found scattered throughout my findings as bureaucratic demands and immovable eligibility categories. These demands of RFR policy, and the barriers and exclusions therein, institute structural violence; the emotional, material and mental strain of which greatly inhibit former refugee capabilities for successful resettlement in Aotearoa NZ. I therefore consider RFR policy to be not only exclusionary towards those who trouble heteronormative ideas of the family, but to be the undoing of the very purpose for which it was created; to aid in resettlement outcomes for former refugees.

\section{Policy Recommendations}

Considerations for policy reform hinged on both reducing the strain on former refugees within bureaucratic processes and expanding family definitions. Participants contributed largely practical solutions which could be applied immediately. Recommendations included:

- Expand definitions of family.

- Place greater emphasis on applicant need over relational eligibility.

- Establish a more compassionate interview process which offers greater discretion in assessment of familial relationships.

- Provide funding for legal aid.

- Re-open second tier family support category pathways and increase the number of places available.

- Reduce housing and financial costs of sponsor.

However, analysis and findings have also shown here that more pertinent to address are the wider issues of lacking consultation with former refugees in processes of policy review and 
formation, and underlying issues of RFR policy inappropriacy to refugee context and circumstance.

In reflecting on policy recommendations, I return to the formation of my conceptual framework of marginality. What has become clear is that in applying a lens of marginality, issues of power, voice and agency, and the dominance of Eurocentric heteronormative ideas within rights-based approaches to development are revealed. By centring queer subjects, and their discourses which counter this, in the formation and implementation of resettlement policy, the need for these reforms is mitigated by default of policy already being tailored to those who need it most. In the application of queer/marginal frameworks to the bureaucratic minutia of RFR policy pathways lies a case for queering rights-based development and the refugee resettlement nexus therein.

So too has this research highlighted the prevalence of embedded exclusion within policy which sits at the migration-development nexus. Aotearoa NZ as a case study here has shown that myriad exclusions, and in some instances failures to fulfil international obligations to refugee resettlement (Mahony et al., 2017), still exists in a relatively benign liberal democracy. Looking to resettlement globally and the commitment within the SDGs to "leave no one behind", it is crucial to necessitate resettlement policy that embraces diverse cultural understandings of family and frameworks of accountability based on the inclusion and protection of marginalised groups. More work may be needed in development studies to understand how this accountability to marginalised groups can happen at an international scale.

As Skilbrei (2020) points out, while it is at times problematic that research in the migrationdevelopment nexus must often go alongside the frameworks and goals of the end users (politicians, bureaucrats, and governments), suggestions for policy reform resultant from research which captures the needs and recommendations of those within systems of resettlement is unique in its role as "a bridge between advocacy and the state" (Skilbrei, 2020, p. 14). My participants felt this keenly, as represented in their desire for policy recommendations to be included in this thesis. 


\section{Future Research:}

\section{On Structural Violence}

This thesis was to the best of my knowledge a first attempt in the literature to apply queer theory to refugee family reunification policy. In applying a lens of exclusion and marginality which centres those who deviate from the hetero norm/status quo, I began a process of exposing the specific aspects of RFR policy which exclude and harm. While my intention was to inquire rather than declare, this process of inquiry has touched upon some significant areas of concern within policy processes. These findings point toward the embeddedness of structural violence within policy concerned with marginal groups, collating and analysing the various manifestations of which were outside of this thesis scope. I suggest these topics, touched upon in my findings, each deserve further research attention:

- The forced 'choice' of DNA testing and its impacts upon RFR applicants; considering a case for the abolishment of this process and the valorisation of genetic connection over kinship relations therein.

- The definition of "immediate family" within RFR policy. Towards a new (old) definition of kinship.

- Family wellbeing in resettlement spaces and repurposing RFR policy towards keeping families together.

- Indigenising approaches to refugee family reunification; a reimagination of policy.

- Understanding the intersections of asylum seeker/convention refugee equity and RFR policy pathways

- Understanding the impact of legal aid on former refugee access to justice.

- Issues and solutions in provision of welfare support for residents arriving via RFSC pathway and their sponsors.

- Investigating the gendered dynamics of adult dependent eligibility in RFSC category applicants. 
Investigating further these areas of structural violence within RFR policy and process would also give opportunity to further the case for alternate policy approaches based upon the recommendations of former refugees and driven by indigenous values of hospitality and guardianship.

\section{On Rainbow Community Experiences}

My research set out to inquire as to the experiences and exclusions of rainbow community former refuges undergoing RFR in Aotearoa NZ. What I did not anticipate was that my participant base and literature searches would expose the limited knowledge on LGBTQIA+ experiences in either published research or in the resettlement service provision space. I have reflected on this at some length in my explorations of silence within interview transcripts.

Although pursuing further the resettlement experiences and perspectives of the former refugee rainbow community was, again, beyond the scope of this thesis, in seeking at least to ask these questions, I have presented a case for further research. The intersections of the refugee background rainbow community and the discriminatory experience of those granted convention refugee status are significant. Further research on this relatively untouched intersection would showcase the potential of queer theory for refugee resettlement policy reform, for it foregrounds the perspectives of those most marginalised, in this instance those with 'double marginality' (Buscher, 2011; Randazzo, 2005) and presents this as a baseline for change. In doing so, it intrinsically ruptures power, self-congratulation within humanitarian discourse, the exclusion of bodies which trouble norms, and indeed what is considered normative.

\section{Reflections on Thesis Form}

A certain abstraction takes place in the academic form, a cold disentanglement of that which holds our bodies and communities together. It is a challenge to document rage and heartbreak, grief and trauma in the appendices of an academic thesis. It is even more so a challenge to do justice the intersecting, complex, and deeply personal exclusionary experience embedded within systems of structural violence that former refugees in this country face. I also believe there is an inherent audacity I must recognise in seeking to undertake this research as a cis-gendered, female, white, tauiwi, privileged researcher. 
Scholars, particularly queer scholars, have sought to challenge this idea of an academic form, forging new ways to present research. Four Arrows (2008) offers a rubric grounded in indigenous ontology and the spirit of resistance for students who want to make their dissertation "more than a series of hoop-jumping machinations that cause them to lose the vitality and meaningfulness of their research"(2008, p. 1). Compiling a list of components which form or indicate the authentic dissertation Four Arrows reifies ideas that research should "regard the people's version of reality" describing orientations of resistance, virtues of humility, recognition of researcher's voice, and so forth (2008, pp. 1-3). Four Arrows points further to the use of innovative ethnographic methods, as many others have (Benson \& Nagar, 2006; Katz, 1992; Kindon, 2003; Meloni, 2020; Rose, 1997), in expanding the active and evolving nature of academic fieldwork presentation which challenges objectivity.

In setting out to 'do' this research, I wrestled with my intentions to challenge the academic form through my thesis presentation and the reality of policy analysis and interacting with its actors in its necessitation of more traditional qualitative approaches. In queer theory I found both an ontological and epistemological orientation which seeks to respect and uplift the multiplicity of culturally determined ways of thinking and living, gives space to marginal people's reality and in doing so challenges oppression as contribution to social justice. However, perhaps paradoxically, the nuts and bolts of this thesis are more traditional in presentation; a linear flow of chapters which document interview methods and analytical frameworks indistinguishable from what one expects of a normative master's thesis. I have therefore grown to view this thesis as a bridge between my aims and heart as a researcher and the language of the very world I wish to challenge. On one bank is my resonance with rupture, the disturbing of norms and centring of peoples lived reality over embedded ideas of societal organisation. On the other, lies the language and structure of policy, academic rationality, built precariously upon "the pitfalls of a male-dominated, white-Western world" (Four Arrows, 2008, p. 2) and oblivious to the discourses which resist it. The form of this thesis draws from the language and style of each, a traditional structure of signposts (context, methods, findings, conclusions) used consciously to lure, to question, and to queer(y). 
In seeing this thesis as a bridge, superfluous a metaphor as that may be, I recognise its role as a structure of utility. The river that runs between these two banks is the rage and heartbreak of injustice and resistance, which I cannot fully understand, nor can I push. Therefore, this thesis takes its position as a bridge between what were seemingly (to me) dissonant spaces (academic abstraction and the emotionality of recognising injustice) prompting those who encounter it and who recognise its form, to meet in the middle, stop and gaze upon the river, taking in its challenge and change, following its expansion into an ocean of opportunity. In this sense I feel my thesis has been 'authentic' also spanning the two realms from which I have emerged, that of western academia and that of my experiences with activism and lessons from resettlement communities and spaces. In doing so, I have recognised and reflected on the absent voices throughout this work, and upon the impossibility of certain ways of knowing for me, given my relative privileges and continued unlearning of colonial threads within the fabric of Aotearoa NZ's society.

\section{Final Reflections}

In my introductory chapters I documented the backdrop of Aotearoa NZ's humanitarian identity on the geo-political stage, reified by public commitments to UNHCR conventions on the rights of refugees and within these, family reunification. I also noted concerted efforts to promote this identity as epitomised by the Prime Minister's message of inclusion and welcome in the wake of the Christchurch terror attacks. This message reflects the concerted efforts of NGOs, volunteers, lawyers and various individuals in governments who are doing their best to ensure former refugees are supported in resettlement here.

However, my findings show that current policy processes of family reunification work to prevent, harm, and exclude many former refugees from resettling with family in Aotearoa NZ. Applying a queer lens of marginality to this research has enabled me to dig further into why this may be, recognising the colonial roots of imposed hetero-norms, and thus the need to reform policy from the space of the margins; from the discourses of rupture. So too has this research revealed to me the omnipresence of the 'status quo' and its constructive/destructive role in socio- 
political life. Norms are a litmus test of power in this way, the hetero-norm to me reflects a neoliberal colonial dominance in Aotearoa NZ that renders former refugees as deviant, or marginal.

Reflecting upon this ongoing process of social exclusion, I therefore consider the call for Refugee Family Reunification policy reform as one to overturn the status quo- to queer 'the family', involve former refugees in the reform process as experts with inside knowledge, and to thereby consider what currently is outside the colonial text, by listening to the subaltern speak. 


\section{References}

ActionStation. (2016, March 31). 20,000 sign refugee petition; Labour will double refugee quota, says Little. Scoop. http://wellington.scoop.co.nz/?p=87564

Ager, A., \& Strang, A. (2008). Understanding integration: a conceptual framework . Journal of Refugee Studies, 21(2), 166-191.

https://heinonline.org/HOL/P?h=hein.journals/jrefst21\&i=170

Aikman, H. (2019). Creating kin, remaking kinship: an exploration of queer experiences of motherhood in Aotearoa New Zealand. Victoria University of Wellington.

Amnesty International. (2019). Organisations call on Govt to act on growing refugee crisis. Scoop Politics. https:/www.scoop.co.nz/stories/PO1912/S00136/organisations-call-ongovt-to-act-on-growing-refugee-crisis.htm

Amnesty International. (2020). Human rights in Asia-Pacific review of 2019. www.amnesty.org Auckland Refugee Family Trust. (2020). Stories - Auckland Refugee Family Trust. https://arft.org.nz/stories

Baldwin, J. (Ed.). (2006). Redefining culture : perspectives across the disciplines Lawrence Erlbaum Associates.

Barata, L. P., Starks, H., Kelley, M., Kuszler, P., \& Burke, W. (2015). What DNA can and cannot say: perspectives of immigrant families about the use of genetic testing in immigration. Stanford Law \& Policy Review, 26, 597-638.

Beaglehole, A. (2009). Looking back and glancing sideways: refugee policy and multicultural nation-building in New Zealand. In K. Neuman \& G. Tavan (Eds.), Does History Matter?: Making and debating citizenship, immigration and refugee policy in Australia and New Zealand (p. 105). ANU E Press. 
Benson, K., \& Nagar, R. (2006). Collaboration as resistance? Reconsidering the processes, products, and possibilities of feminist oral history and ethnography. Gender, Place \& Culture, 13(5), 581-592. https://doi.org/10.1080/09663690600859083

Berlant, L., \& Warner, M. (1995). Guest column: what does queer theory teach us about X? PMLA, 110(3), 343-349. http://www.jstor.org/stable/462930

Bhabha, H. K. (2012). The location of culture. Taylor and Francis. https://doi.org/10.4324/9780203820551

Bhagwat, -Hemangi, \& Arekar, M. (2018). On the margins: theorising Spivak's "can the subaltern speak?" Ars Artium Research Journal of Humanities and Social Sciences, 6, 3844. http://www.arsartium.o

Black, R. (2001). Fifty years of refugee studies: From theory to policy. International Migration Review, 35(1), 57-78. https://doi.org/10.1111/j.1747-7379.2001.tb00004.x

Bloch, M., \& Schneider, D. M. (1972). American kinship: a cultural account. In Man (Vol. 7, Issue 4). University of Chicago Press. https://doi.org/10.2307/2799972

Bloom, A, \& Udahemuka, M. (2014). 'Going through the doors of pain': asylum seeker and Convention refugee experiences in Aotearoa New Zealand. Kōtuitui: New Zealand Journal of Social Sciences Online, 9(2), 70-81. https://doi.org/10.1080/1177083X.2014.939664

Bloom, Alia, O’Donovan, T., \& Udahemuka, M. (2013). "Marking time”: experiences of successful asylum seekers in Aotearoa New Zealand - Community Research. http://www.communityresearch.org.nz/research/marking-time-experiences-of-successfulasylum-seekers-in-aotearoa-new-zealand/

Burford, J. (Jamie). (2010). (The) Margin(s) Speak! A multifaceted examination of practising 'men who have sex with men' development in Bangkok. Victoria University of Wellington. 
Burr, V. (1995). An introduction to social constructivism. Routledge.

Buscher, D. (2011). Unequal in exile: gender equality, sexual identity and refugee status. Amsterdam Law Forum, 3(2), 92. https://doi.org/10.37974/alf.177

Butler, J. (1993). Bodies that matter : on the discursive limits of "sex" . Routledge.

Butler, J., \& Walsh, M. (2002). Antigone's claim: kinship between life and death. In J. Butler \& M. Walsh (Eds.), Australian feminist studies (Vol. 17, Issue 37, pp. 117-118).

Carsten, J. (Ed.). (2000). Cultures of relatedness : new approaches to the study of kinship . Cambridge University Press.

Changemakers Refugee Forum. (2009). Refugee family reunification in Wellington (Issue July).

Cheek, J. (2008). The SAGE encyclopedia of qualitative research methods (L. M. Given (Ed.)). SAGE Publications, Inc. https://doi.org/10.4135/9781412963909

Choummanivong, C., Poole, G. E., \& Cooper, A. (2014). Refugee family reunification and mental health in resettlement. Kotuitui, 9(2), 89-100. https://doi.org/10.1080/1177083X.2014.944917

Collins, H. (2010). Creative research : the theory and practice of research for the creative industries . AVA Academia.

Community Law. (2019). Law Manual - Community Law. https://communitylaw.org.nz/legalinformation/

Cornwall, A, Corrêa, S., \& Jolly, S. (2008). Development with a body : sexualities, development and human rights. Zed Books.

Cornwall, Andrea, \& Jolly, S. (2006). Introduction: sexuality matters. IDS Bulletin, 37(5), 1-11. https://doi.org/10.1111/j.1759-5436.2006.tb00295.x

Cornwall, Andrea, \& Nyamu-Musembi, C. (2004). Putting the 'rights-based approach' to 
development into perspective. Third World Quarterly, 25(8), 1415-1437.

https://doi.org/10.1080/0143659042000308447

Crabtree, S. M. (2019). Reflecting on reflexivity in development studies research. Development in Practice, 29(7), 927-935. https://doi.org/10.1080/09614524.2019.1593319

Cram, F. (2014). Measuring Māori wellbeing: a commentary. MAI Journal, 3(1), 19-32.

Courtland- Robinson, W. (2003). The causes, consequences, and challenges of developmentinduced displacement. The Brookings Institution-SAIS project on internal displacement risks and rights, The Brookings Institution-SAIS.

DeLauretis, T. (1991). Queer theory, lesbian and gay studies: an introduction. Differences: A Journal of Feminist Cultural Studies, 3(2), iii-xviii.

Department of Labour (DoL). (2004). Refugee voices: a journey towards resettlement - summary report (pdf). Department of Labour (DoL). http://www.mbie.govt.nz/publicationsresearch/research/migration/RefugeevoicesExecutiveSummary.pdf

Derrida, J. (1978). Writing and difference . University of Chicago Press.

Derrida, J. (1997). Of grammatology (Corrected). Johns Hopkins University Press.

Dilley, P. (1999). Queer theory: under construction? International Journal of Qualitative Studies in Education, 12(5), 457-472. https://doi.org/10.1080/095183999235890

Durie, M. (2003). Nga Kahui Pou : launching Maori futures. Huia (NZ) Ltd. http://ebookcentral.proquest.com/lib/vuw/detail.action?docID=1359701

E Tū. (2018). Our ancestors enjoyed loving whānau relationships. etuwhanau.org.nz

Edelman, L. (2004). No future : queer theory and the death drive . Duke University Press.

Edwards, B. (2019, March 19). Political roundup: politicians' words under scrutiny after Christchurch terror attacks. NZ Herald. 
https://www.nzherald.co.nz/nz/news/article.cfm?c_id=1\&objectid=12214352

Ercan, S. A., \& Marsh, D. (2016). Qualitative methods in political science. In H. Keman \& J. Woldendorp (Eds.), Handbook of research methods and applications in political science. Edward Elgar Publishing.

Escobar, A. (1992). Imagining a post-development era? Critical thought, development and social movements. Social Text, 31/32, 20-56. https://doi.org/10.2307/466217

Estivill, J. (2003). Concepts and strategies for combating social exclusion. An overview. International Labour Organization. http://www.ilo.org/step

Feldstein, S. (2017, October 16). How U.S. policies are worsening the global refugee crisis Carnegie Endowment for International Peace. Carnegie Endowment For International Peace. https://carnegieendowment.org/2017/10/16/how-u.s.-policies-are-worsening-globalrefugee-crisis-pub-73480

Fine, M. (1998). Chapter 4: Working the hyphens: Reinventing self and other in qualitative research. In N. K. Denzin \& Y. . Lincoln (Eds.), The Landscape of Qualitative Research (1st Ed.) (pp. 130-155). SAGE Publications.

Fitzgerald, H. K. S. (2017). Ngā wāhine kaha from Syria: the experience of former refugee women from Syria resettling in Aotearoa New Zealand [Victoria University of Wellington]. http://researcharchive.vuw.ac.nz/handle/10063/6874

Ford, K. M. (2012). Contesting representations of refugee-background women (and men) as 'needy' and 'problematic' in healthcare literature in Aotearoa New Zealand: Advancing the case for a capability-driven model [Victoria University of Wellington]. http://researcharchive.vuw.ac.nz/handle/10063/2525

Foucault, M. (1971). Orders of discourse: Inaugural lecture delivered at College de France. 
Social Science Information, 10(2), 7-30.

Foucault, M. (1972). The archaeology of knowledge; and, the discourse on language (M.

Foucault (Ed.)). Pantheon Books.

Foucault, M. (1980). Power/knowledge : selected interviews and other writings, 1972-1977 (C.

Gordon (Ed.)). Harvester Press.

Foucault, M. (1994). Polemic, politics and problematizations. In Ethics: subjectivity and truth.

(Vol. 1, pp. 111-119). The New Press.

Foucault, M. (1995). Discipline and punish : the birth of the prison. In Discipline \& punish (2nd Vintag). Vintage Books.

Foucault, M. (2002). The order of things : an archaeology of the human sciences . Routledge. https://doi.org/10.4324/9780203996645

Foucault, M. (2006a). History of madness (J. Khalfa (Ed.)). Routledge.

Foucault, M. (2006b). Michel Foucault: Psychiatric power: lectures at the Collège de France, 1973-1974. In J. Lagrange, G. Burchell, F. Ewald, A. Fontana, \& A. I. Davidson (Eds.), Michel Foucault: Psychiatric Power: Lectures at the Collège de France, 1973-1974. (pp. 382-382). Palgrave Macmillan.

Foucault, M. (2008). The birth of biopolitics : lectures at the Collège de France, 1978-79 (M. Senellart (Ed.)). Palgrave Macmillan.

Four Arrows (D.T Jacobs). (2008). The authentic dissertation : alternative ways of knowing, research, and representation. Routledge.

Fraser, M. (1999). Classing Queer: Politics in competition. Theory, Culture \& Society, 16(2), 107-131. https://doi.org/10.1177/02632769922050575

Fraser, N. (2010). Injustice at intersecting scales: On "social exclusion" and the "global poor." 
European Journal of Social Theory, 13(3), 363-371.

https://doi.org/10.1177/1368431010371758

Fukuda-Parr, S. (2016). From the Millennium Development Goals to the Sustainable

Development Goals: shifts in purpose, concept, and politics of global goal setting for development. Gender and Development, 24(1), 43-52.

https://doi.org/10.1080/13552074.2016.1145895

Galtung, J. (1969). Violence, peace, and peace research. Journal of Peace Research, 6(3), 167191. http://www.jstor.org/stable/422690

Garber, L. (2001). Identity poetics : race, class, and the lesbian-feminist roots of queer theory. Columbia University Press.

Garland, D. (2014). What is a "history of the present"? On Foucault's genealogies and their critical preconditions. Punishment \& Society, 16(4), 365-384. https://doi.org/10.1177/1462474514541711

Gergen, K. J. (1985). Social constructionist inquiry: Context and implications - The Social Construction of the Person (K. J. Gergen \& K. E. Davis (Eds.); pp. 3-18). Springer New York. https://doi.org/10.1007/978-1-4612-5076-0_1

Graham, L. J. (2005). Discourse analysis and the critical use of Foucault. Australia Association for Research in Education, 11(4), 1-15. https://doi.org/10.1177/0959354301114006

Granados Moreno, P., Ngueng Feze, I., \& Joly, Y. (2017). Does the end justify the means? A comparative study of the use of DNA testing in the context of family reunification. Journal of Law and the Biosciences, 4(2), 250-281. https://doi.org/10.1093/JLB/LSX012

Gray, A. (2008). Refugee resettlement: A literature review (A. Gray (Ed.)). Department of Labour. www.immigration.govt.nz/research 
Gready, P. (2008). Rights-Based approaches to development: What is the value-added? Development in Practice, 18(6), 735-747. http://www.jstor.org/stable/27751980

Griek, I. (2009). The «rights turn» in refugee protection: an analysis of UNHCR's adoption of the human rights based approach. Yearbook on Humanitarian Action and Human Rights, 6, 73-90. http://revista-derechoshumanos.deusto.eshttp//revista-derechoshumanos.deusto.es Gupta, A. (2012). Red tape: Bureaucracy, structural violence, and poverty in India. Duke University Press.

Halperin, D. M. (1995). Saint Foucault : towards a gay hagiography. Oxford University Press.

Haraway, D. J. (1991). Simians, cyborgs, and women : the reinvention of nature . Routledge.

Hart, G. (2002). Geography and development: development/s beyond neoliberalism? power, culture, political economy. Progress in Human Geography, 26(6), 812-822. https://doi.org/10.1191/0309132502ph405pr

Healy, S., Huygens, I., Murphy, T., Parata, H., Kawariki., T., \& Whangarei., N. W. (2012). Ngāpuhi speaks : He Wakaputanga o te rangatiratanga o Nu Tireni and Te Tiriti o Waitangi $=$ independent report, Ngapuhi Nui Tonu claim. In Wakaputanga and Te Tiriti o Waitangi, independent report on Ngāpuhi Nui Tonu claim. Te Kawariki \& Network Waitangi Whangarei.

Held, V. (2006). The ethics of care personal, political, and global . Oxford University Press. Heron, J, \& Reason, P. (2006). Handbook of action research: concise paperback edition. Handbook of Action Research.

Heron, John, \& Reason, P. (2008). The SAGE handbook of action research (2nd ed.). SAGE Publications Ltd. https://doi.org/10.4135/9781848607934

Humpage, L. (2019). Refugee protection and settlement policy in New Zealand - The Palgrave 
handbook of ethnicity (S. Ratuva (Ed.); pp. 1689-1710). Springer Singapore. https://doi.org/10.1007/978-981-13-2898-5_125

Iddamalgoda, G. (2019). Kia Ora Te Whanau (speech to Wellington vigil for the victims of the Christchurch mosque terrorist attacks). In Public Speech. Liberation (blog). https://liberation.typepad.com/liberation/2019/03/gayaal-iddamalgoda-kia-ora-te-whanuaspeech-to-wellington-vigil-for-the-victims-of-the-christchurch-.html

Immigration New Zealand. (2012). New Zealand refugee resettlement strategy . https://www.immigration.govt.nz/documents/refugees/refugeeresettlementstrategy.pdf IMSED. (2010). IMSED research work programme summary of findings. Department of Labour. www.immigration.govt.nz/research

Jeppesen, S. (2016). Heteronormativity. In A. Goldberg (Ed.), The SAGE encyclopedia of LGBTQ studies (pp. 493-496). SAGE Publications, Inc. https://doi.org/10.4135/9781483371283.n183

Johnstone, T. (2018, June). 'How do you settle when your loved ones are in danger?' . The Spinoff. https://thespinoff.co.nz/parenting/02-06-2018/how-do-you-settle-when-your-lovedones-in-danger/

Jolly, S. (2011). Why is development work so straight? Heteronormativity in the international development industry. Development in Practice, 21(1), 18-28. https://doi.org/10.1080/09614524.2011.530233

Jørgensen, M., \& Phillips, L. (2002). Discourse analysis as theory and method. SAGE Publications Ltd. https://doi.org/10.4135/9781849208871

Kabeer, N. (2000). Social exclusion, poverty and discrimination: Towards an analytical framework. IDS Bulletin, 31(4), 83-97. https://doi.org/10.1111/j.1759- 
5436.2000.mp31004009.x

Kabeer, Naila. (1994). Social exclusion : concepts, findings and implications for the MDGs. Institute of Development Studies, 1-33.

Kabeer, Naila. (2015). Tracking the gender politics of the Millennium Development Goals: struggles for interpretive power in the international development agenda. Third World Quarterly, 36(2), 377-395. https://doi.org/10.1080/01436597.2015.1016656

Kamri-McGurk, U. (2012). Resettlement experiences of Burmese women from refugee backgrounds in Wellington, Aotearoa New Zealand [Victoria University of Wellington]. http://researcharchive.vuw.ac.nz/handle/10063/2588

Kapoor, I. (2015). The Queer Third World. Third World Quarterly, 36(9), 1611-1628. https://doi.org/10.1080/01436597.2015.1058148

Katz, C. (1992). All the world is staged: Intellectuals and the projects of ethnography. Environment and Planning D: Society and Space, 10(5), 495-510. https://doi.org/10.1068/d100495

Keeble, A. (2017). Refugee reunification in Nelson free legal help report.

Kindon, S. (2003). Participatory video in geographic research: a feminist practice of looking? Area, 35(2), 142-153. https://doi.org/10.1111/1475-4762.00236

Kirby, S., \& Hay, I. (1997). (Hetero)sexing space: gay men and "straight" space in Adelaide, South Australia. The Professional Geographer, 49(3), 295-305. https://doi.org/10.1111/0033-0124.00078

Kirsch, M. H. (2000). Queer theory and social change. Routledge.

Kothari, S., \& Harcourt, W. (2004). Introduction: The violence of development. Development, 47(1), 3-7. https://doi.org/10.1057/palgrave.development.1100024 
Kritzman, L. D. (1988). The concern for truth: An interview with Michel Foucault. In L. D. Kritzman (Ed.), Politics, philosophy, culture : interviews and other writings, 1977-1984 (pp. 255-267). Routledge.

Kukutai, T., \& Rata, A. (2017). From mainstream to manaaki Indigenising our approach to immigration. In D. Hall (Ed.), Fair borders? Migration policy in the twenty-first century (pp. 26-45). Bridget Williams Books.

Lacan, J. (1973). Le Séminaire, Livre XI: les quatre concepts fondamentaux de la psychanalyse, 1964 [Seminar, book XI: The four fundamental concepts of psychoanalysis, 1964] (J.-A. Miller (Ed.)).

Langford, M. (2010). A poverty of rights: six ways to fix the MDGs. IDS Bulletin, 41(1), 83-91. https://doi.org/10.1111/j.1759-5436.2010.00108.x

Lemke, T. (2002). Foucault, governmentality, and critique. Rethinking Marxism, 14(3), 49-64. https://doi.org/10.1080/089356902101242288

Lévi-Strauss, C. (1970). The elementary structures of kinship (Rev. ed.). Social Science Paperbacks in association with Eyre \& Spottiswoode.

Luibhéid, E. (2008). Queer/Migration: An unruly body of scholarship. GLQ, 14(2-3), 169-190. https://doi.org/10.1215/10642684-2007-029

Mahony, C., Marlowe, J., Baird, N., \& Humpage, L. (2017). Aspirational yet precarious: compliance of New Zealand refugee settlement policy with international human rights obligations. International Journal of Migration and Border Studies, 3(1), 5. https://doi.org/10.1504/ijmbs.2017.10002158

Manning, E. (2009). Queerly disrupting methodology. Paper presented at the The Celebrating Graduate Scholarship Conference. 
Marlowe, J. M., Bartley, A., \& Hibtit, A. (2014). The New Zealand Refugee Resettlement Strategy: implications for identity, acculturation and civic participation. Kötuitui: New Zealand Journal of Social Sciences Online, 9(2), 60-69.

https://doi.org/10.1080/1177083X.2014.934847

Matthews, S. J. (2010). Postdevelopment Theory. In Oxford research encyclopedia of international studies. https://doi.org/10.1093/acrefore/9780190846626.013.39

MBIE. (2019). Proposed community resettlement framework presented at community consultation meeting November $26^{\text {th }} 2019$

MBIE. (2020). Refugee family reunification figures obtained under Official Information Act 1982 request to the Ministry of Business Innovation and Employment.

McBrien, J. L. (2014). I ōrea te tuātara ka patu ki waho: Competing priorities in the New Zealand refugee resettlement strategy. www.fulbright.org.nz

McEwan, C., \& Goodman, M. K. (2010). Place geography and the ethics of care: Introductory remarks on the geographies of ethics, responsibility and care. Ethics, Place \& Environment, 13(2), 103-112. https://doi.org/10.1080/13668791003778602

Mckenzie, S., \& Carter, K. (2010). Measuring Whānau: A review of longitudinal studies in New Zealand. MAI Review, 3(3), 1-11. http://review.mai.ac.nz

Meloni, F. (2020). A boat taking on water: Rethinking emotions and the politics of knowledge in ethnographic research with "hard-to-reach" and marginalised populations. Emotion, Space and Society, 36, 100708. https://doi.org/10.1016/j.emospa.2020.100708

MFAT. (2020). Our work with the UN $\mid$ New Zealand Ministry of Foreign Affairs and Trade. https://www.mfat.govt.nz/en/peace-rights-and-security/work-with-the-un-and-otherpartners/ 
Mikaere, A. (1994). Maori women, caught in the contradictions of a colonised reality. Waikato Law Review, 2, 125-149.

https://www.waikato.ac.nz/law/research/waikato_law_review/pubs/volume_2_1994/7

Moeke-Pickering, T. M. (1996). Maori identity within whanau: A review of literature. https://hdl.handle.net/10289/464

Moewaka Barnes, H., \& McCreanor, T. (2019). Colonisation, hauora and whenua in Aotearoa. Journal of the Royal Society of New Zealand, 49(sup1), 19-33.

https://doi.org/10.1080/03036758.2019.1668439

Moulin, C. (2012). Ungrateful subjects? Refugee protest and the logic of gratitude. In P. Nyers \& K. Rygiel (Eds.), Citizenship, migrant activism and the politics of movement. Routledge.

Nahmias, P., \& Baal, N. . (2019, December 2). Including forced displacement in the SDGs: a new refugee indicator. UNHCR Blogs. https://www.unhcr.org/blogs/including-forceddisplacement-in-the-sdgs-a-new-refugee-indicator/

New Zealand Government. (2018, September 19). Refugee quota increases to 1500 in 2020. Beehive.Govt.Nz. https://www.beehive.govt.nz/release/refugee-quota-increases-1500-2020 New Zealand Government. (2020). Wellbeing Budget 2020 Rebuilding Together. https://budget.govt.nz/budget/pdfs/wellbeing-budget/b20-wellbeing-budget.pdf New Zealand House of Representatives. (2017). Confidence and supply agreement between the New Zealand Labour Party and the Green Party of Aotearoa New Zealand. New Zealand House of Representatives. https://www.parliament.nz/media/4487/nzlp__gp_c_s_agreement.pdf of Business, M. (2018). Immigration factsheets, refugees and asylum seekers. Office of the Minister of Immigration. (2018). Increasing the annual refugee quota to 1,500 
places. Ministry of Business Innovation and Employment.

https://www.mbie.govt.nz/assets/80e9118e7e/cabinet-paper-annual-refugee-quota-proposedincrease-2018.pdf

Oswald, R. F., Kuvalanka, K. A., Blume, L. B., \& Berkowitz, D. (2009). Queering "the family." In Handbook of feminist family studies (pp. 43-55).

https://doi.org/10.4135/9781412982801.n4

Palmary, I., \& Nunez, L. (2009). The orthodoxy of gender mainstreaming: Reflecting on gender mainstreaming as a strategy for accomplishing the Millennium Development Goals. Journal of Health Management, 11(1), 65-78. https://doi.org/10.1177/097206340901100105

Pande, R. (2017). Strategic Essentialism. In International encyclopedia of geography: People, the earth, environment and technology (pp. 1-6). John Wiley \& Sons, Ltd. https://doi.org/10.1002/9781118786352.wbieg1170

Patton, M. Q. (2002). Qualitative research and evaluation methods (M. Q. Patton (Ed.); 3 ed.). Sage Publications.

Petersen, N., \& Henning, E. (2018). Service learning and the practice of social justice and care. Journal of Human Behavior in the Social Environment, 28(4), 436-448. https://doi.org/10.1080/10911359.2017.1418697

The Fundamental Principles of the Red Cross, (1979). https://www.icrc.org/en/doc/resources/documents/misc/fundamental-principlescommentary-010179.htm

Poole, G. E. (Gary E., \& Wise Group (N.Z.). Te Pou o te Whakaaro Nui. (2010). Therapies for refugees, asylum seekers, and new migrants : best and promising practice guide for mental health and addiction services. The National Centre of Mental Health Research, Information 
and Workforce Development.

https://www.mentalhealth.org.nz/assets/ResourceFinder/Talking-Therapies-for-RefugeesAsylum-Seekers-and-New-Migrants.pdf

Popke, J. (2006). Geography and ethics: everyday mediations through care and consumption. Progress in Human Geography, 30(4), 504-512. https://doi.org/10.1191/0309132506ph622pr

Power, M. (2003). Rethinking development geographies. In Rethinking Development Geographies. Routledge Taylor \& Francis Group. https://doi.org/10.4324/9780203006184 Rabinow, P., \& Rose, N. (2003). Foucault Today. In The essential Foucault: selections from the essential works of Foucault, 1954-1984. New Press. https://www.researchgate.net/publication/265009701

Radcliffe, S. A. (2005). Development and geography: Towards a postcolonial development geography? Progress in Human Geography, 29(3), 291-298. https://doi.org/10.1191/0309132505ph548pr

RainbowYOUTH, InsideOUT, Intersex Trust of Aotearoa New, Zealand, Tīwhanawhana Trust, Love Life Fono, OUTLine NZ, Rainbow Wellington, Kāhui Tū Kaha, Silver Rainbow, Aotearoa Crisis Care Movement, Body Positive, Changing Minds, New Zealand AIDS Foundation, New Zealand Post Primary Teachers', Association, Adolescent Health Research Group, University of Auckland, Mental Health Foundation of New, \& Zealand. (2018). Rainbow communities, mental health and addictions a submission to the government inquiry into mental health and addiction - Oranga Tāngata, Oranga Whānau.

Randazzo, T. J. (2005). Social and legal barriers: In E. Luibhéid \& L. Cantú (Eds.), Queer Migrations (NED-New, pp. 30-60). University of Minnesota Press. 
http://www.jstor.org/stable/10.5749/j.ctttt4g7.6

RASNZ, \& Colmar Brunton. (2020). New Zealanders 'perceptions of refugees survey report 2020.

Refugee Family Reunification Trust. (2020). Refugee Family Reunification Trust Newsletter 2019/2020. Refugee Family Reunification Trust newsletter.

https://refugeefamilyreunificationtrust.org.nz/wp-content/uploads/2020/02/2019-

RFRT_newsletter.pdf

Rich, A. (1980). Compulsory heterosexuality and lesbian existence. Signs, 5(4), 631-660. http://www.jstor.org/stable/3173834

Riggs, D. W., \& Peel, E. (2016). Critical kinship studies: An introduction to the field. In Critical Kinship Studies: An Introduction to the Field. Palgrave Macmillan. https://doi.org/10.1057/978-1-137-50505-7

Robinson, J. (2003). Postcolonialising geography: Tactics and pitfalls. Singapore Journal of Tropical Geography, 24(3), 273-289. https://doi.org/10.1111/1467-9493.00159

Rogers, S., \& Wilmsen, B. (2020). Towards a critical geography of resettlement. Progress in Human Geography, 44(2), 256-275. https://doi.org/10.1177/0309132518824659

Rose, G. (1997). Situating knowledges: positionality, reflexivities and other tactics. Progress in Human Geography, 21(3), 305-320. https://doi.org/10.1191/030913297673302122

Rousseau, C., Rufagari, M. C., Bagilishya, D., \& Measham, T. (2004). Remaking family life: Strategies for re-establishing continuity among Congolese refugees during the family reunification process. Social Science and Medicine, 59(5), 1095-1108. https://doi.org/10.1016/j.socscimed.2003.12.011

Rt Hon Jacinda Ardern. (2017). Speech from the throne . In beehive.govt.nz. 
https://www.beehive.govt.nz/speech/speech-throne-2017

Rubin, G. (1975). The traffic in women: Notes on the 'political economy' of sex. In R. R. Reiter (Ed.), Toward an anthropology of women (pp. 157-210). Monthly Review Press.

Sachs, W. (2009). The development dictionary: A guide to knowledge as power. Zed Books. http://ebookcentral.proquest.com/lib/vuw/detail.action?docID $=482404$

Salleh, A. (2016). Climate, water, and livelihood skills: A post-development reading of the SDGs. Globalizations, 13(6), 952-959. https://doi.org/10.1080/14747731.2016.1173375

Samuels, J. (1999). Dangerous liaisons: queer subjectivity, liberalism and race. Cultural Studies, 13(1), 91-109. https://doi.org/10.1080/095023899335383

Schneider, D. M. (David M. (1984). A critique of the study of kinship . University of Michigan Press.

Schwöbel-Patel, C., \& Ozkaramanli, D. (2017). The construction of the "grateful refugee" in law and design. Queen Mary Human Rights Review, 4(1), 1-10. http://www.unhcr.org/uk/1951refugee-convention.html.

Sen, A. (2000). Social exclusion: concept, application, and scrutiny.

Sen, A. (2001). Development as freedom . Oxford University Press.

Silver, H., \& Miller, S. M. (2003). Social exclusion. Indicators, 2(2), 5-21. https://doi.org/10.1080/15357449.2003.11069166

Skilbrei, M.-L. (2020). Taking on the categories, terms and worldviews of the powerful: the pitfalls of trying to be relevant. Identities, 1-17. https://doi.org/10.1080/1070289X.2020.1805884

Spivak, G. C. (1988). Can the subaltern speak? In C. Nelson \& L. Grossberg (Eds.), Marxism and the interpretation of culture (p. 271). University of Illinois Press. 
Spivak, G. C. (1993). In a word: Interview. In Outside in the teaching machine (pp. 1-26). Routledge.

Spivak, G. C. (1996). Subaltern studies: deconstructing histiography. In D. Landry \& G. M. MacLean (Eds.), The Spivak reader : selected works of Gayatri Chakravorty Spivak (pp. 203-237). Routledge.

Strategic Social Policy Group. (2008). Diverse communities - exploring the migrant and refugee experience in New Zealand.

Struckmann, C. (2018). A postcolonial feminist critique of the 2030 Agenda for Sustainable Development: a South African application. Agenda, 32(1), 12-24. https://doi.org/10.1080/10130950.2018.1433362

Stuart, E., \& Woodroffe, J. (2016). Leaving no-one behind: can the Sustainable Development Goals succeed where the Millennium Development Goals lacked? Gender and Development, 24(1), 69-81. https://doi.org/10.1080/13552074.2016.1142206

Tang, D. T. S. (2007). The research pendulum. Journal of Lesbian Studies, 10(3-4), 11-27. https://doi.org/10.1300/J155v10n03_02

Tingvold, L., Middelthon, A. L., Allen, J., \& Hauff, E. (2012). Parents and children only? Acculturation and the influence of extended family members among Vietnamese refugees. International Journal of Intercultural Relations, 36(2), 260-270. https://doi.org/10.1016/j.ijintrel.2011.03.005

Todd, K. (2019, June 20). Flood of support for refugees arriving in Christchurch | RNZ News. Radio New Zealand. https://www.rnz.co.nz/news/national/392467/flood-of-support-forrefugees-arriving-in-christchurch

Turner, W. B. (William B. (2000). A genealogy of queer theory. Temple University Press. 
UN. (2015). United Nations Transforming Our World: the 2030 Agenda for Sustainable Development. A/RES/70/1. In United Nations (Vol. 16301, Issue October). https://www.un.org/en/development/desa/population/migration/generalassembly/docs/global compact/A_RES_70_1_E.pdf

UNHCR. (2001). Protecting the family: Challenges in implementing policy in the resettlement context. Annual tripartite consultations on resettlement, June, 20-21. https://www.unhcr.org/3b30baa04.pdf

UNHCR. (2008). UNHCR Note on DNA testing to establish family relationships in the refugee context. Human Rights, 1-8. https://www.refworld.org/docid/48620c2d2.html

UNHCR. (2010). Convention and protocol relating to the status of refugees. https://www.unhcr.org/3b66c2aa10.html

United Nations. (2019). Global compact for migration | Refugees and Migrants. https://refugeesmigrants.un.org/migration-compact

Vaast, C., \& Mills, E. (2018). Gender, sexuality and development. In C. Mason (Ed.), Routledge handbook of queer development studies. (pp. 57-69). Routledge. https://doi.org/10.4324/9781315529530-5

Valocchi, S. (2005). Not yet queer enough: the lessons of queer theory for the sociology of gender and sexuality. Gender \& Society, 19(6), 750-770. https://doi.org/10.1177/0891243205280294

Von Braun, J., \& Gatzweiler, F. W. (2014). Marginality: addressing the nexus of poverty, Exclusion and Ecology. https://doi.org/10.1007/978-94-007-7061-4

Wagenaar, H. (2011). Meaning in action : interpretation and dialogue in policy analysis . M.E. Sharpe. 
Waitt, G. (2016). Doing Foucauldian discourse analysis - revealing social realities. In I. Hay (Ed.), Qualitative research methods in human geography (4th ed, pp. 287-312). Oxford University Press. https://contentstore.cla.co.uk//secure/link?id=c70ae78c-4c36-e711-80c9005056af4099

Waitt, G., \& Warren, A. (2008). 'Talking shit over a brew after a good session with your mates': surfing, space and masculinity. Australian Geographer, 39(3), 353-365. https://doi.org/10.1080/00049180802270549

Walker, R. (2004). Ka whawhai tonu mātou = Struggle without end . In Struggle without end (Rev. ed.). Penguin.

Walker, T. (2017). Whānau - Māori and family - Description of whānau. In Te Ara - the encyclopedia of New Zealand. Ministry for Culture and Heritage Te Manatu Taonga. https://teara.govt.nz/en/whanau-maori-and-family/page-2

Walters, L. (2018, June 15). NZ works to double refugee quota as others close their borders | Stuff.co.nz. Stuff NZ. https:/www.stuff.co.nz/national/politics/104837520/nz-works-todouble-refugee-quota-as-others-close-their-borders

Watson, K. (2005). Queer theory. https://doi.org/10.1177/0533316405049369

Weber, H. (2017). Politics of 'leaving no one behind': contesting the 2030 Sustainable Development Goals Agenda. Globalizations, 14(3), 399-414. https://doi.org/10.1080/14747731.2016.1275404

Weems, M. E. (2001). I speak from the wound in my mouth [University of Illinois at UrbanaChampaign]. In ProQuest Dissertations and Theses. https://www.ideals.illinois.edu/handle/2142/80457 Weston, K. (1997). Families we choose : lesbians, gays, kinship. (2nd ed.). Columbia University 
Press.

Williams, H. A. (1990). Families in refugee camps. Human Organization, 49(2), 100-109. http://www.jstor.org/stable/44126440

Williams, M. (2016, November). Refugee resettlement and family reunification. NZ Law Society, Issue 461.

Wilmsen, B. (2011). Family separation: the policies, procedures, and consequences for refugee background families. Refugee Survey Quarterly, 30(1), 44-64. https://doi.org/10.1093/rsq/hdq045

Winchester, H. P. M., \& Rofe, M. W. (2010). Qualitative research and its place in human geography. In I. Hay (Ed.), Qualitative research methods in human geography (3rd ed, pp. 3-24). OUP Canada.

Yacob-Haliso, O. (2016). Intersectionality and durable solutions for refugee women in Africa. Journal of Peacebuilding \& Development, 11(3), 53-67. https://doi.org/10.1080/15423166.2016.1236698 


\section{Appendices}

\section{Appendix A. Aide-memoire}

\section{INTERVIEW AIDE-MÉMOIRE FOR THE RESEARCH THESIS: “Queer(Y)Ing Resettlement in Aotearoa: An Inquiry into The Importance of Family Reunification Pathway Reform for Former Refugees."}

\section{INTRODUCTIONS AND QUESTIONS}

A. Introduction and expectations (can take place prior to interview)

$>$ Researcher introduces self and topic and notes awareness of positionality

$>$ Researcher outlines how long this interview will run, consent processes, recording processes and overall objective of interview

\section{B. Participant context}

Participant is encouraged to share their background and current work or involvement in relation to the research topic (FR Policy).

How does your organisation/role/advocacy work interact with FR processes? / How do you personally interact with FR processes?

Participant asked to share why this work is important to them and what specifically about it interests, enthuses, and or frustrates them about their work in this field. Personal reflections, anecdotes, and practical examples are encouraged as participants are prompted to elaborate on the following:

What are the known barriers you are aware of in seeking FR / as a community/gov figure when working in the FR space?

Do these relate to current policy stipulations, and if so how?

What are your initial observations regarding the work that you do in the FR space and how it intersects (or doesn't) with refugee background members of the rainbow community OR non- 'nuclear' family set ups?

What are the strengths of New Zealand's refugee family reunification pathway, how can these be built upon, expanded or protected? / In an ideal world what would you change about RFR policy? 


\section{OVERARCHING RESEARCH TOPIC FOR DISCUSSION}

This research aims to explore three main questions, each may be used as a prompt for discussion in turn according to participant experiences, knowledges and interest or speculation:

$>$ In what ways do common barriers relating to former refugees successfully engaging in family reunification processes relate to embedded heteronormative/western assumptions around family?

$>$ Is family reunification policy exclusionary? In what ways, and how might this be adversely affecting those who identify as LGBTQIA+?

$>$ How has/is family reunification pathway utilised by former refugees for the protection of LGBTQIA+ family members or selves?

\section{PARTICIPANT OPINIONS/ IDEAS/ SUGGESTION}

Building on conversation, if not already discussed, participants and researcher alike may engage in co-inquiry to ask the bigger question of what might policy reform look like in the family reunification space?

\section{CONCLUDING REMARKS AND WRAP UP}

Participant offered opportunity to make any final comments and next steps are discussed 


\section{Appendix B. Ethics Approval}

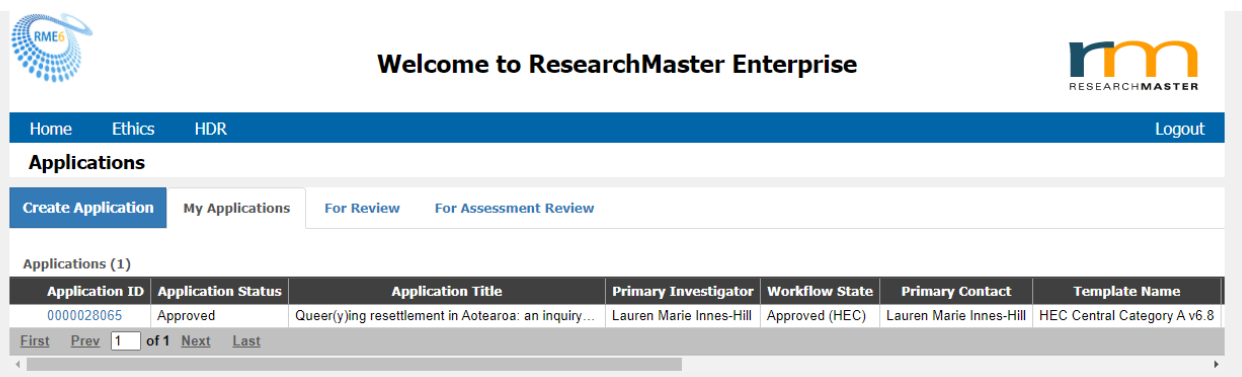

Login id: inneslaur [ETH003M]

ResearchMaster Enterprise: 6.16 .5 (41409)

Copyright @2020 ResearchMaster Pty tot

Human ethics application approval 0000028065. Automated Email, Do Not Reply Inbox $x$

\section{researchmaster-help@vuw.ac.nz}

to

Dear Lauren,

Thank you for your application for ethical approval (Queer(y)ing resettlement in Aotearoa: an inquiry into the importance of family reunification pathway reform for former refugees., reference 0000028065 ), which has now been considered by the Standing Committee of the Human Ethics Committee.

Your application is approved as of today. Your approval applies for three years from the date of this email.

If you would like to receive a formal letter please contact the HEC Administrator (ethicsadmin@vuw.ac.nz).

Best wishes with the research.

Judith Loveridge, Convenor

Human Ethics Committee

*****This is an automated email. Do not reply to this email address

Queries for the central Human Ethics Committee can be sent to ethicsadmin@vuw.ac.nz 


\section{Appendix C: Data Obtained Under OIA Request}

\section{MINISTRY OF BUSINESS, INNOVATION \& EMPLOYMENT \\ HIKINA WHAKATUTUKI}

20 August 2020

Lauren Innes-Hill

Linneshill@gmail.com

File No: DOIA 2021-0203

Dear Lauren

Thank you for your request of 27 July 2020 to the Ministry of Business, Innovation \&

Employment (the Ministry) under the Official Information Act 1982 (the Act):

- Total number of applications received/filed under Refugee Family Support Category in 2019

- Number of approved Refugee Family Support Category applications

- total number intake (arrivals) via quota family reunification residence category in 2019

- total number intake of quota refugees in 2019

- total number intake of convention refugees in 2019

- total number intake (arrivals) under the refugee family support category in 2019.

Information in response to your request is outlined in the tables in Appendix A. You can also find more information on our website at:

https://www.immigration.govt.nz/documents/statistics/statistics-refugee-and-protection.pdf

I trust this information fulfils your request. If you wish to discuss this response, please email INZOfficialCorrespondence@mbie.govt.nz.

Yours sincerely

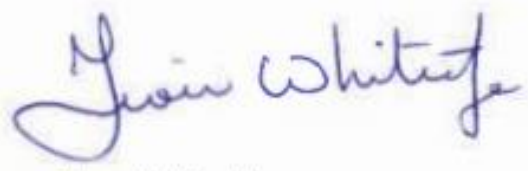

Fiona Whiteridge

General Manager - Refugee and Migrant Services

Immigration New Zealand 


\section{Appendix A}

Table 1: Refugee Family Support Category (RFSC) for calendar year 2019

\begin{tabular}{|l|l|l|l|}
\hline & $\begin{array}{l}\text { RFSC Residence } \\
\text { Visa Applications } \\
\text { (Persons) lodged } \\
\text { in 2019 }\end{array}$ & $\begin{array}{l}\text { RFSC Residence } \\
\text { Visa Applications } \\
\text { (Persons) approved } \\
\text { in 2019 }\end{array}$ & $\begin{array}{l}\text { RFSC Arrivals in New } \\
\text { Zealand (persons) in } \\
2019\end{array}$ \\
\hline Tier One & 214 & 177 & 153 \\
\hline Tier Two & 527 & 111 & 84 \\
\hline TOTAL & 741 & 288 & 237 \\
\hline
\end{tabular}

Table 2: Refugee Quota Programme for calendar year 2019

\begin{tabular}{|l|l|}
\hline & \multicolumn{1}{|c|}{ Number } \\
\hline Refugee Quota Arrivals (Persons) & 972 \\
\hline $\begin{array}{l}\text { Refugee Quota Arrivals Under } \\
\text { Family Reunification (Persons) }\end{array}$ & 47 \\
\hline TQTAL & 1019 \\
\hline
\end{tabular}

Table 3: Refugee and protection claims approved for calendar year 2019

\begin{tabular}{|l|l|}
\hline & \multicolumn{1}{|c|}{ Number } \\
\hline $\begin{array}{l}\text { Refugee and protection claims } \\
\text { approved (persons) }\end{array}$ & 151 \\
\hline TQTAL & 151 \\
\hline
\end{tabular}


